\title{
Potassium tert-Butoxide Promoted Synthesis of Dihydroquinazolinones
}

Tridev Ghosh, Indradip Mandal, Soumya Jyoti Basak and Jyotirmayee Dash*

School of Chemical Sciences, Indian Association for the Cultivation of Science, 2A \& 2B

Raja S. C. Mullick Road, Jadavpur, Kolkata-700032, India

Correspondence should be addressed to J.D. (ocjd@iacs.res.in)

\section{Table of Contents:}

1.0 $\mathrm{KO}^{t} \mathrm{Bu}$ promoted formation of dihydroquinazolinone $\quad \mathrm{S} 2$

2.0 ESI-MS analysis of radical quenching experiments $\quad$ S8

$\begin{array}{ll}\text { 3.0 HRMS detection of 2-methylpropene } & \text { S10 }\end{array}$

$\begin{array}{ll}\text { 4.0 NMR of all compounds } & \text { S11 }\end{array}$ 


\subsection{Table S1. $\mathrm{KO}^{t} \mathrm{Bu}$ promoted formation of dihydroquinazolinone}

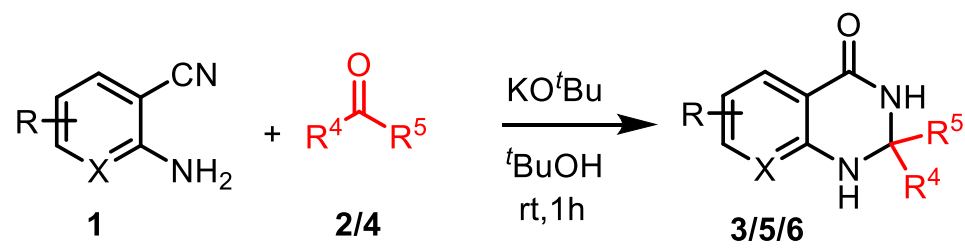

$\mathrm{X}=\mathrm{CH}, \mathrm{N}$

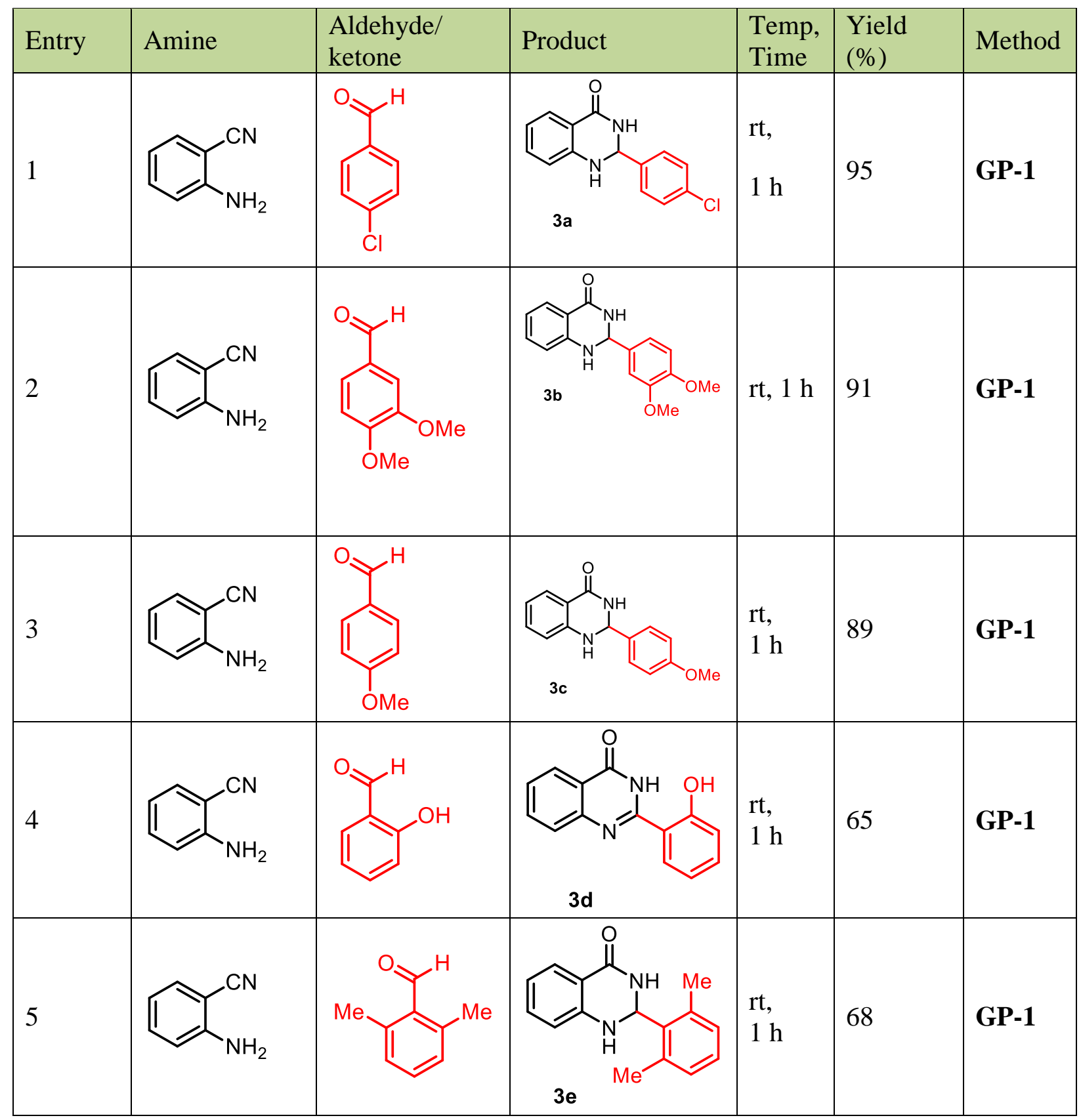




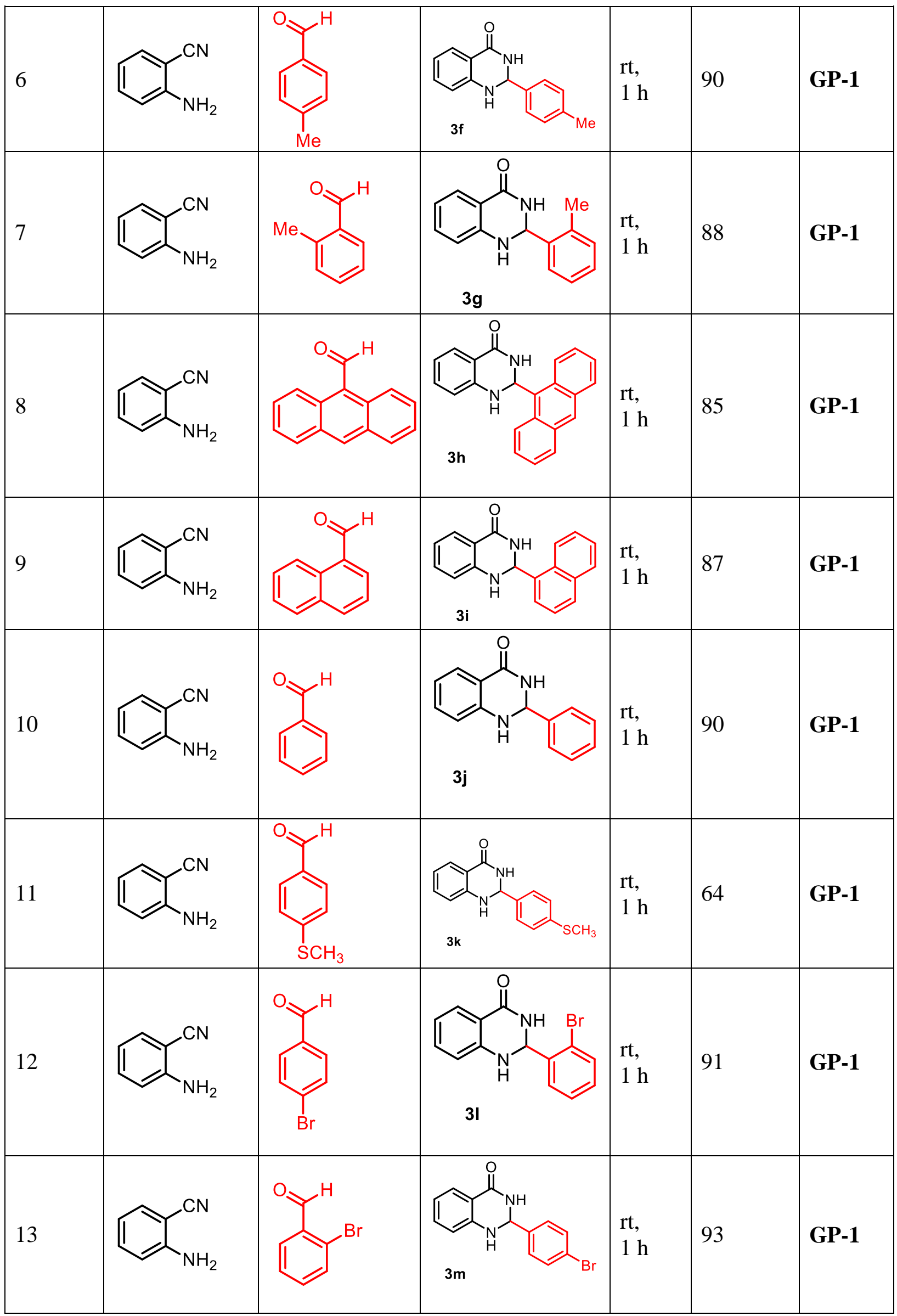

S3 


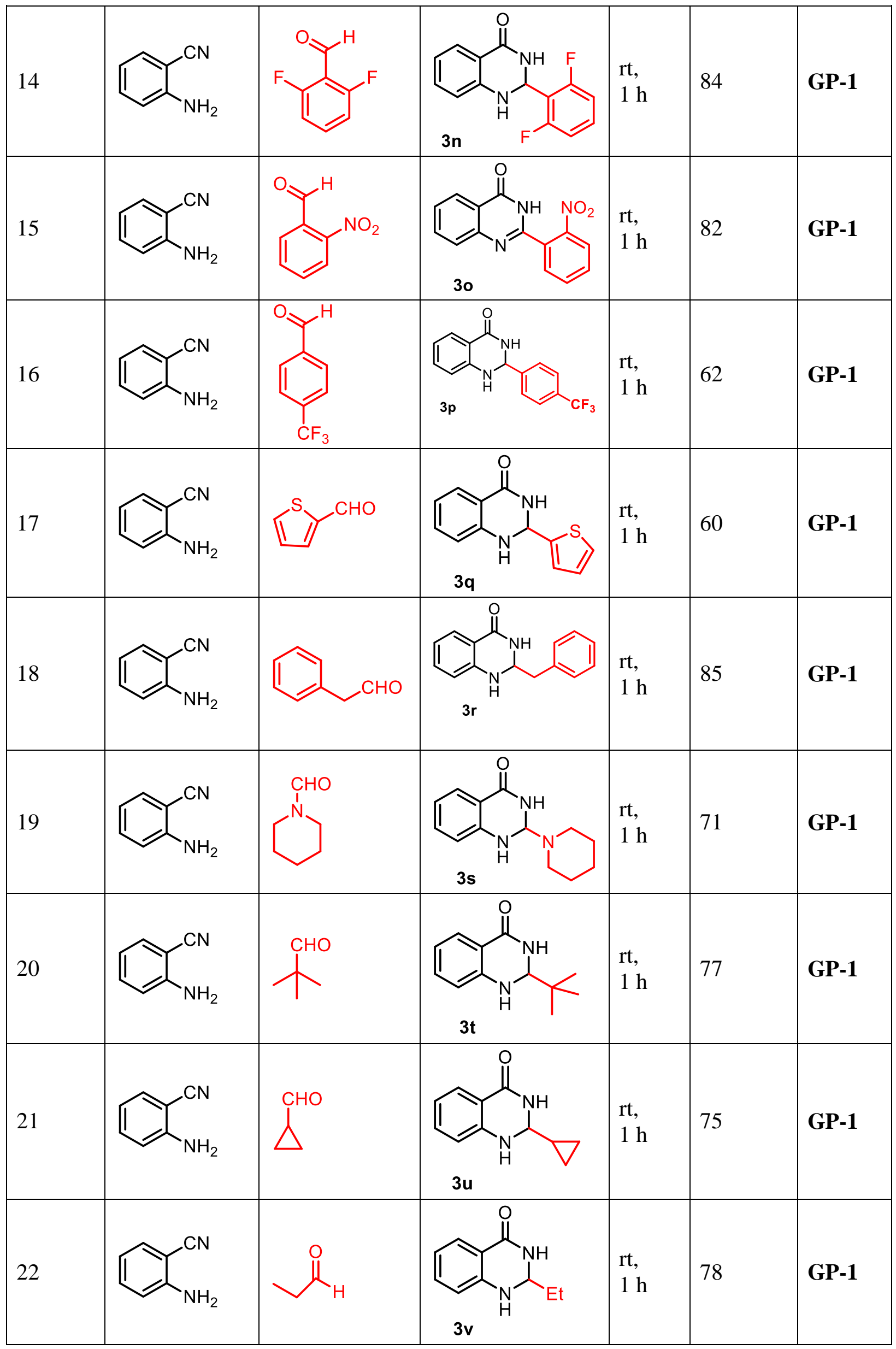

S4 


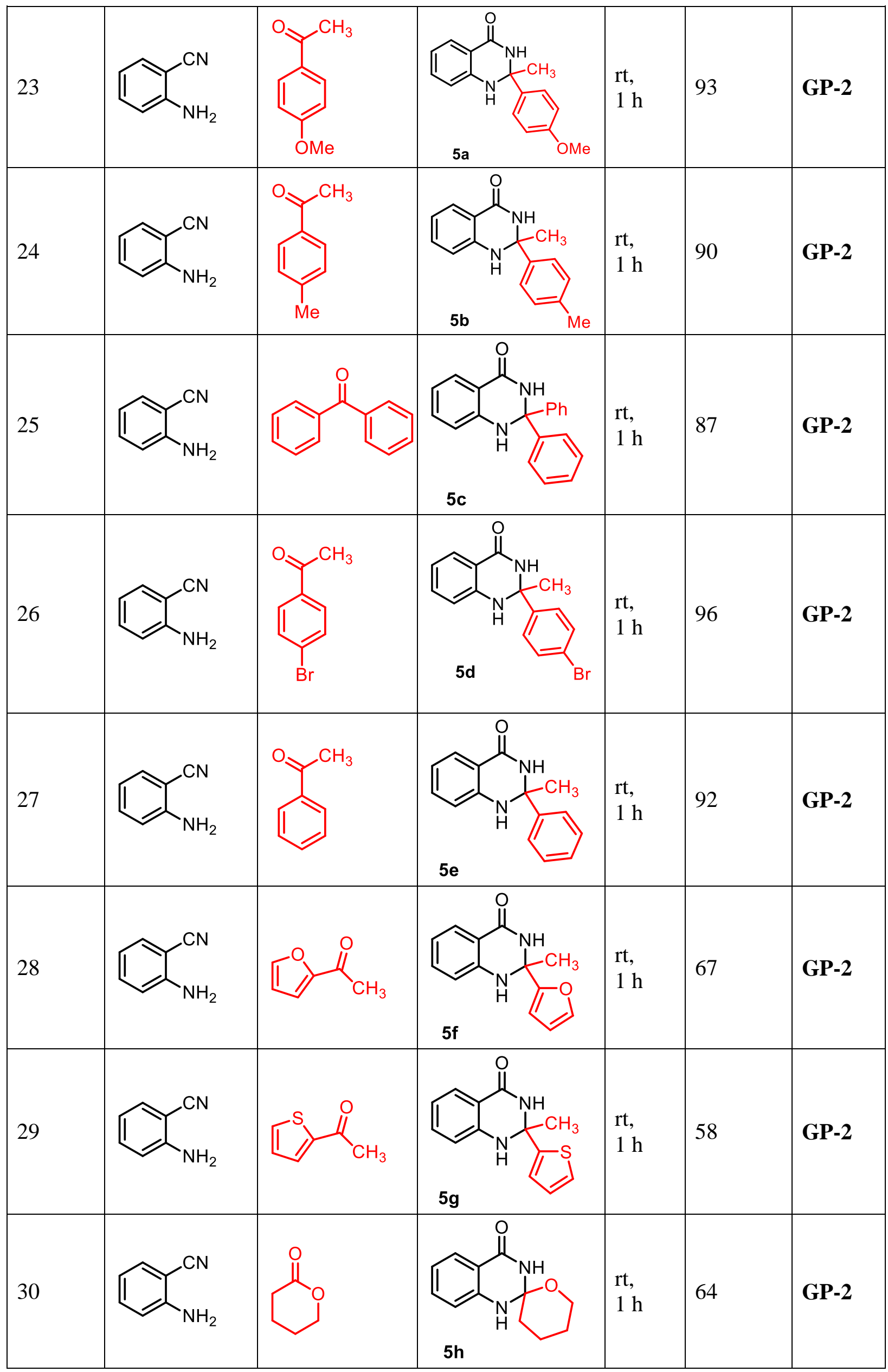

S5 


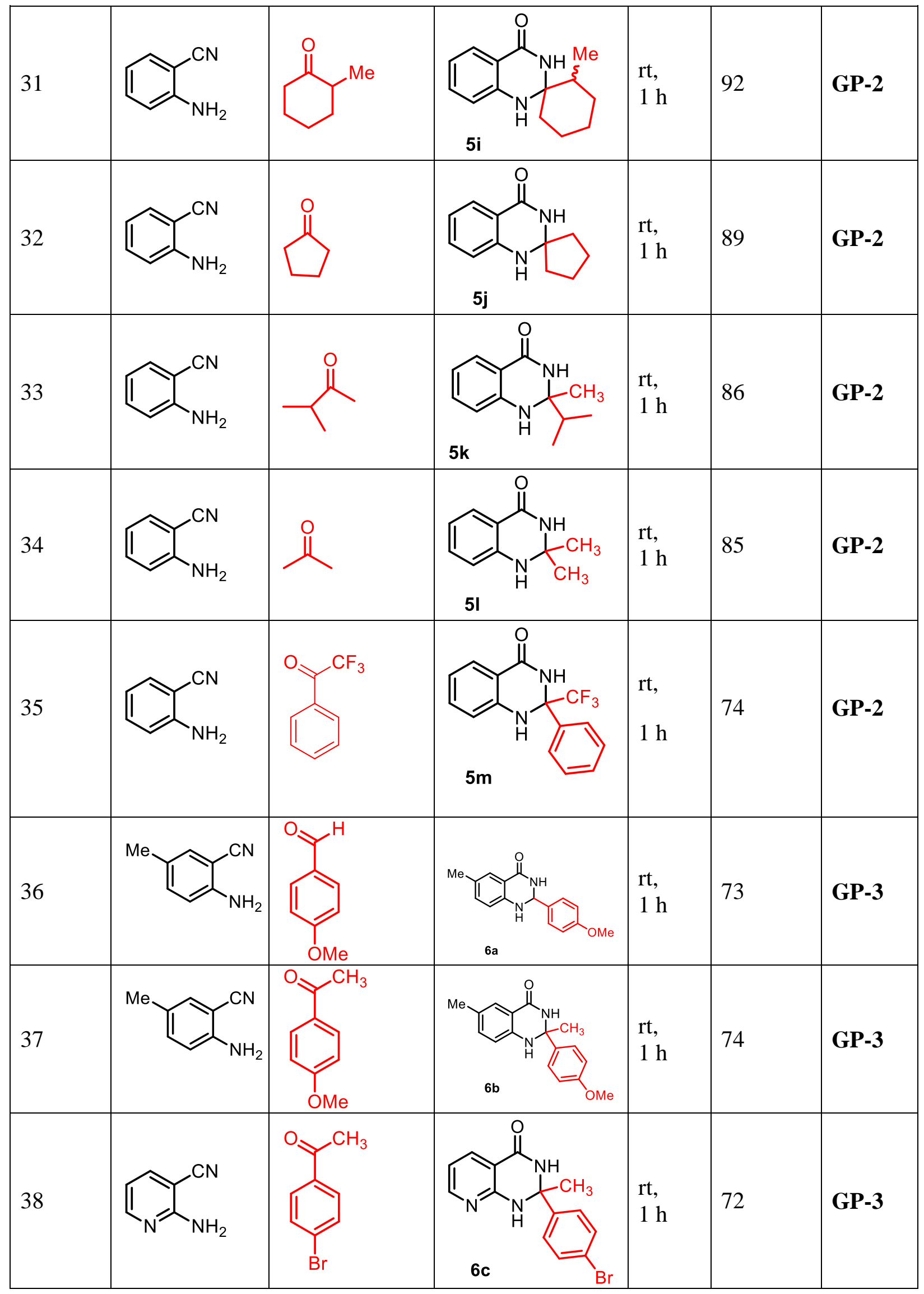




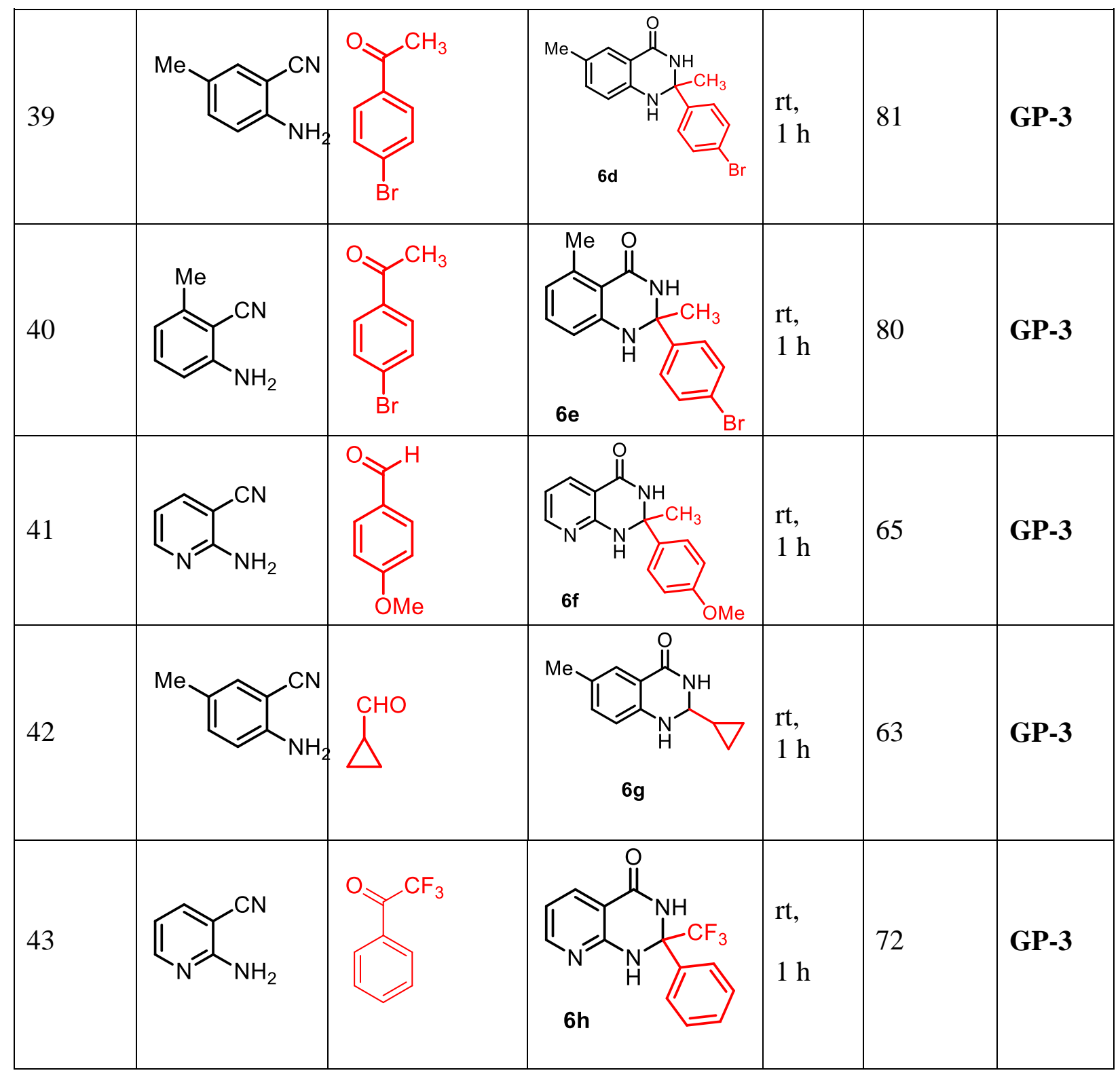




\subsection{ESI-MS analysis of radical quenching experiments:}

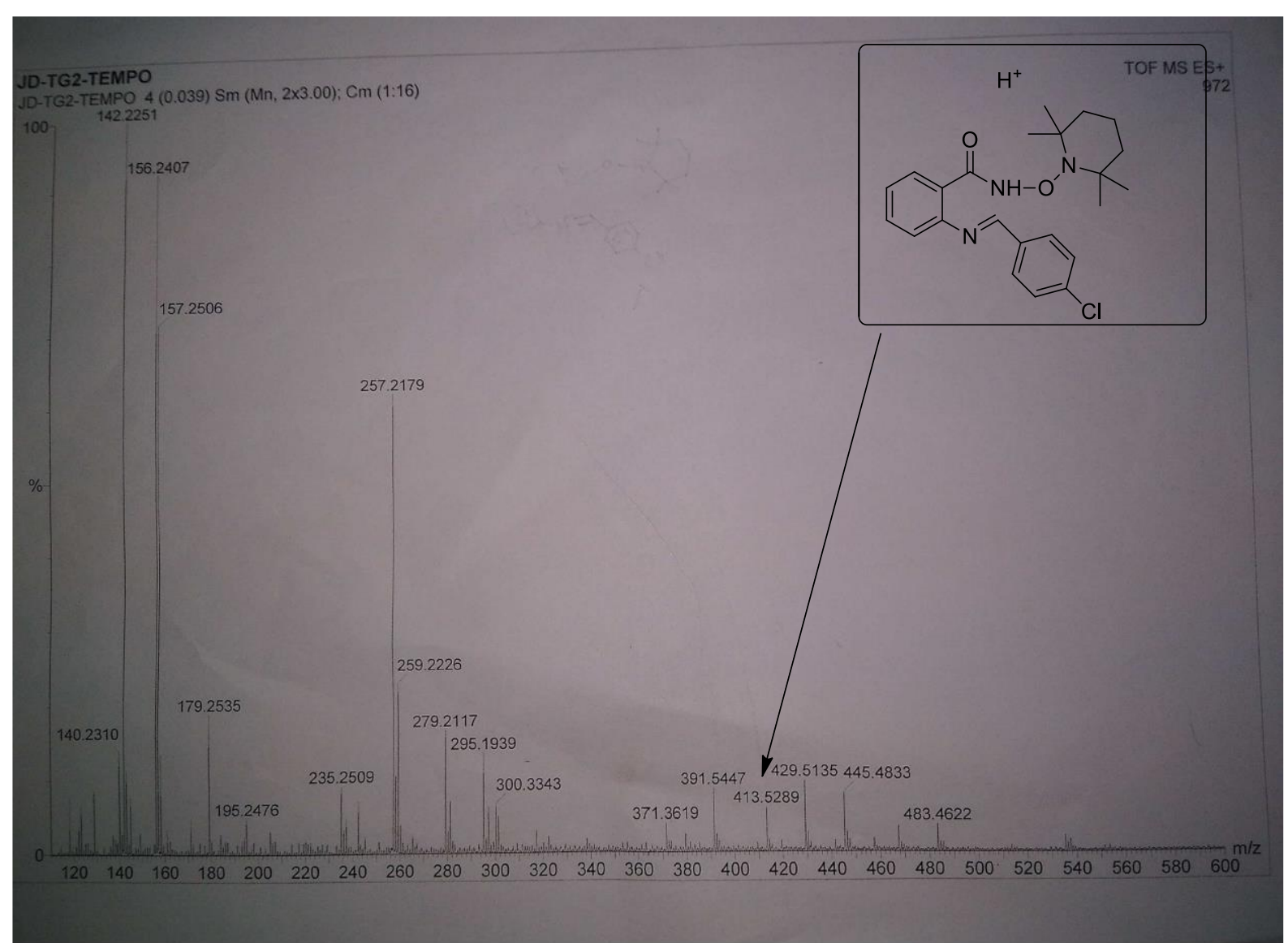

Figure S1. ESI-MS spectra of $\mathrm{KO}^{t} \mathrm{Bu}$ mediated reaction of amine 1a with 4chlorobenzaldehyde $\mathbf{2}$ in the presence of TEMPO radical shows the intermediate amide radical is quenched by the radical scavenger. 


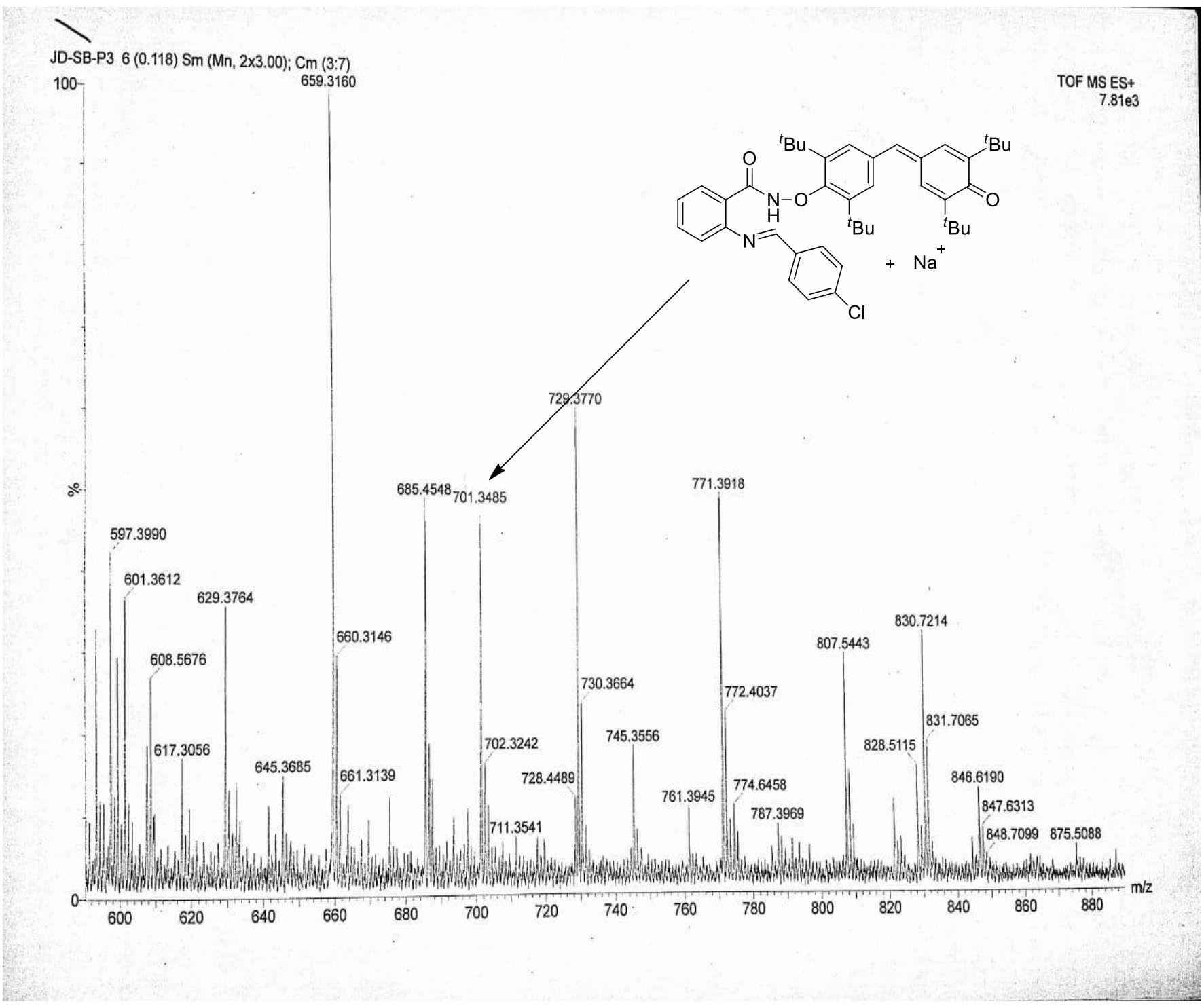

Figure S2. ESI-MS spectra of $\mathrm{KO}^{t} \mathrm{Bu}$ mediated reaction of amine $\mathbf{1 a}$ with 4chlorobenzaldehyde in the presence of galvinoxyl radical shows the quenching of the intermediate amide radical by the radical scavenger. 


\subsection{HRMS detection of 2-methylpropene:}
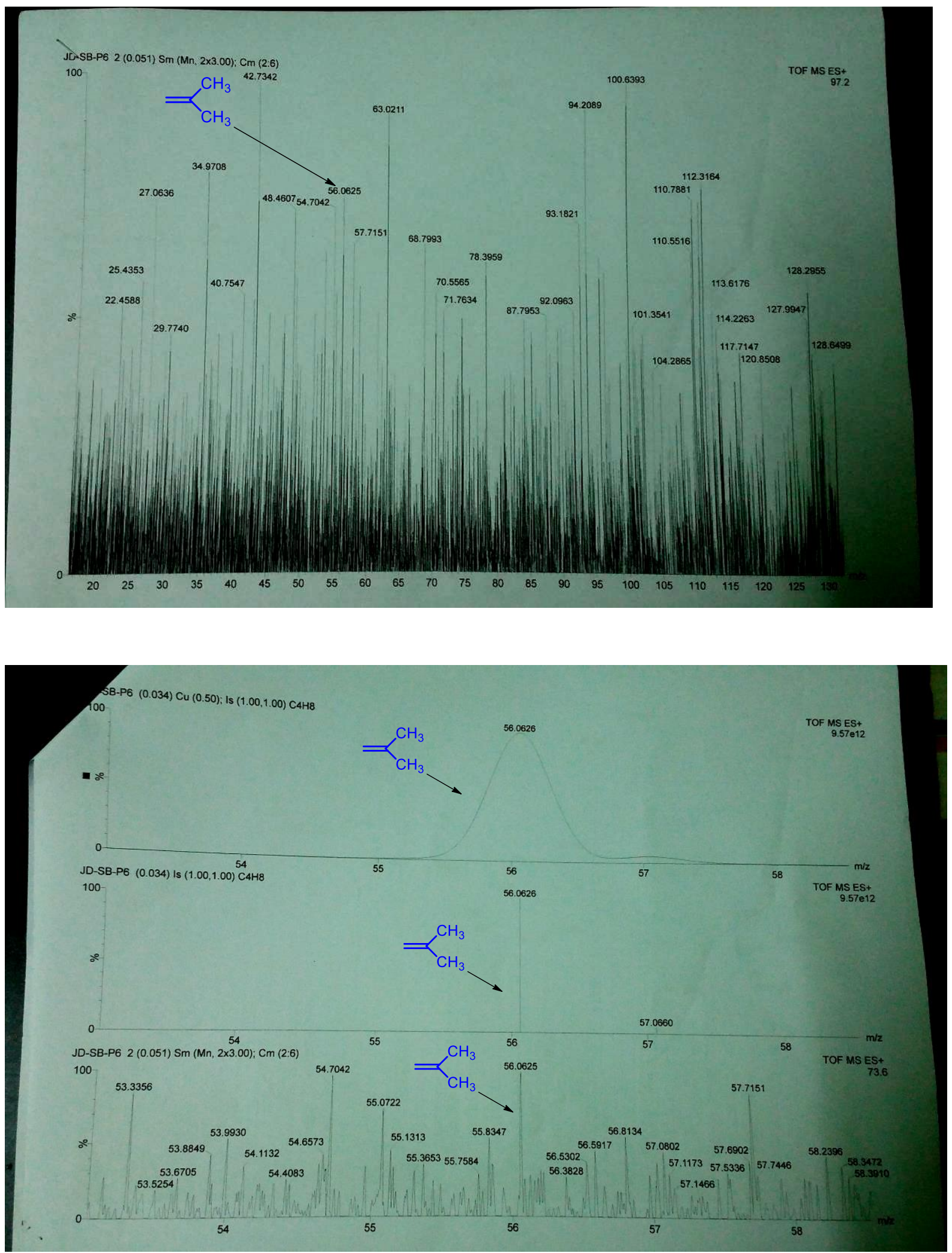

Figure S3. HRMS analysis of the reaction of 2-aminobenzonirtile with $\mathrm{KO}^{t} \mathrm{Bu}$ in ${ }^{t} \mathrm{BuOH}$. 
4.0 NMR of all compounds:

$\underline{{ }^{1} \mathrm{H} \text { and }{ }^{13} \mathrm{C}\left\{{ }^{1} \mathrm{H}\right\} \text { NMR of compound Ba: }}$
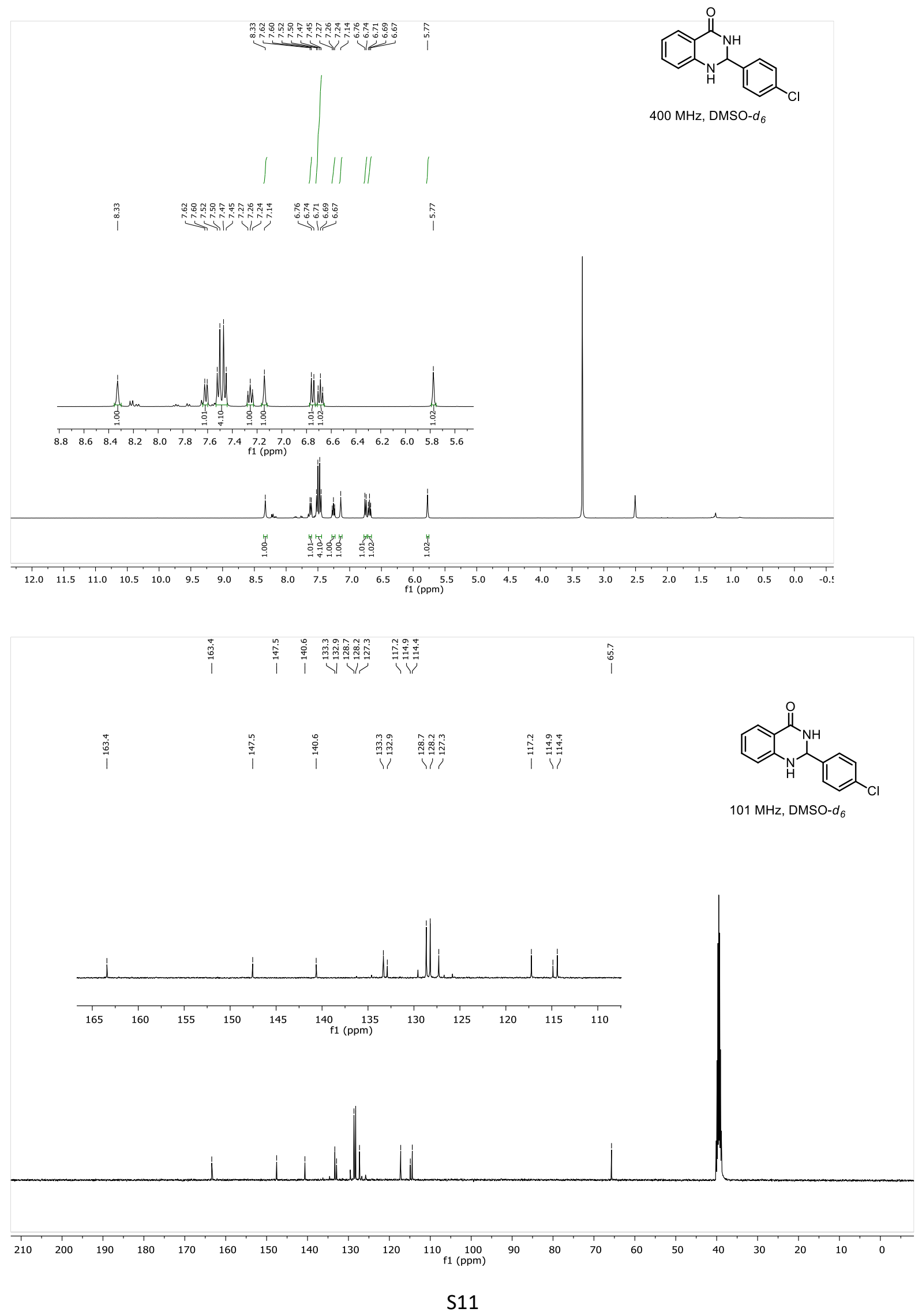


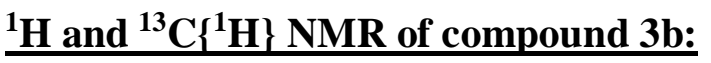
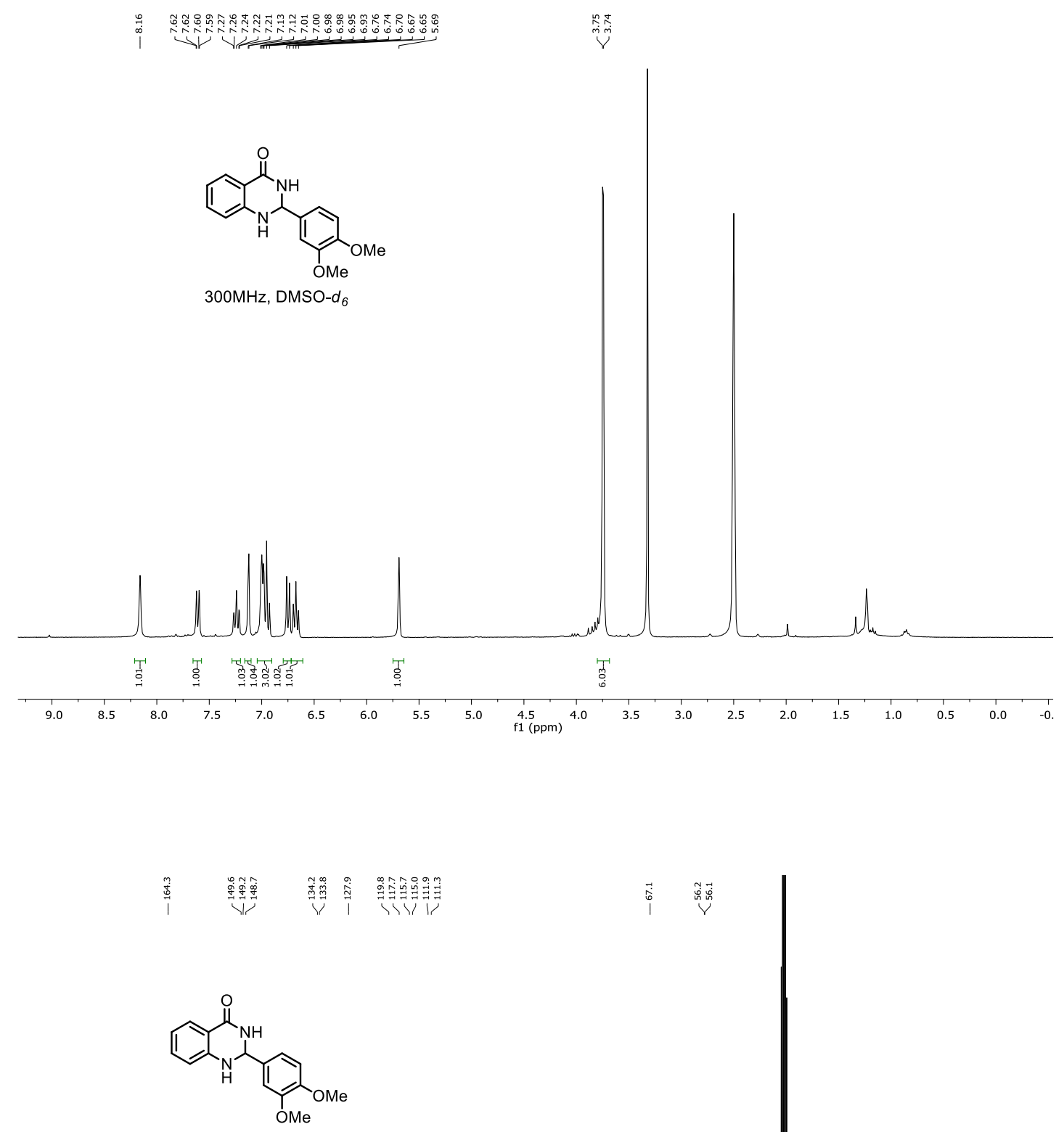

$75 \mathrm{MHz}, \mathrm{DMSO}-d_{6}$

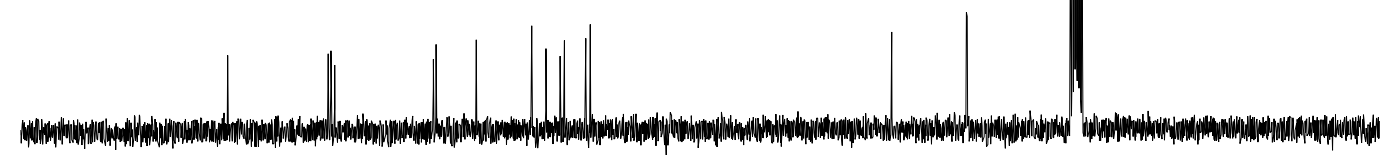

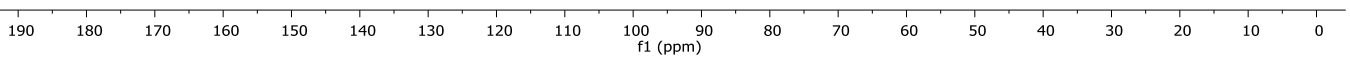


$\underline{{ }^{1} \mathrm{H} \text { and }{ }^{13} \mathrm{C}\left\{{ }^{1} \mathrm{H}\right\} \text { NMR of compound } 3 \mathrm{c}}$
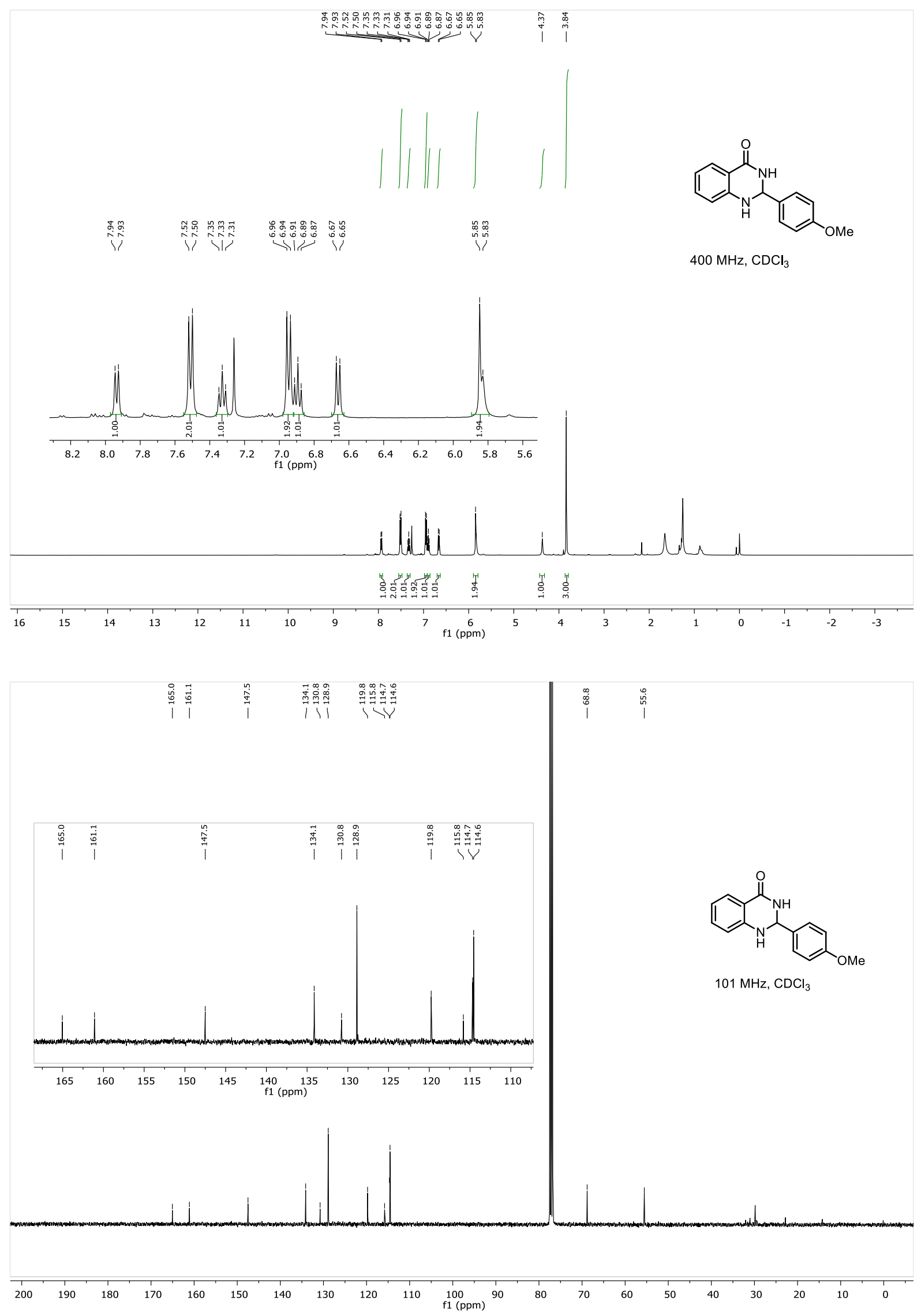

S13 
$\underline{{ }^{1} \mathrm{H} \text { and }{ }^{13} \mathrm{C}\left\{{ }^{1} \mathrm{H}\right\} \text { NMR of compound } 3 \mathrm{~d}:}$
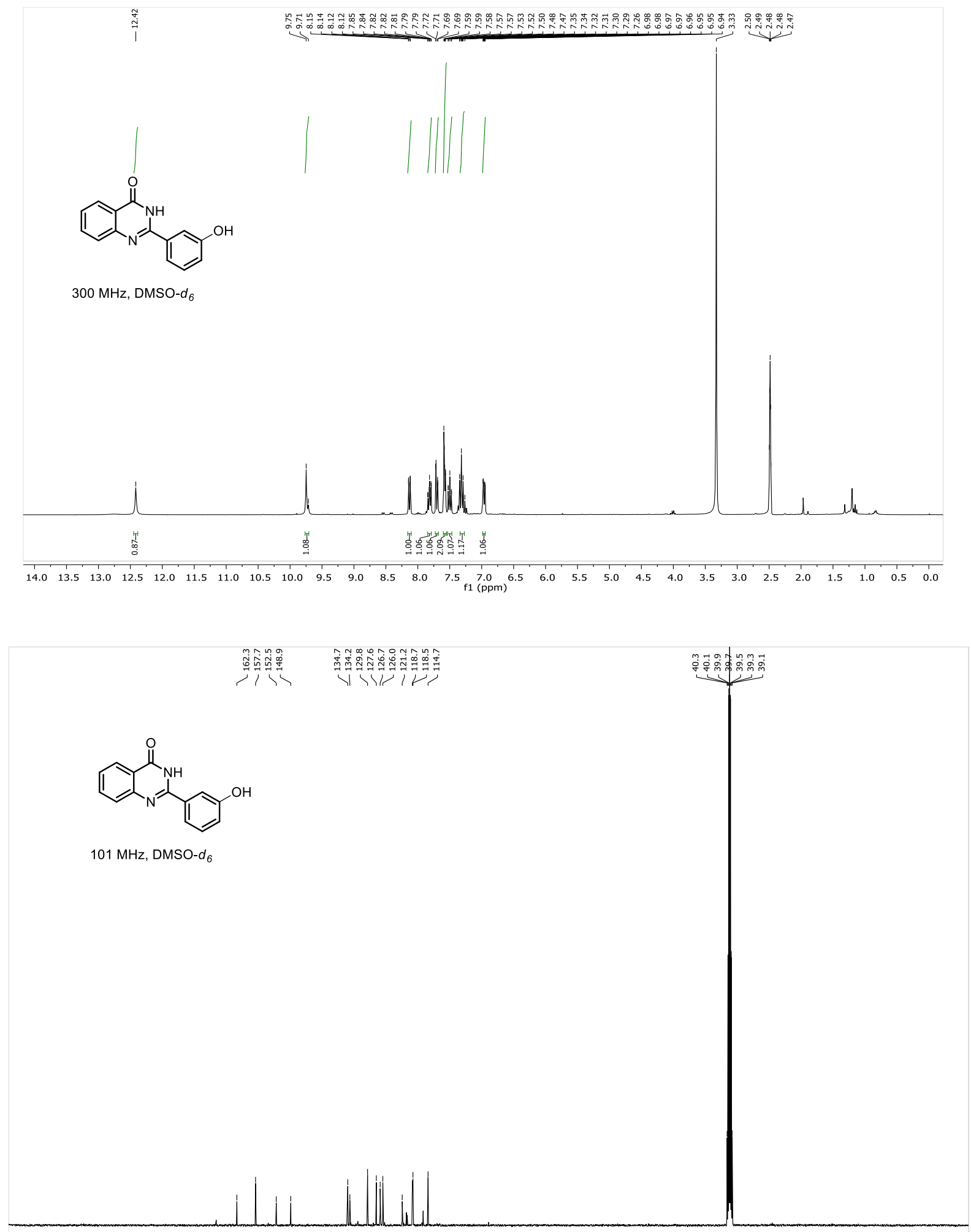

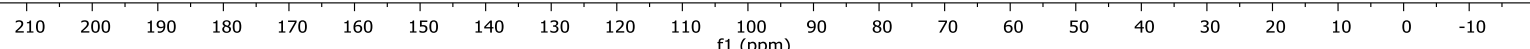


$\underline{{ }^{1} \mathrm{H} \text { and }{ }^{13} \mathrm{C}\left\{{ }^{1} \mathrm{H}\right\} \text { NMR of compound 3e: }}$
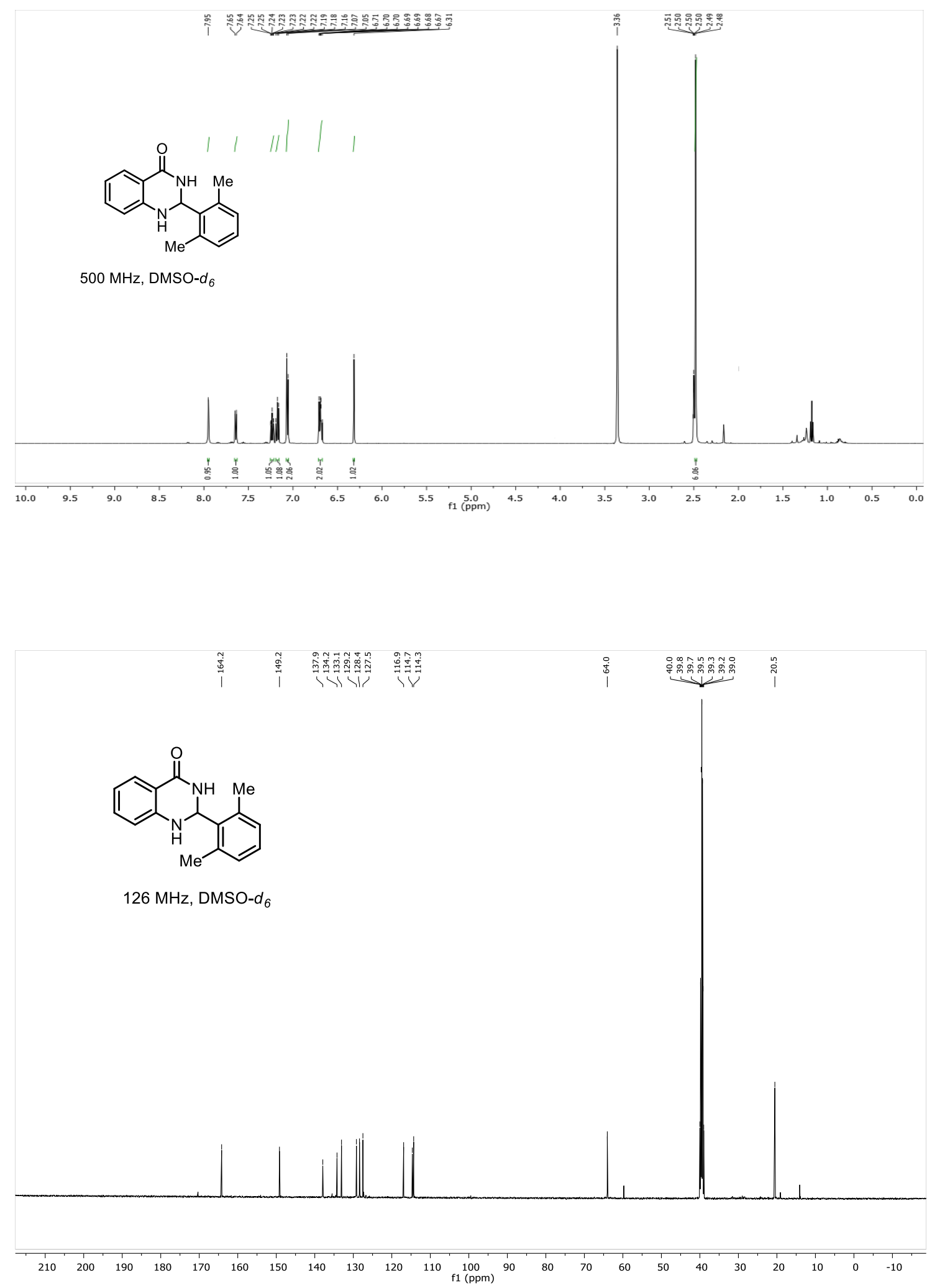
$\underline{{ }^{1} \mathrm{H} \text { and }}{ }^{13} \mathrm{C}\left\{{ }^{1} \mathrm{H}\right\}$ NMR of compound 3f:

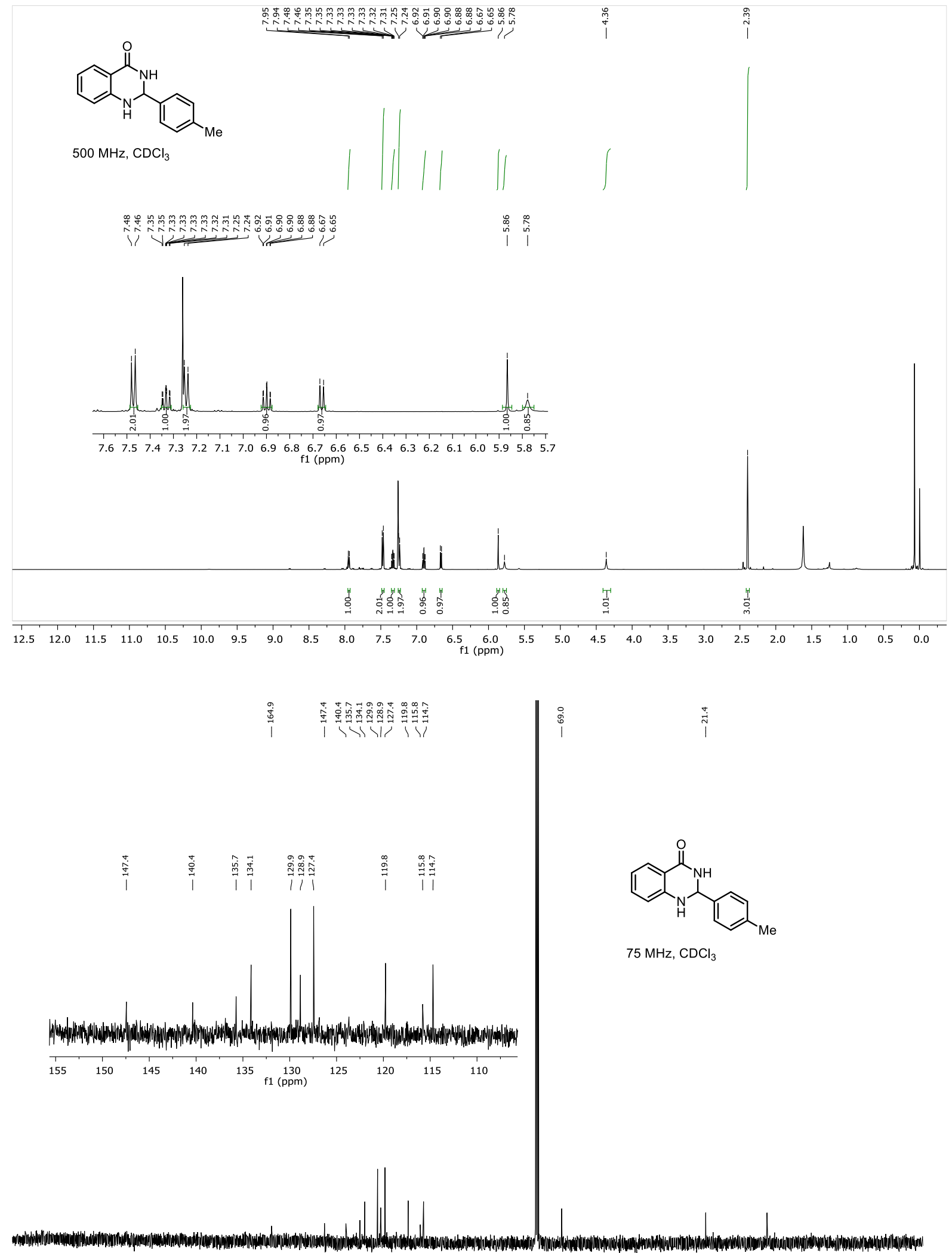

$\begin{array}{llllllllllllllllllllllllllllllllllllll}50 & 240 & 230 & 220 & 210 & 200 & 190 & 180 & 170 & 160 & 150 & 140 & 130 & 120 & 110 & 100 & 90 & 80 & 70 & 60 & 50 & 40 & 30 & 20 & 10 & 0 & -10 & -20 & -30 & -40 & -5\end{array}$ 


\section{$\underline{{ }^{1} \mathrm{H} \text { and }{ }^{13} \mathrm{C}\left\{{ }^{1} \mathrm{H}\right\} \text { NMR of compound 3g: }}$}

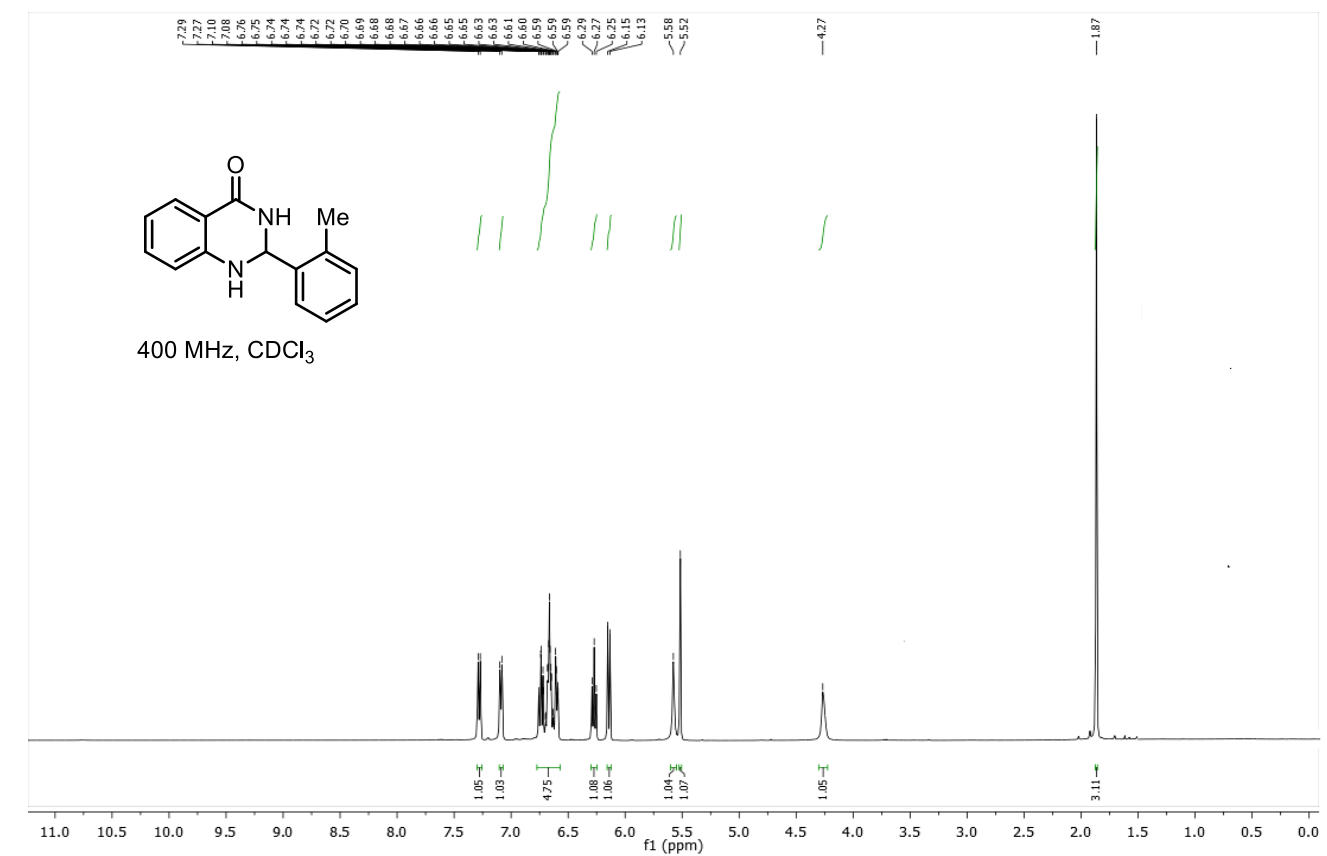

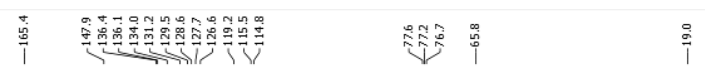

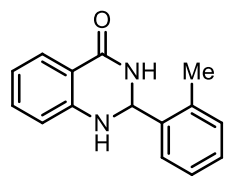

$75 \mathrm{MHz}, \mathrm{CDCl}_{3}$

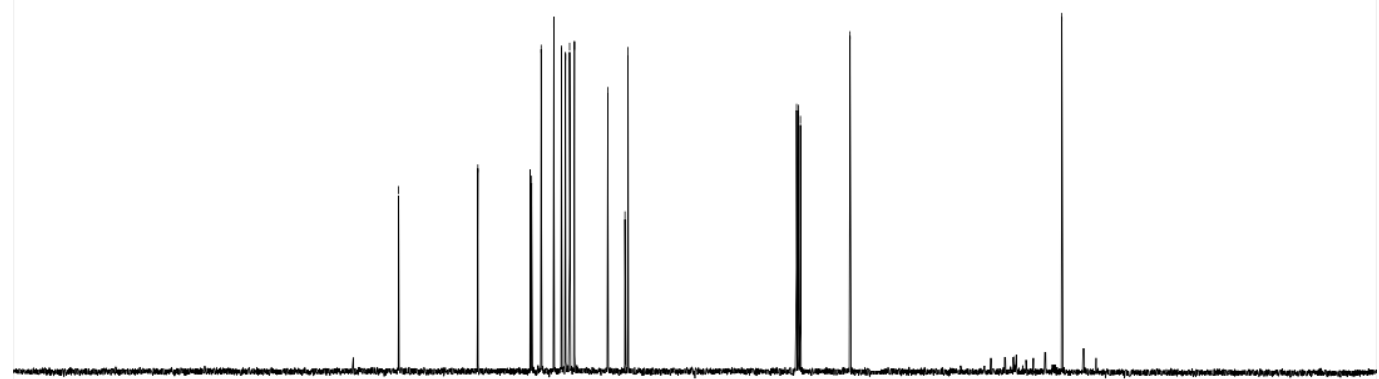

$\begin{array}{lllllllllllllllllllllllllllllllllllll}50 & 240 & 230 & 220 & 210 & 200 & 190 & 180 & 170 & 160 & 150 & 140 & 130 & 120 & 110 & 100 & 90 & 80 & 70 & 60 & 50 & 40 & 30 & 20 & 10 & 0 & -10 & -20 & -30 & -40 & -5\end{array}$ 


\section{${ }^{1} \mathrm{H}$ and ${ }^{13} \mathrm{C}\left\{{ }^{1} \mathrm{H}\right\}$ NMR of compound $3 \mathrm{~h}:$}
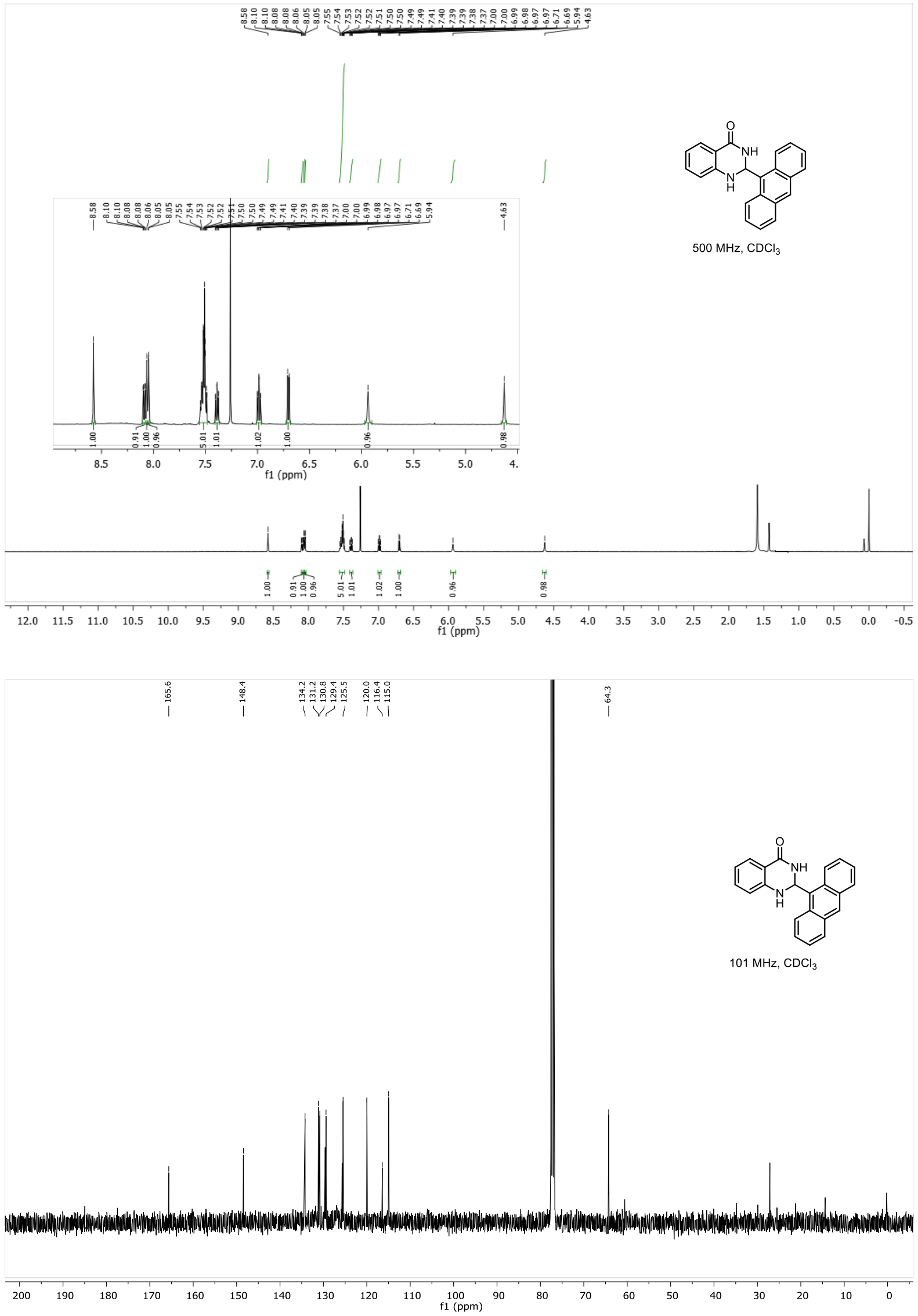


\section{${ }^{1} \mathrm{H}$ and ${ }^{13} \mathrm{C}\left\{{ }^{1} \mathrm{H}\right\}$ NMR of compound $3 \mathrm{i}$ :}

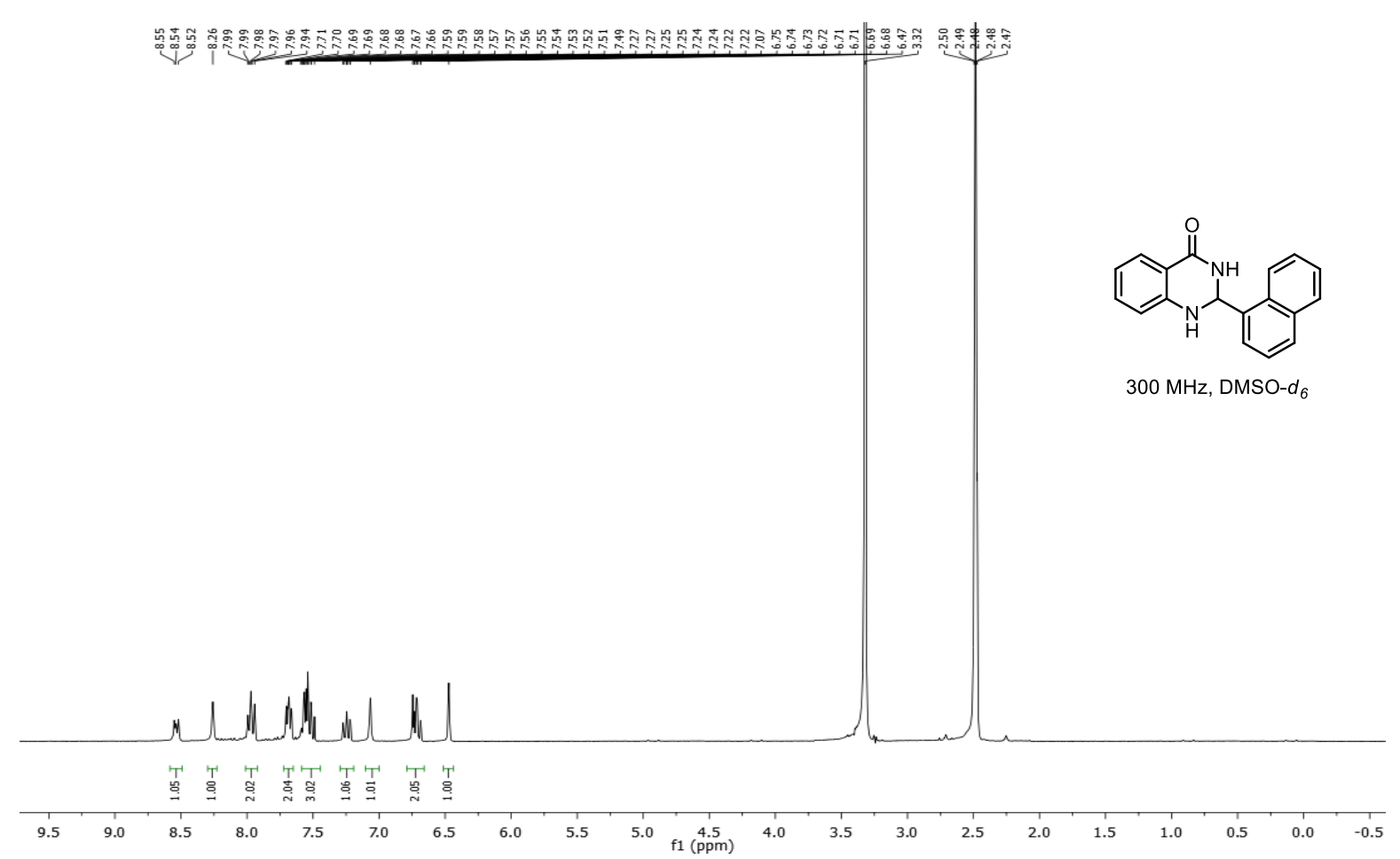

إن

i̊n.

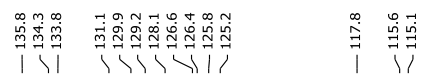

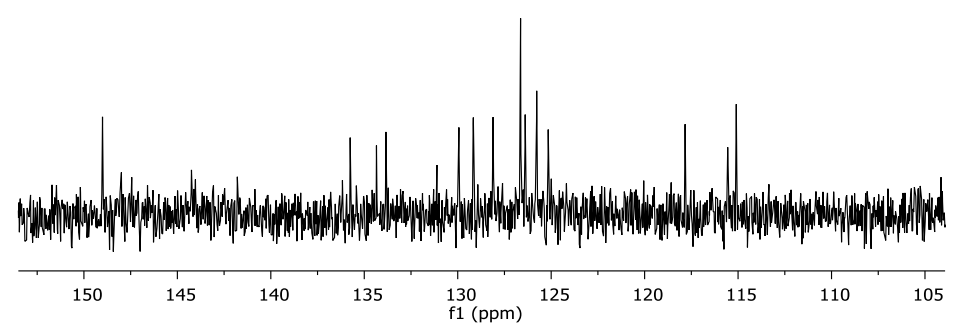

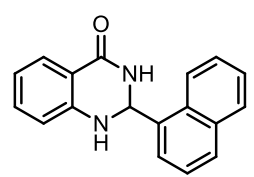

$75 \mathrm{MHz}$, DMSO- $d_{6}$ 
$\underline{{ }^{1} \mathrm{H} \text { and }{ }^{13} \mathrm{C}\left\{{ }^{1} \mathrm{H}\right\} \text { NMR of compound } 3 \mathrm{j}}$ :

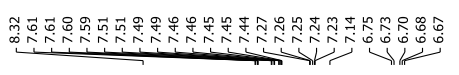

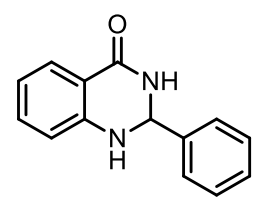

$400 \mathrm{MHz}, \mathrm{DMSO}-d_{6}$
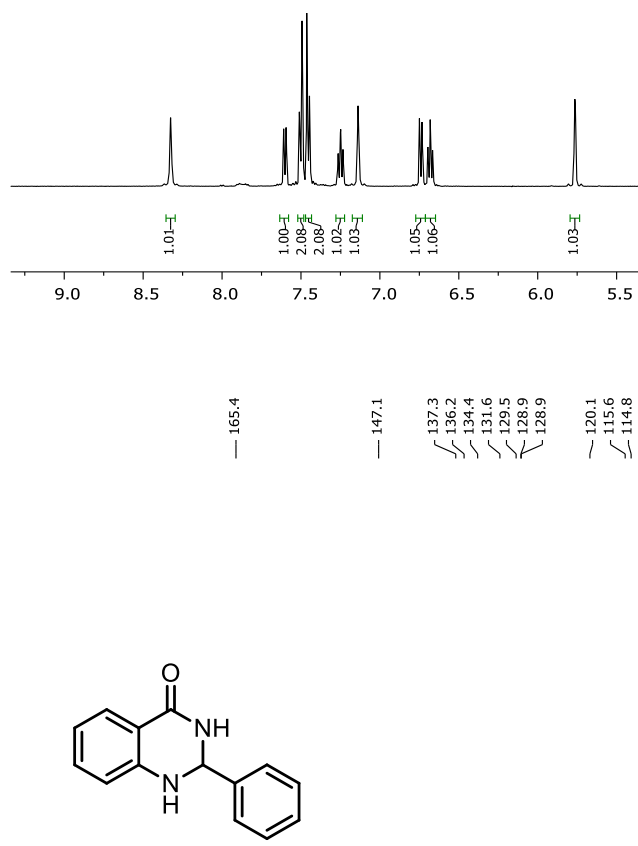

$75 \mathrm{MHz}, \mathrm{CDCl}_{3}$

$\underset{i}{i}$
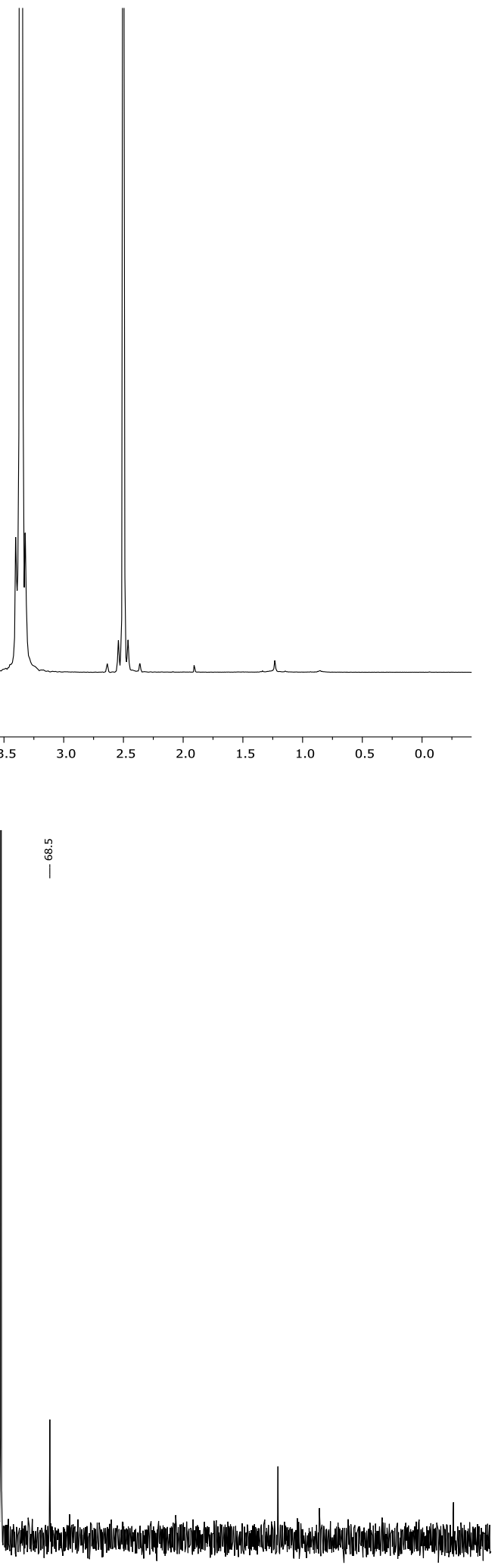

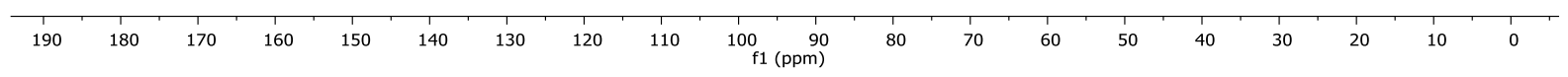

S20 


\section{$\underline{{ }^{1} \mathrm{H} \text { and }{ }^{13} \mathrm{C}\left\{{ }^{1} \mathrm{H}\right\} \text { NMR of compound 3k: }}$}
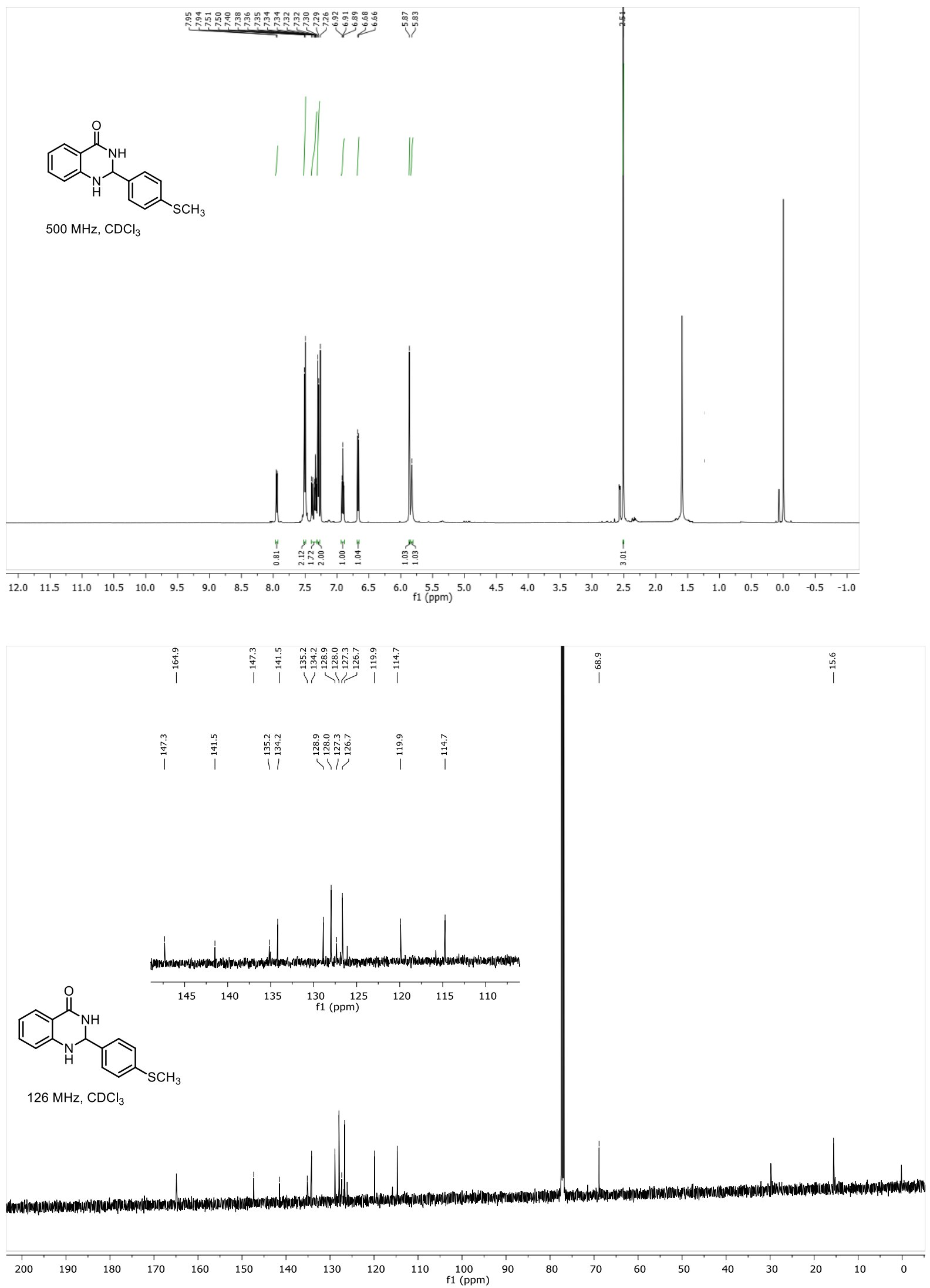
$\underline{{ }^{1} H \text { and }{ }^{13} C}\left\{{ }^{1} H\right\}$ NMR of compound 31:

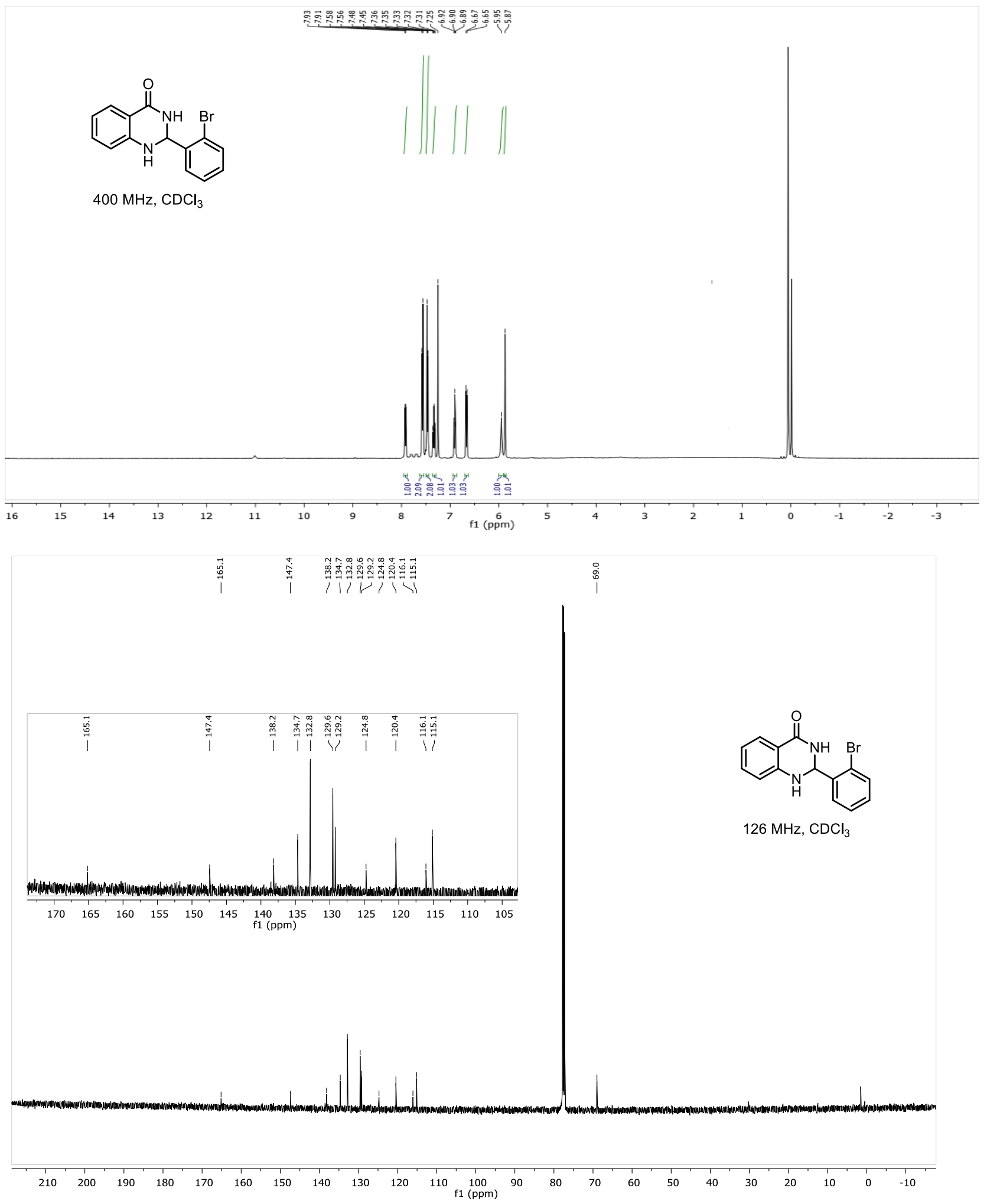

S22 
$\underline{{ }^{1} \mathrm{H} \text { and }{ }^{13} \mathrm{C}\left\{{ }^{1} \mathrm{H}\right\} \text { NMR of compound } 3 \mathrm{~m}}$

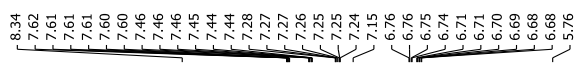
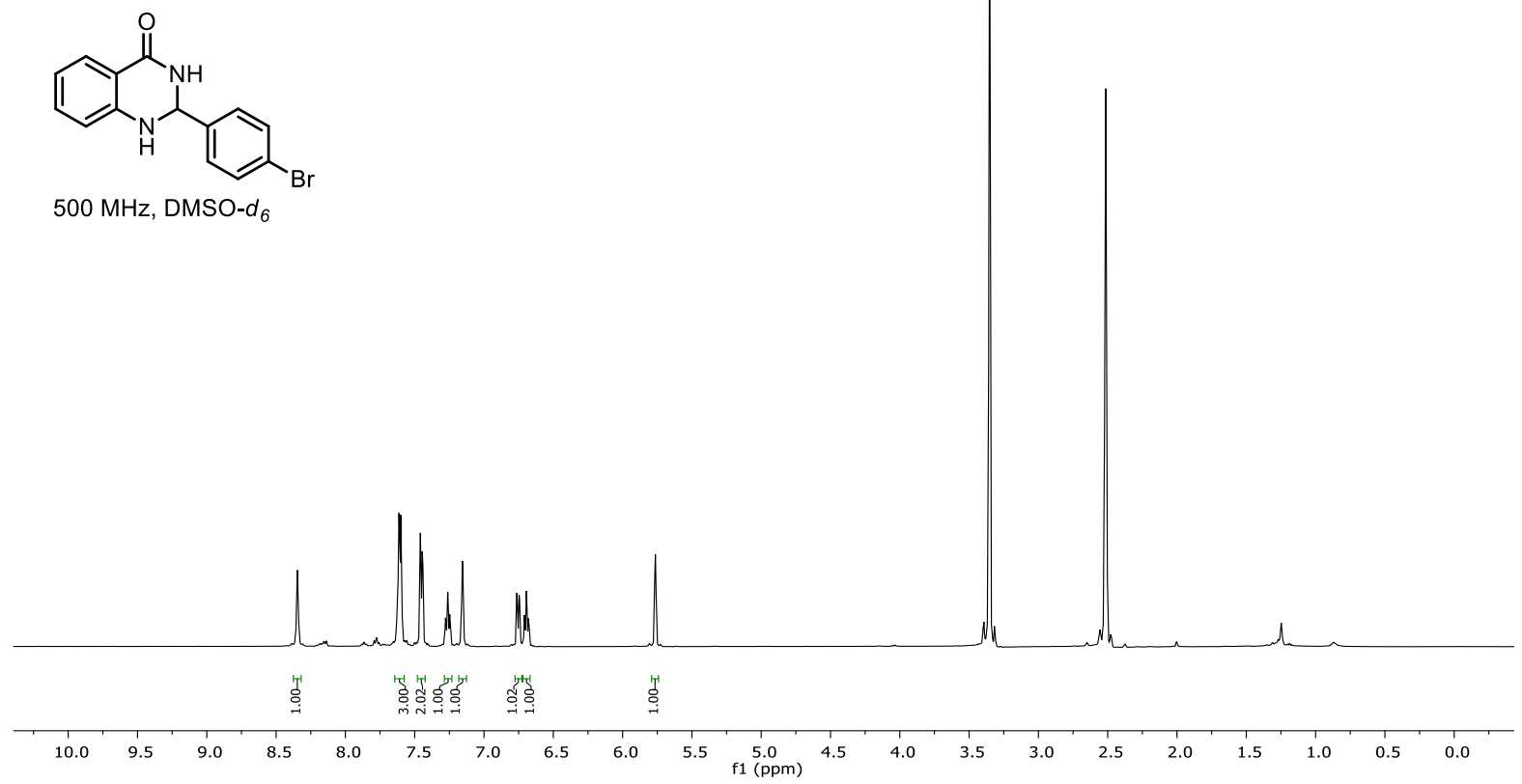

尊等

î̀

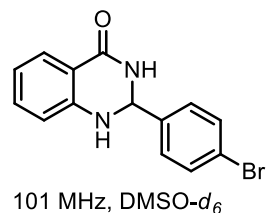

$101 \mathrm{MHz}, \mathrm{DMSO}-d_{6}$
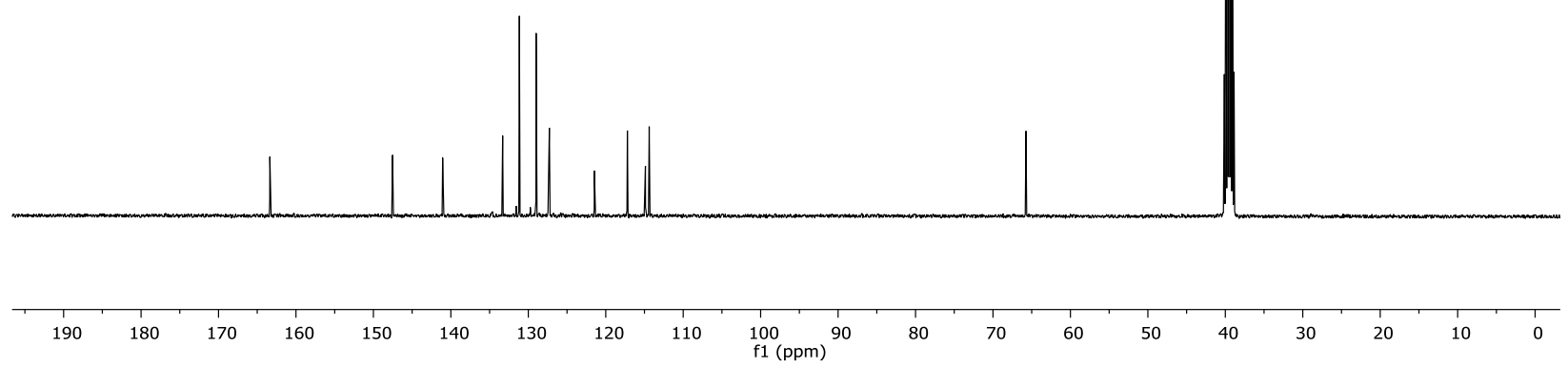

S23 


\section{$\underline{{ }^{1} \mathrm{H} \text { and }{ }^{13} \mathrm{C}\left\{{ }^{1} \mathrm{H}\right\} \text { NMR of compound 3n: }}$}
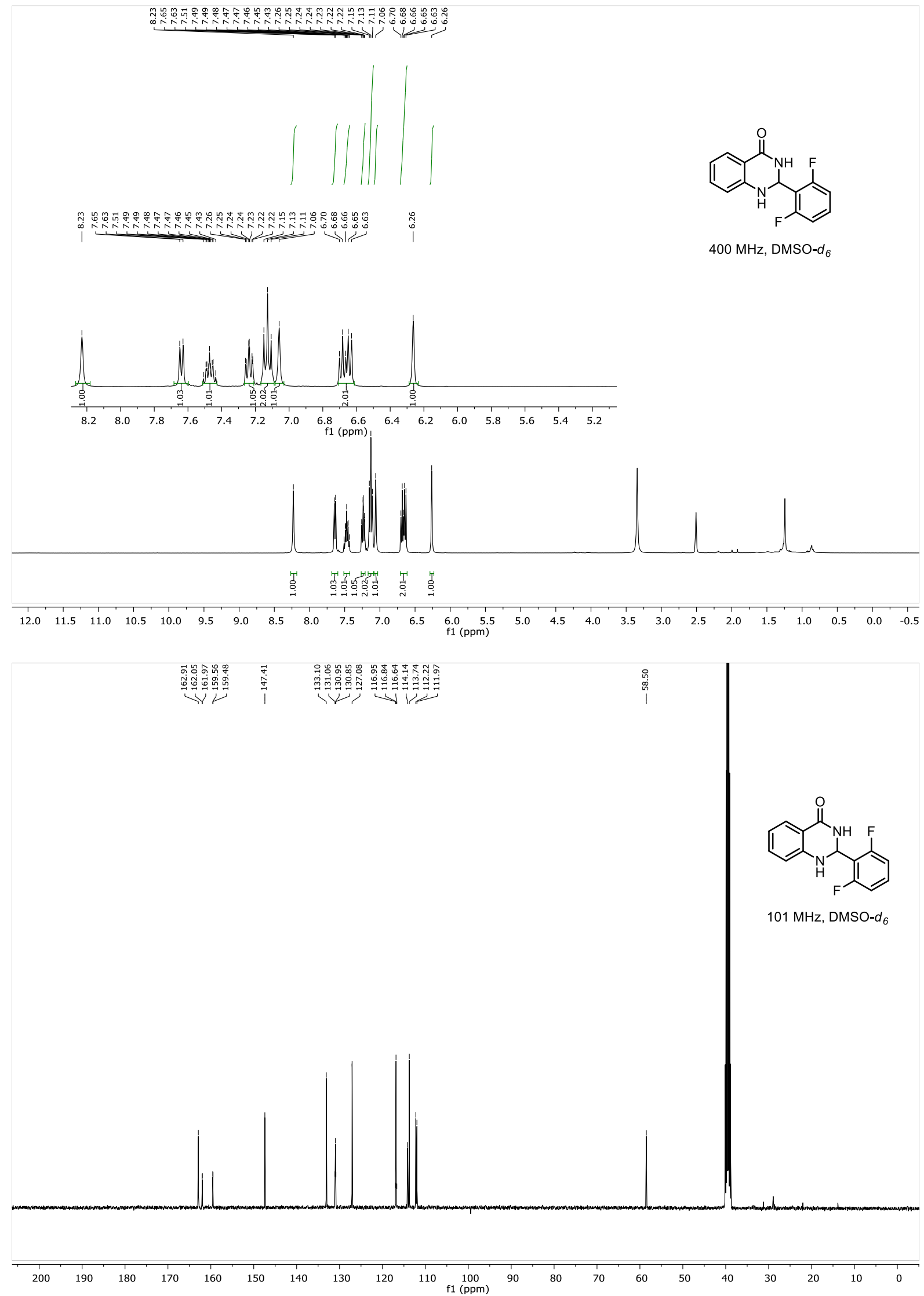


\section{$\underline{{ }^{1} \mathrm{H} \text { and }{ }^{13} \mathrm{C}\left\{{ }^{1} \mathrm{H}\right\} \text { NMR of compound } 30}$}

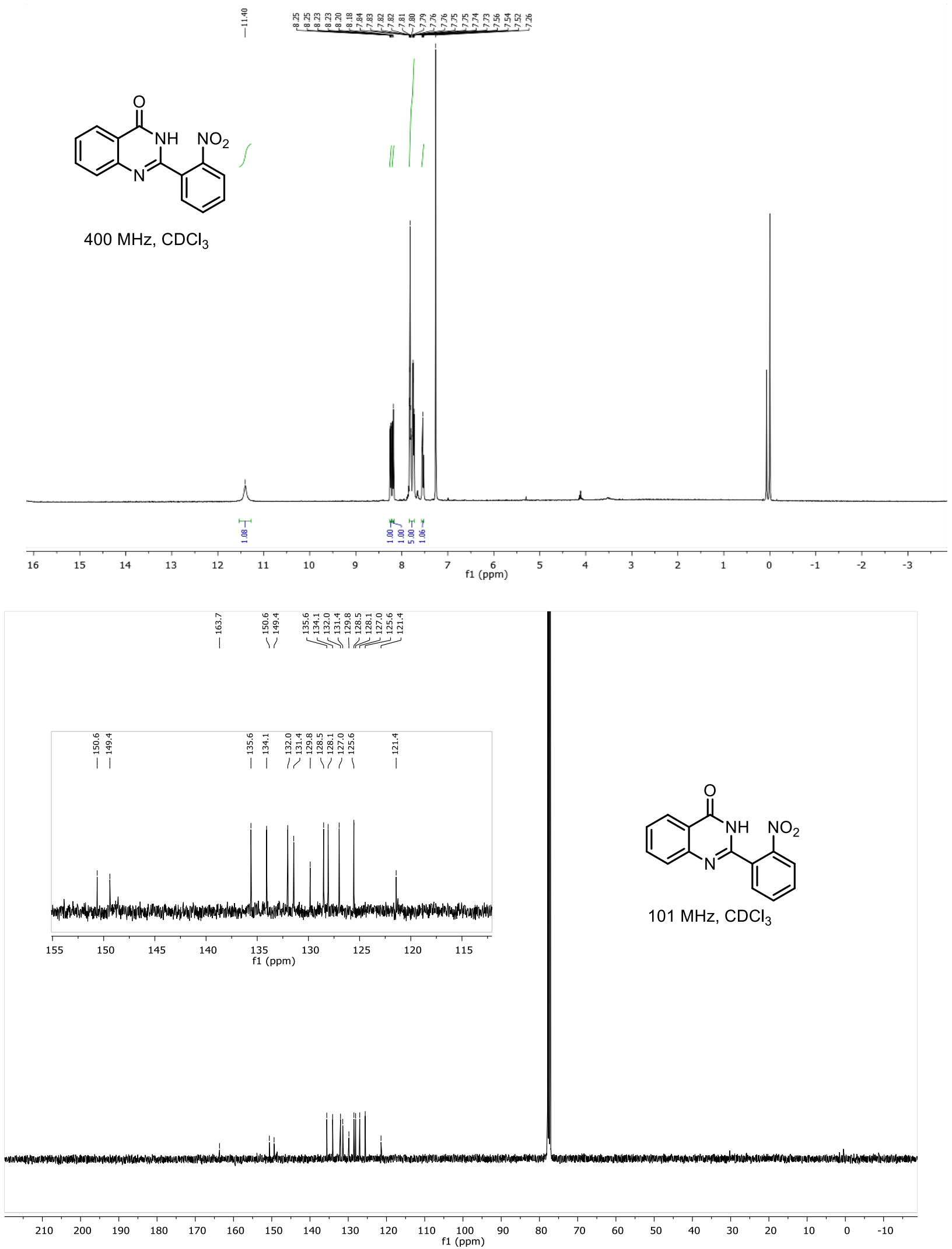




\section{${ }^{1} \mathrm{H}$ and ${ }^{13} \mathrm{C}\left\{{ }^{1} \mathrm{H}\right\}$ NMR of compound $3 \mathrm{p}:$}
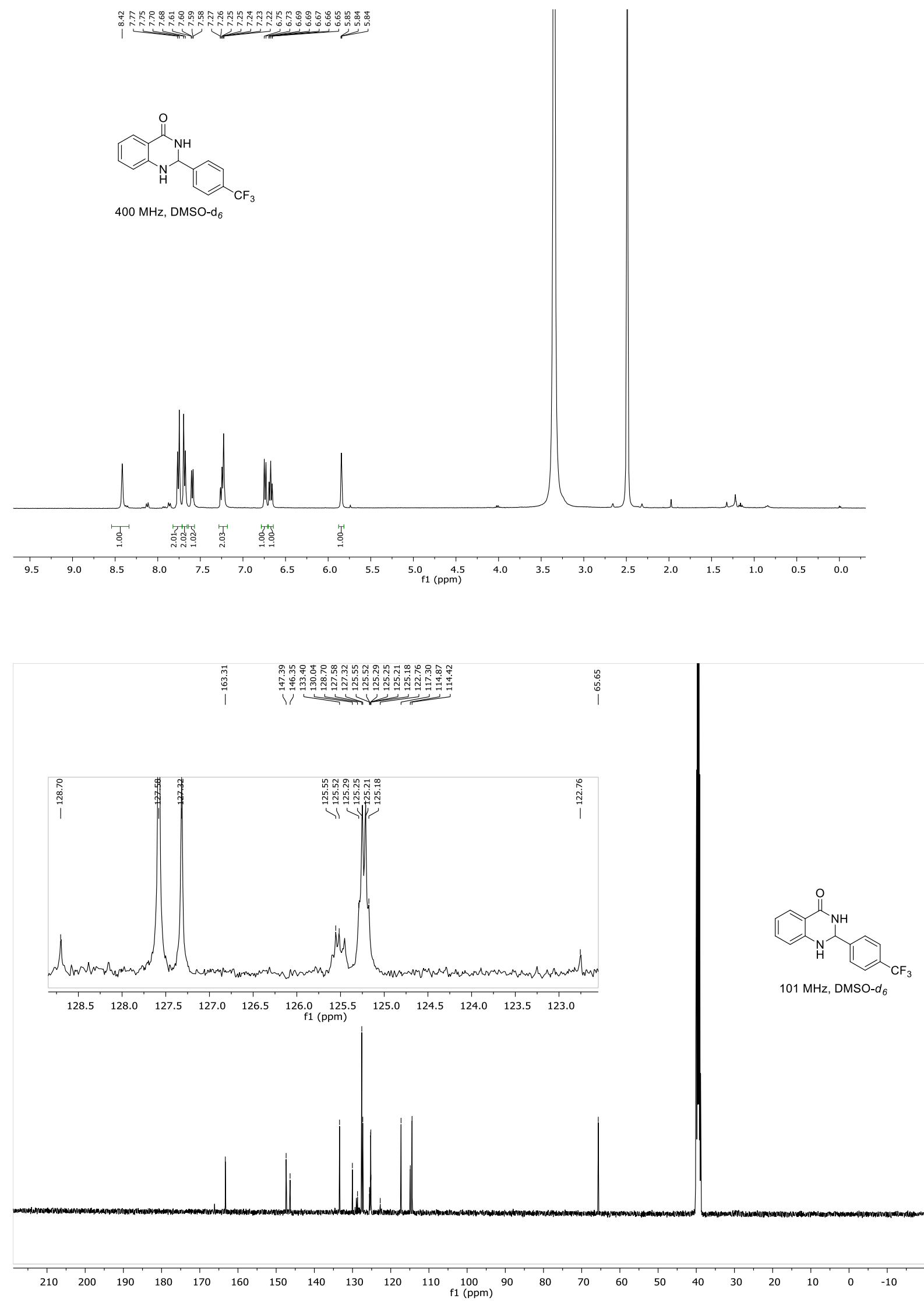


\section{$\underline{{ }^{1} \mathrm{H} \text { and }{ }^{13} \mathrm{C}\left\{{ }^{1} \mathrm{H}\right\} \text { NMR of compound } 3 q \text { : }}$}

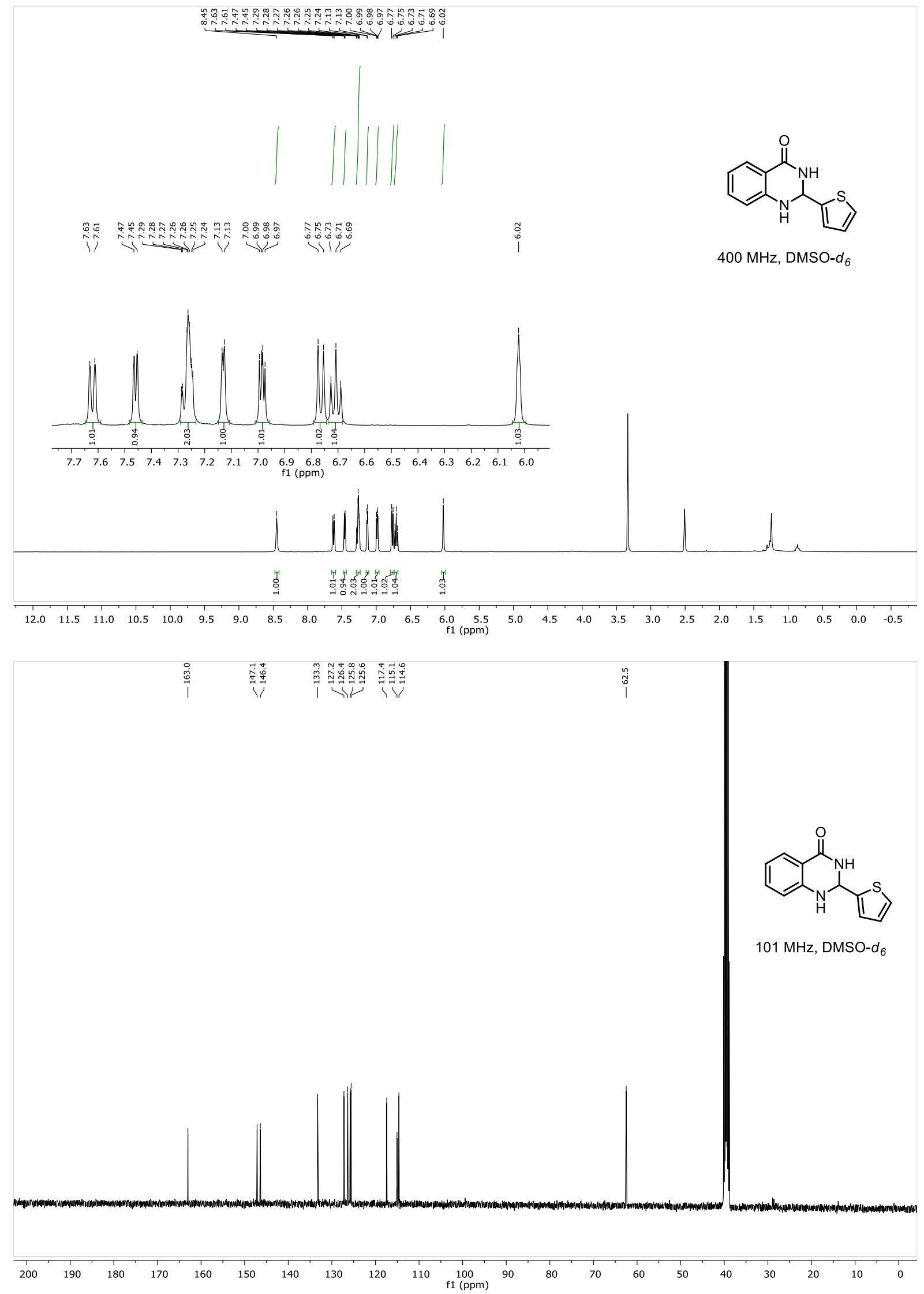


$\underline{{ }^{1} \mathrm{H} \text { and }{ }^{13} \mathrm{C}\left\{{ }^{1} \mathrm{H}\right\} \text { NMR of compound Br: }}$

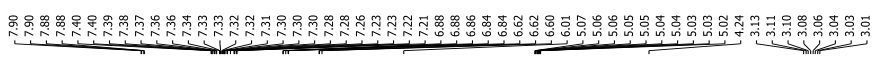

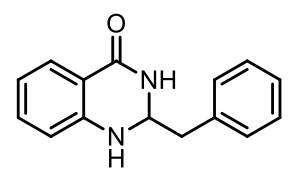

$400 \mathrm{MHz}, \mathrm{CDCl}_{3}$
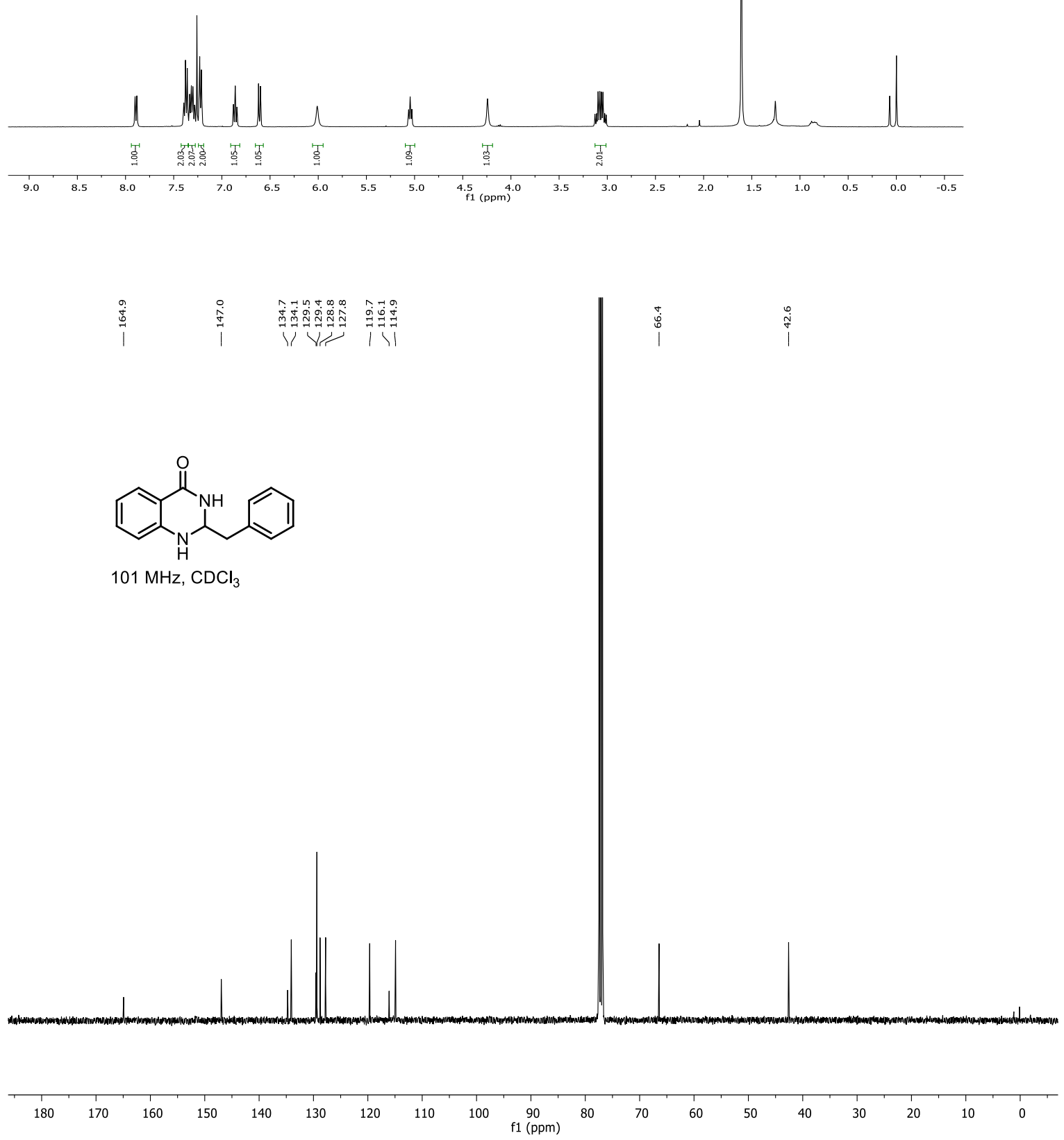

S28 
$\underline{{ }^{1} \mathrm{H} \text { and }{ }^{13} \mathrm{C}\left\{{ }^{1} \mathrm{H}\right\} \text { NMR of compound Bs: }}$

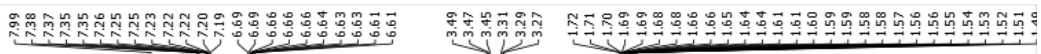<smiles>O=C1NC(N2CCCCC2)Nc2ccccc21</smiles>

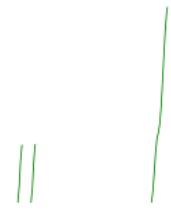

$300 \mathrm{MHz}, \mathrm{CDCl}_{3}$
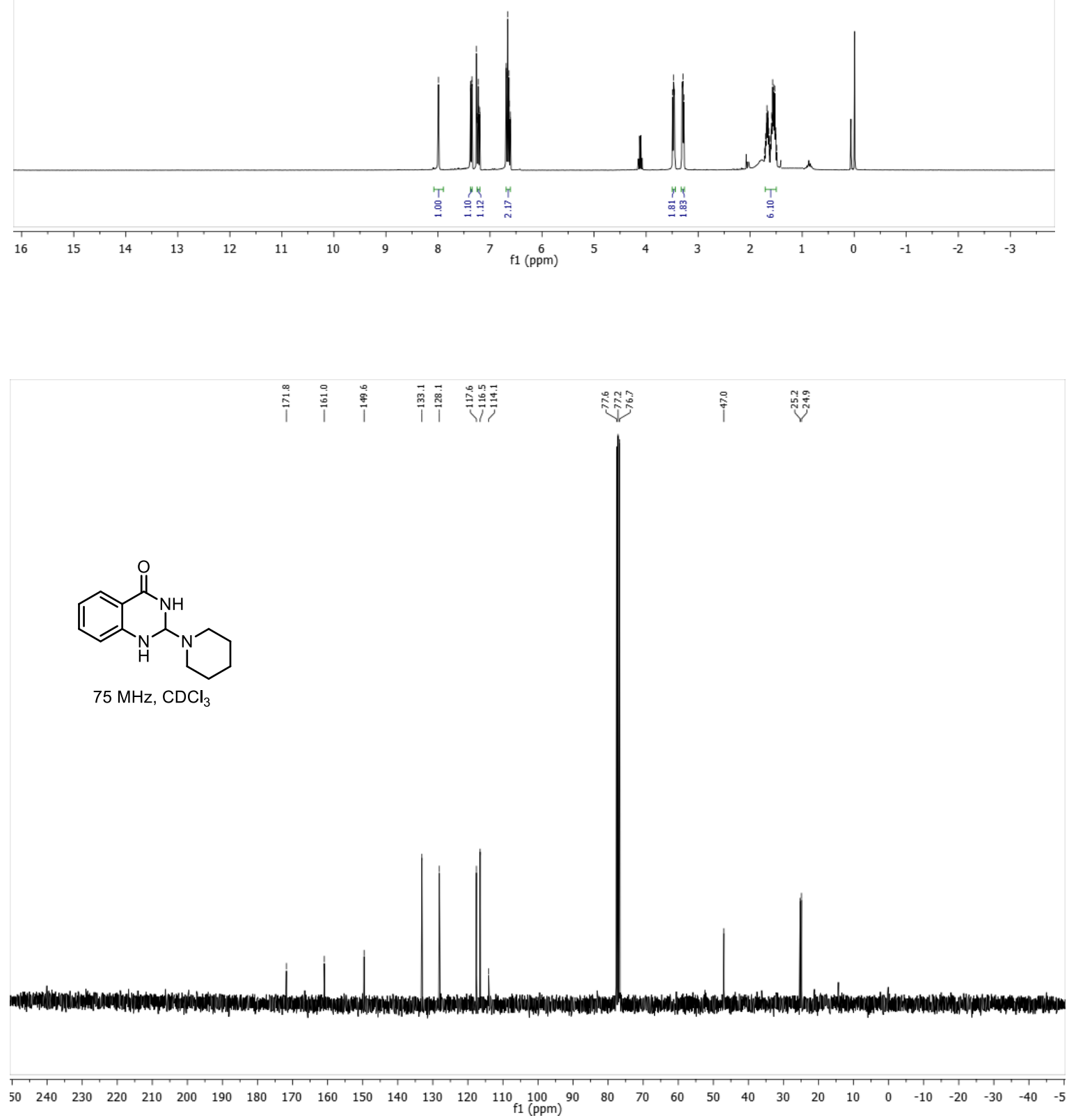

S29 
$\underline{{ }^{1} \mathrm{H} \text { and }{ }^{13} \mathrm{C}\left\{{ }^{1} \mathrm{H}\right\} \text { NMR of compound } 3 \mathrm{t}}$

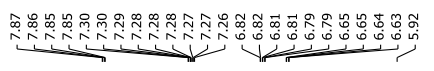

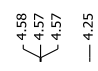

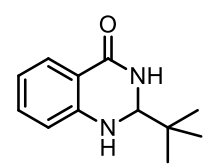

$500 \mathrm{MHz}, \mathrm{CDCl}_{3}$
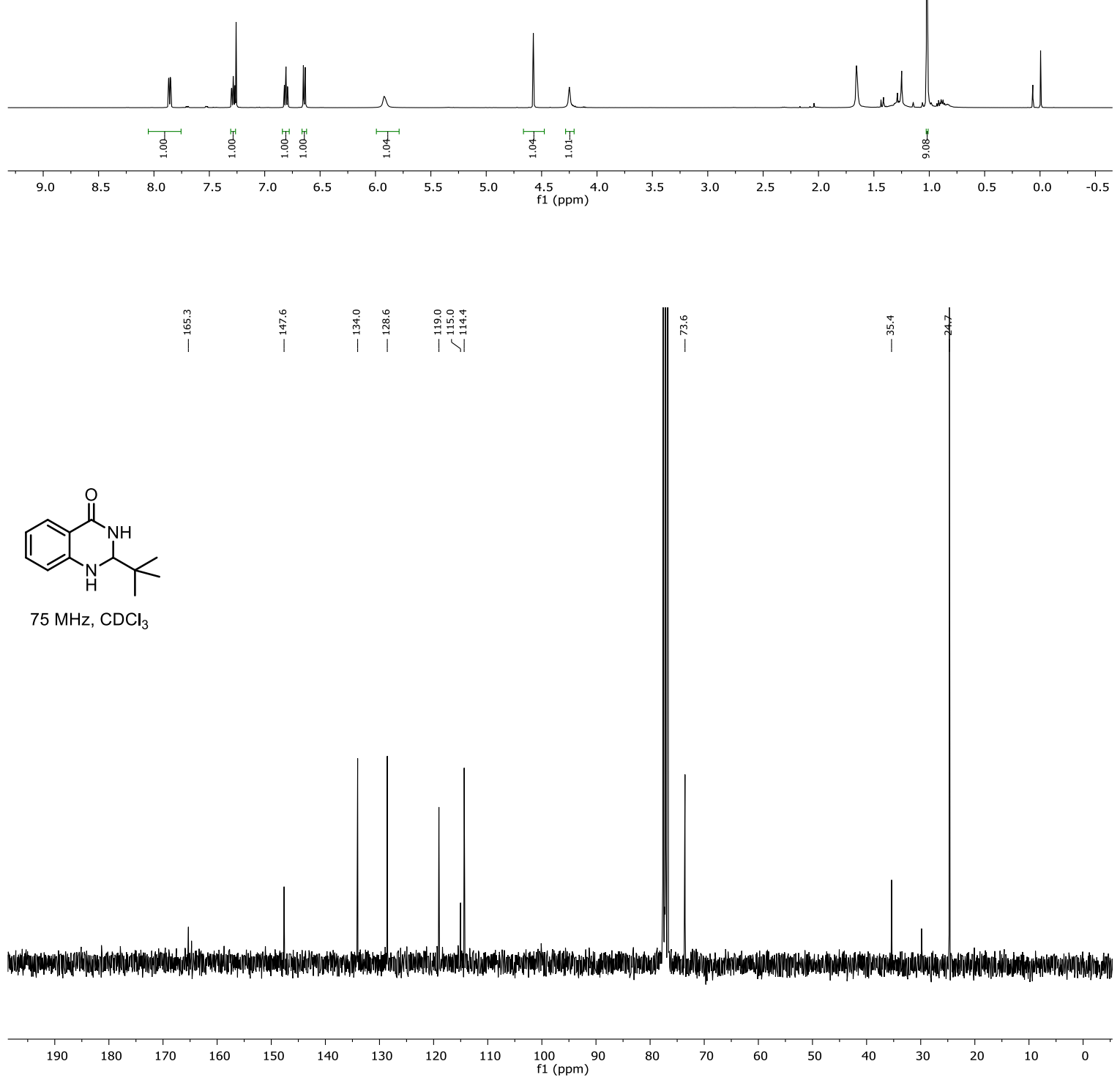

S30 


\section{$\underline{{ }^{1} \mathrm{H} \text { and }{ }^{13} \mathrm{C}\left\{{ }^{1} \mathrm{H}\right\} \text { NMR of compound } 3 \mathrm{u}:}$}

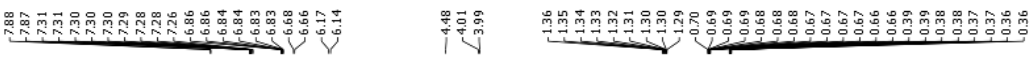<smiles>O=C1NC(C2CC2)Nc2ccccc21</smiles>

$500 \mathrm{MHz}, \mathrm{CDCl}_{3}$

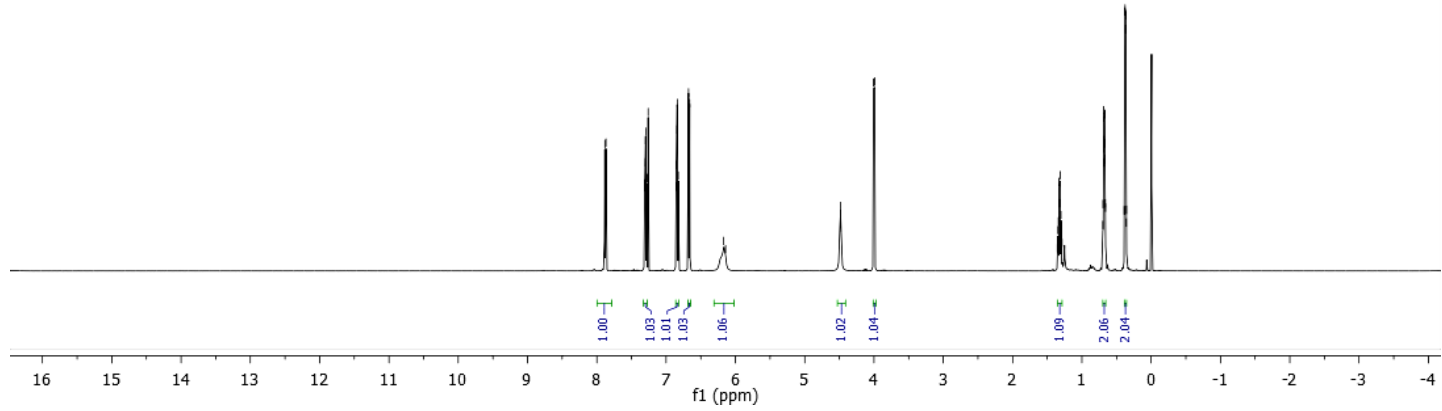

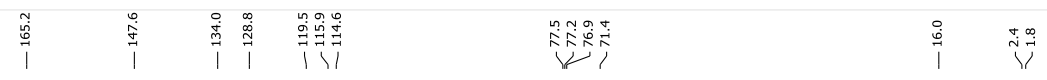<smiles>O=C1NC(C2CC2)Nc2ccccc21</smiles>

$101 \mathrm{MHz}, \mathrm{CDCl}_{3}$

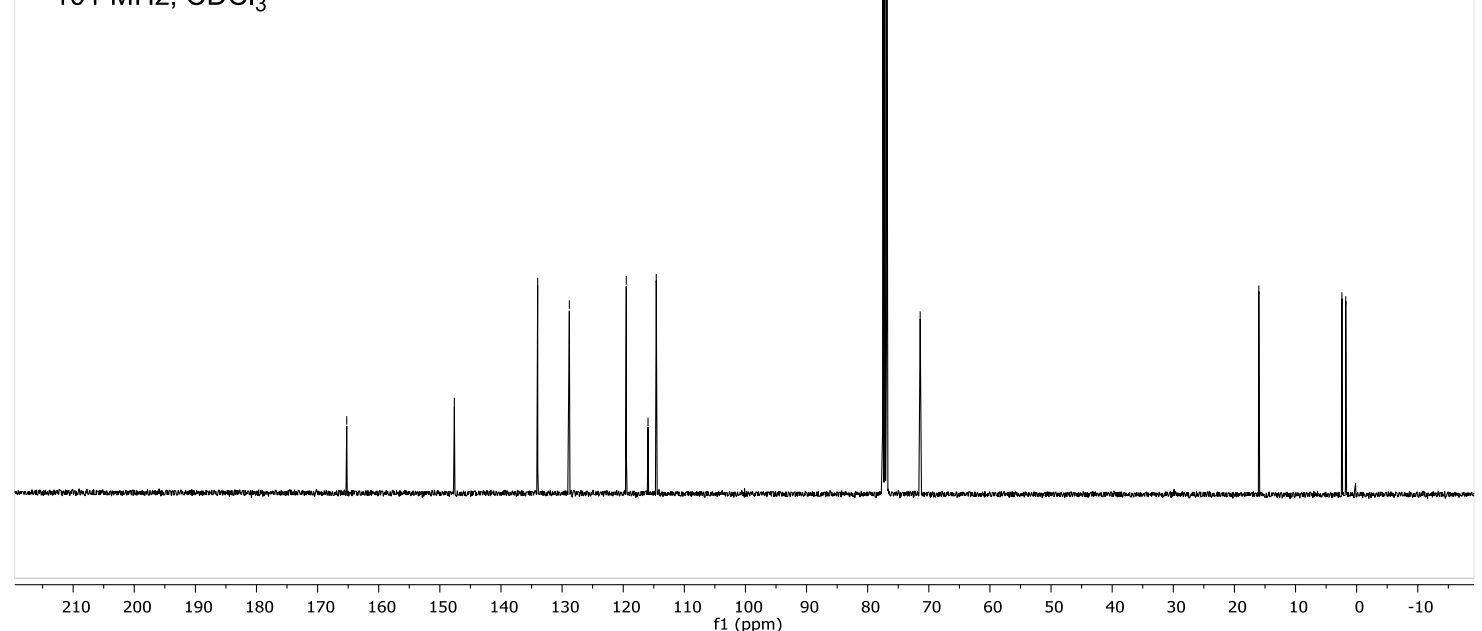


$\underline{{ }^{1} \mathrm{H} \text { and }{ }^{13} \mathrm{C}\left\{{ }^{1} \mathrm{H}\right\} \text { NMR of compound } 3 \mathrm{v}}$ :

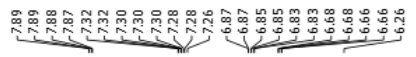

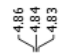

₹

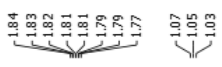

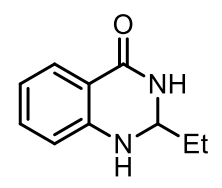

$400 \mathrm{MHz}, \mathrm{CDCl}_{3}$
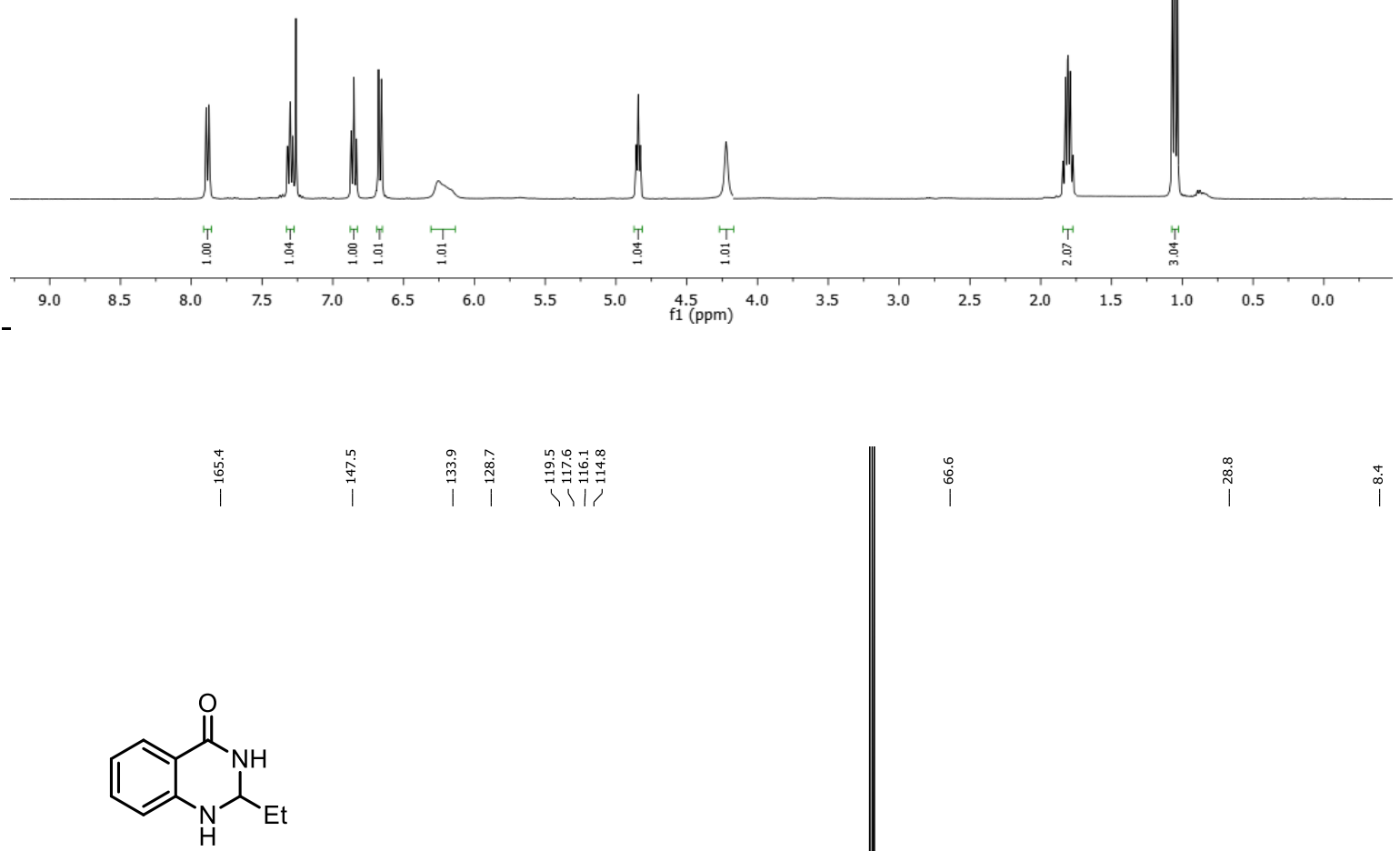

$101 \mathrm{MHz}, \mathrm{CDCl}_{3}$
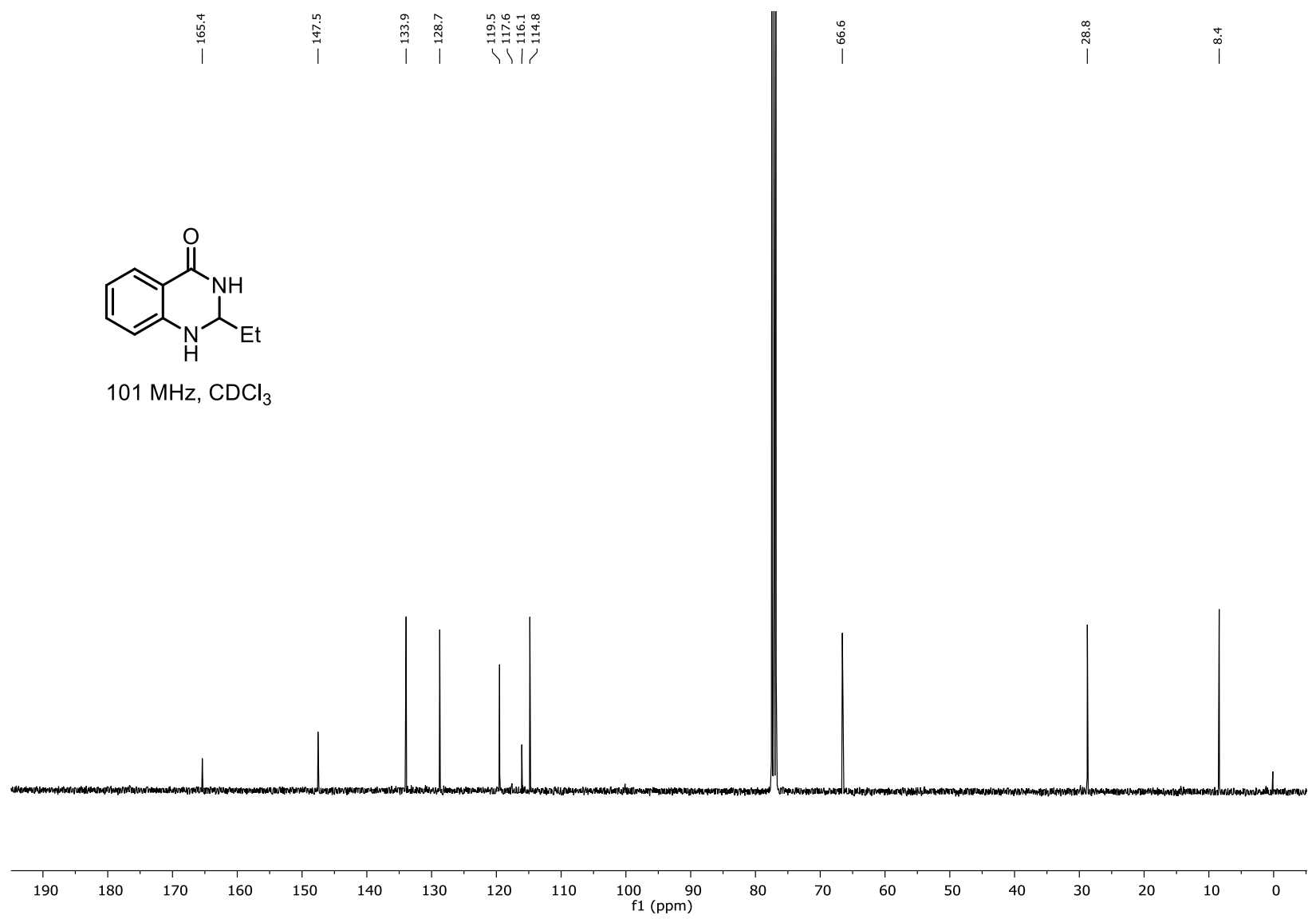

S32 
$\underline{{ }^{1} H \text { and }{ }^{13} \mathrm{C}\left\{{ }^{1} \mathrm{H}\right\} \text { NMR of compound Sa: }}$
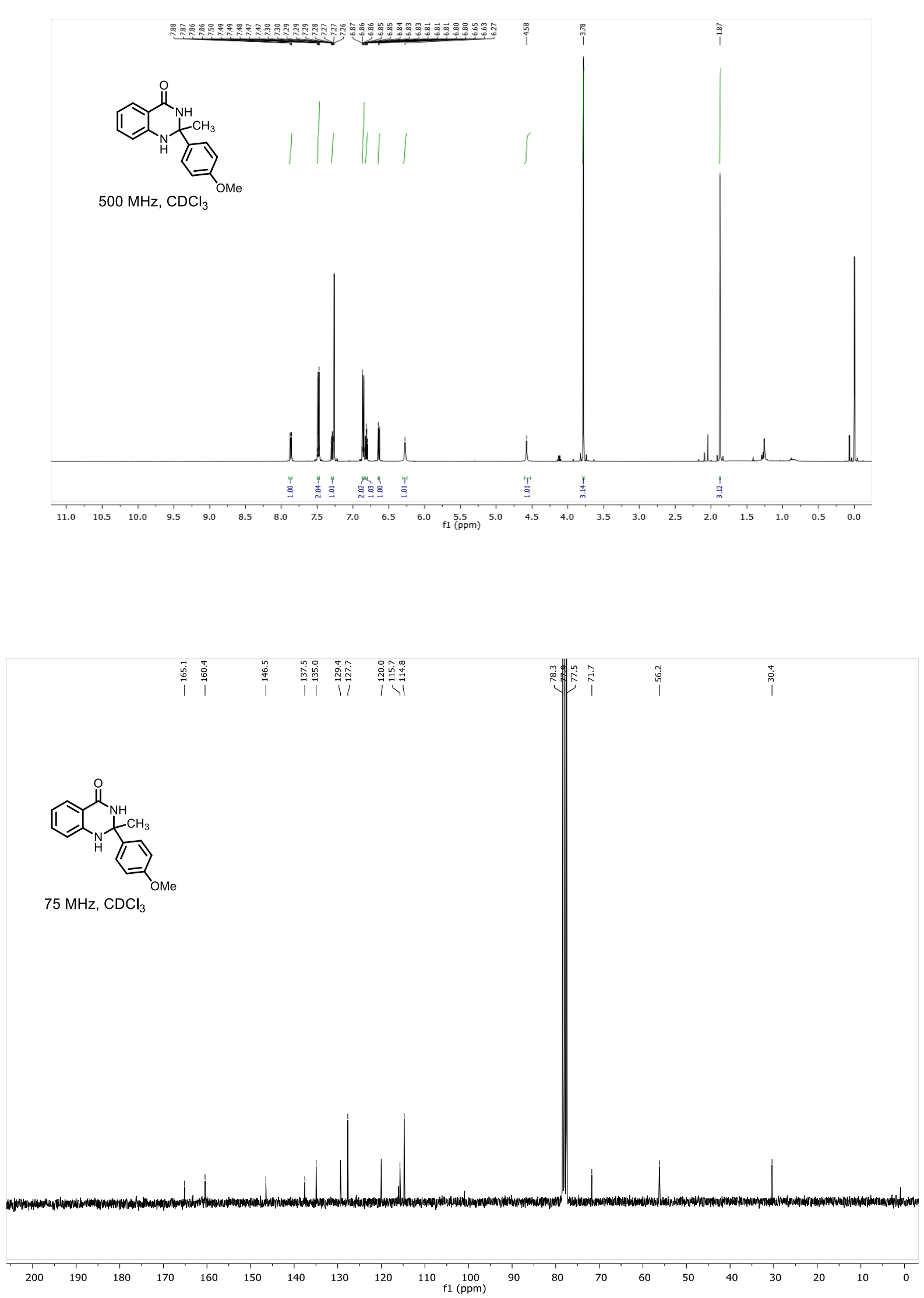

S33 
$\underline{{ }^{1} \mathrm{H} \text { and }{ }^{13} \mathrm{C}\left\{{ }^{1} \mathrm{H}\right\} \text { NMR of compound } 5 \mathrm{~b}:}$

$\underbrace{-10}$

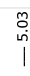

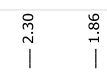
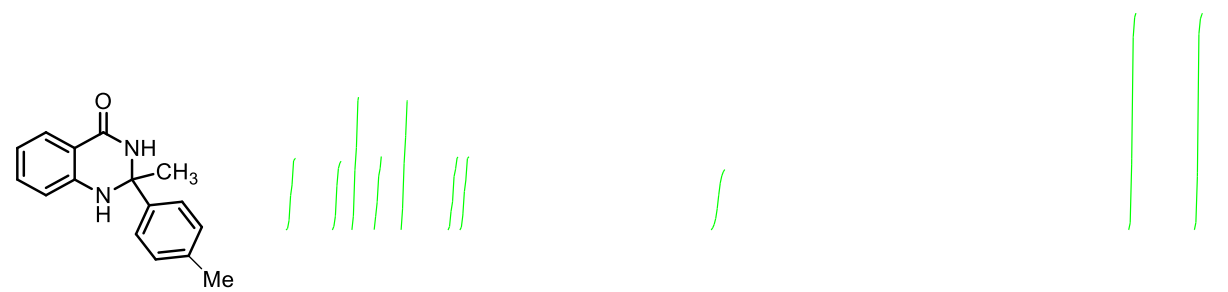

$400 \mathrm{MHz}, \mathrm{CDCl}_{3}$
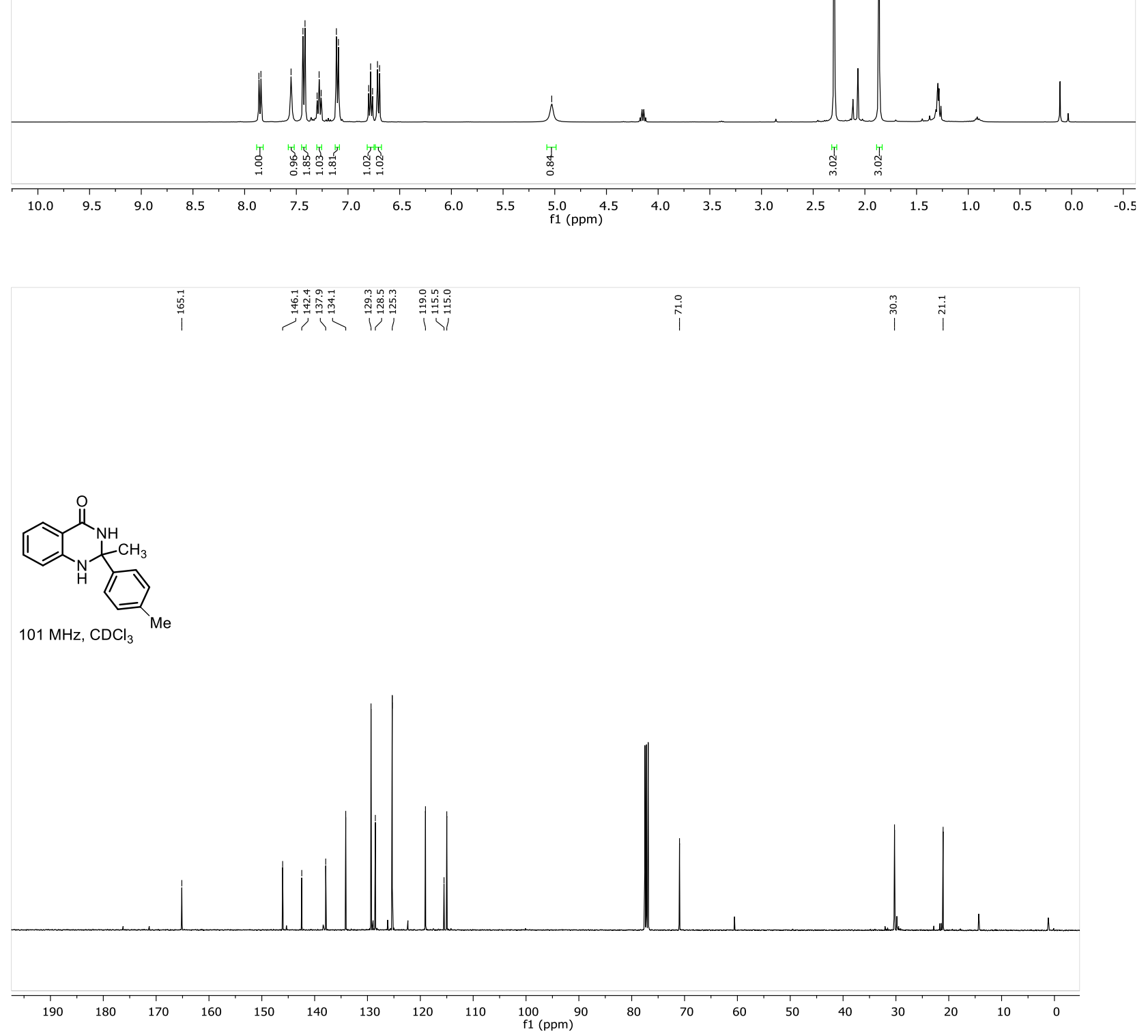

S34 
$\underline{{ }^{1} \mathrm{H} \text { and }{ }^{13} \mathrm{C}\left\{{ }^{1} \mathrm{H}\right\} \text { NMR of compound } 5 \mathrm{c}:}$

Y

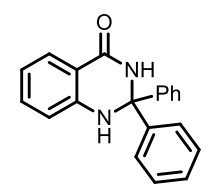

$400 \mathrm{MHz}$, DMSO- $d_{6}$

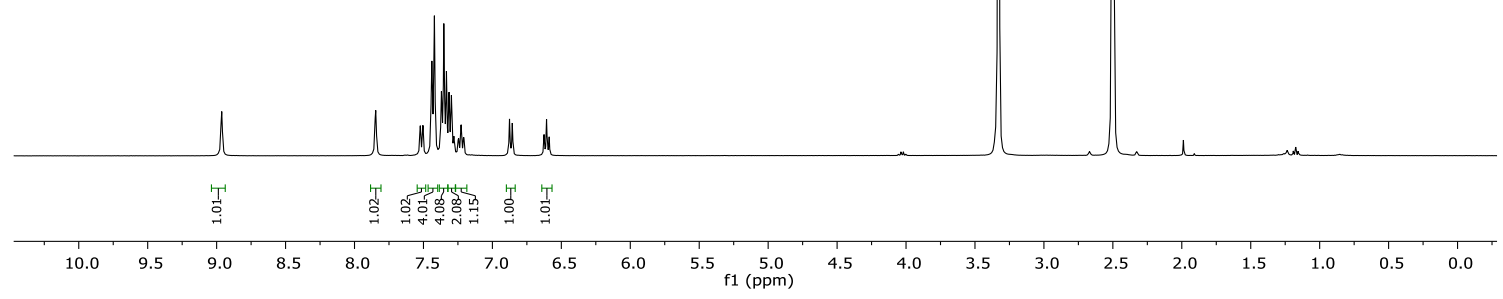

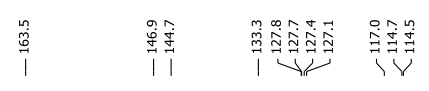
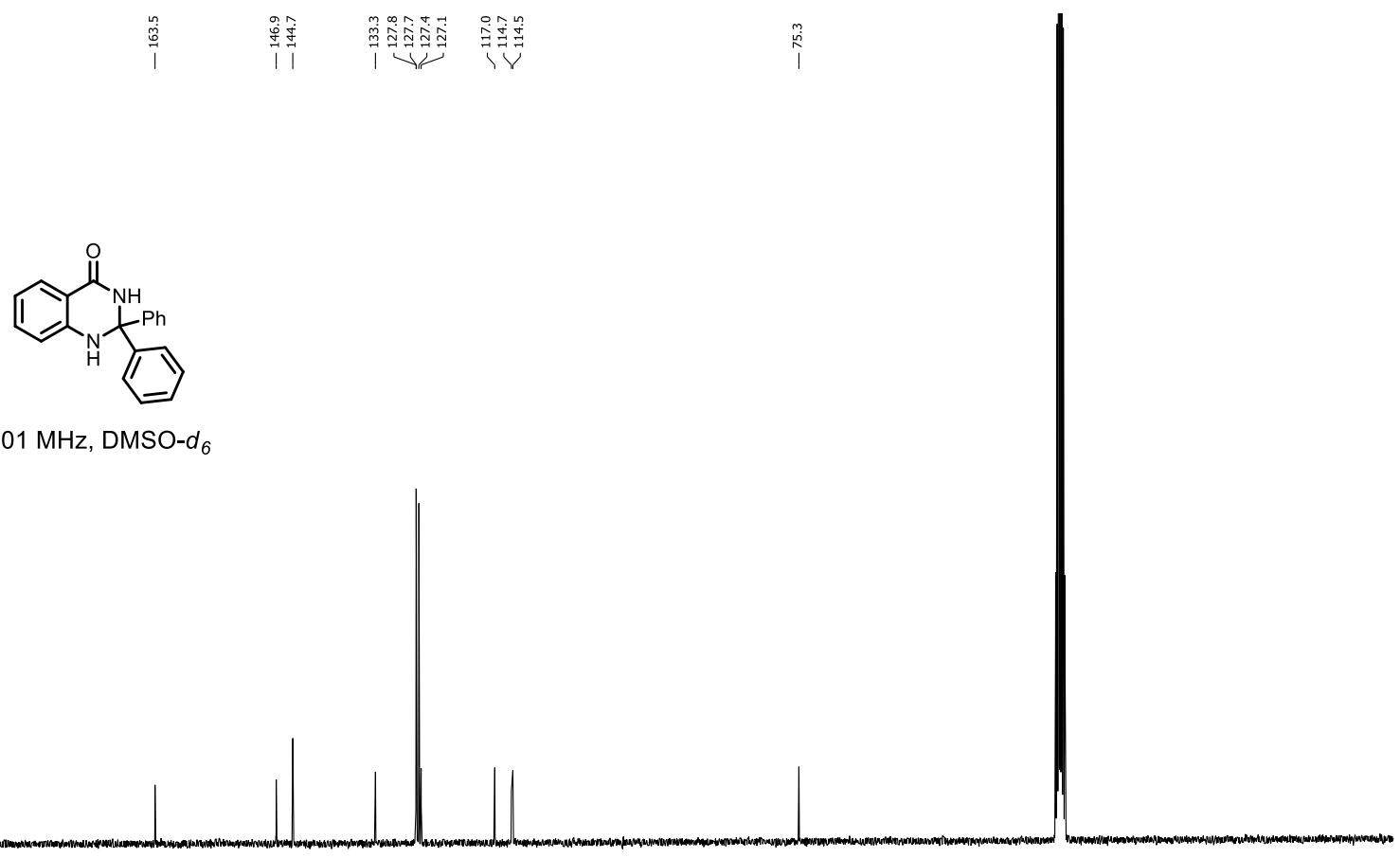

$101 \mathrm{MHz}, \mathrm{DMSO}-d_{6}$

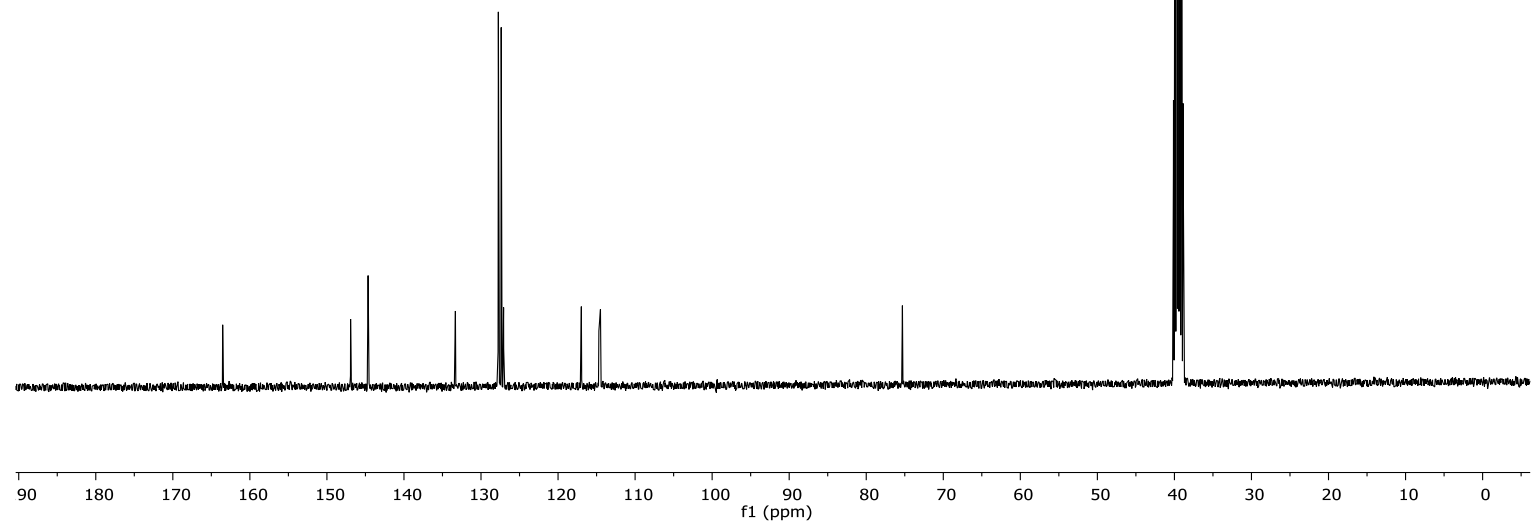

S35 
$\underline{{ }^{1} \mathrm{H} \text { and }{ }^{13} \mathrm{C}\left\{{ }^{1} \mathrm{H}\right\} \text { NMR of compound } 5 \mathrm{~d}:}$

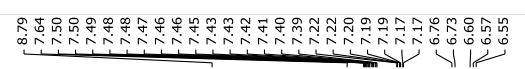

$\stackrel{\vec{P}}{i}$
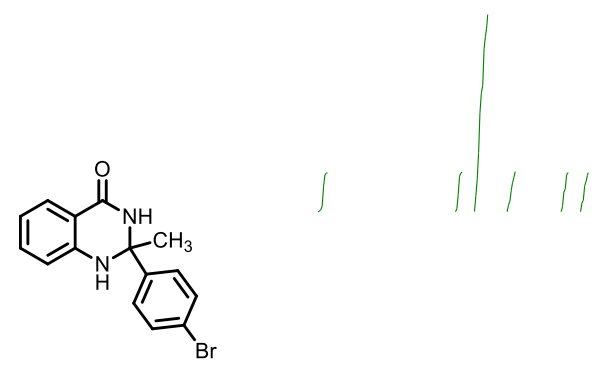

$300 \mathrm{MHz}, \mathrm{DMSO}-d_{6}$
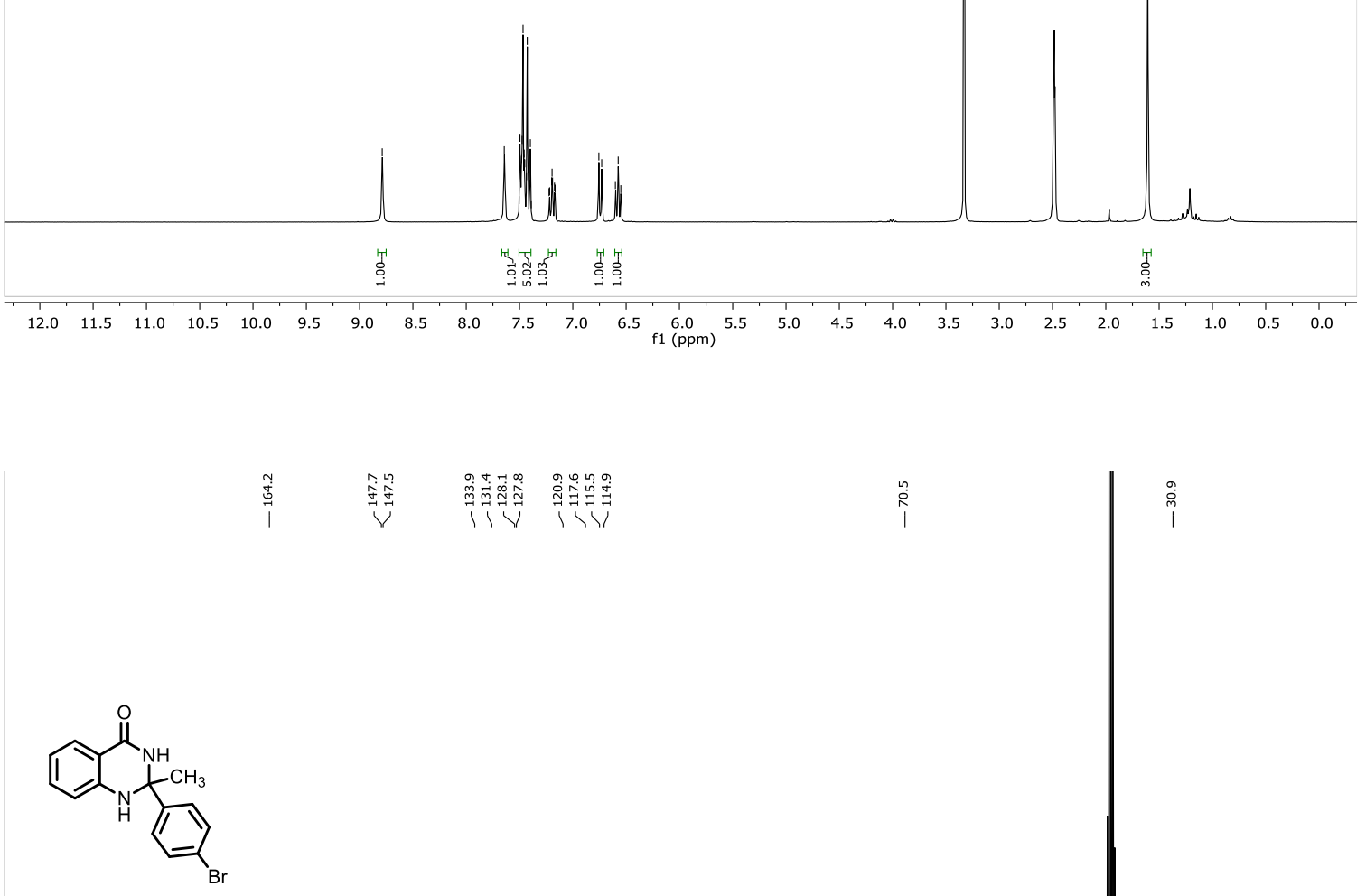

$75 \mathrm{MHz}, \mathrm{DMSO}-d_{6}$

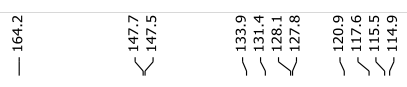
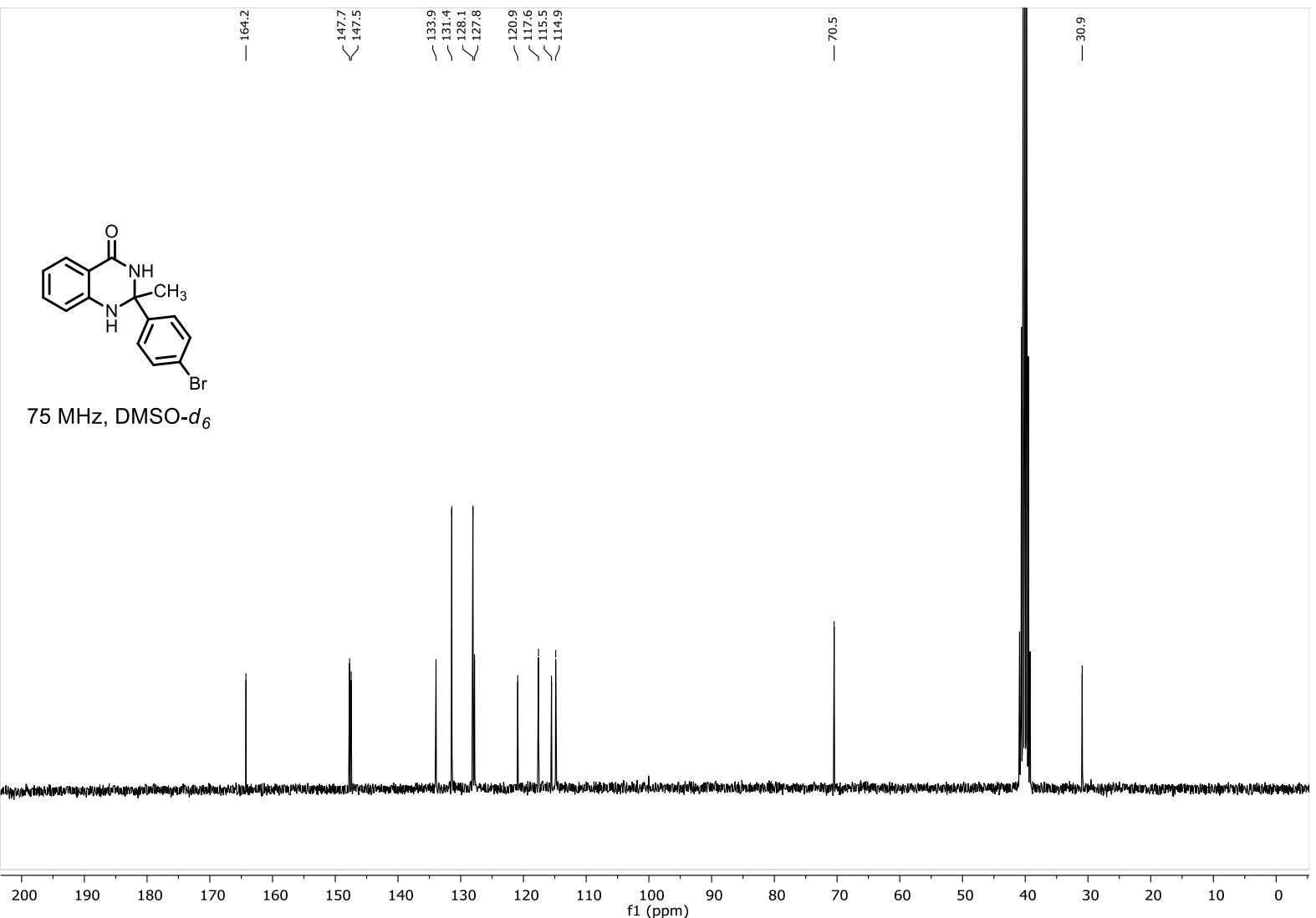

S36 


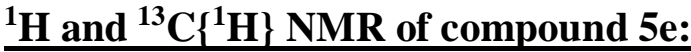

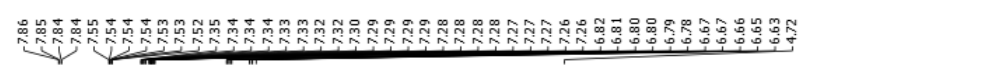

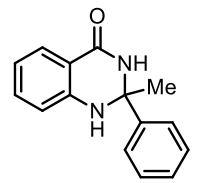

$500 \mathrm{MHz}, \mathrm{CDCl}_{3}$
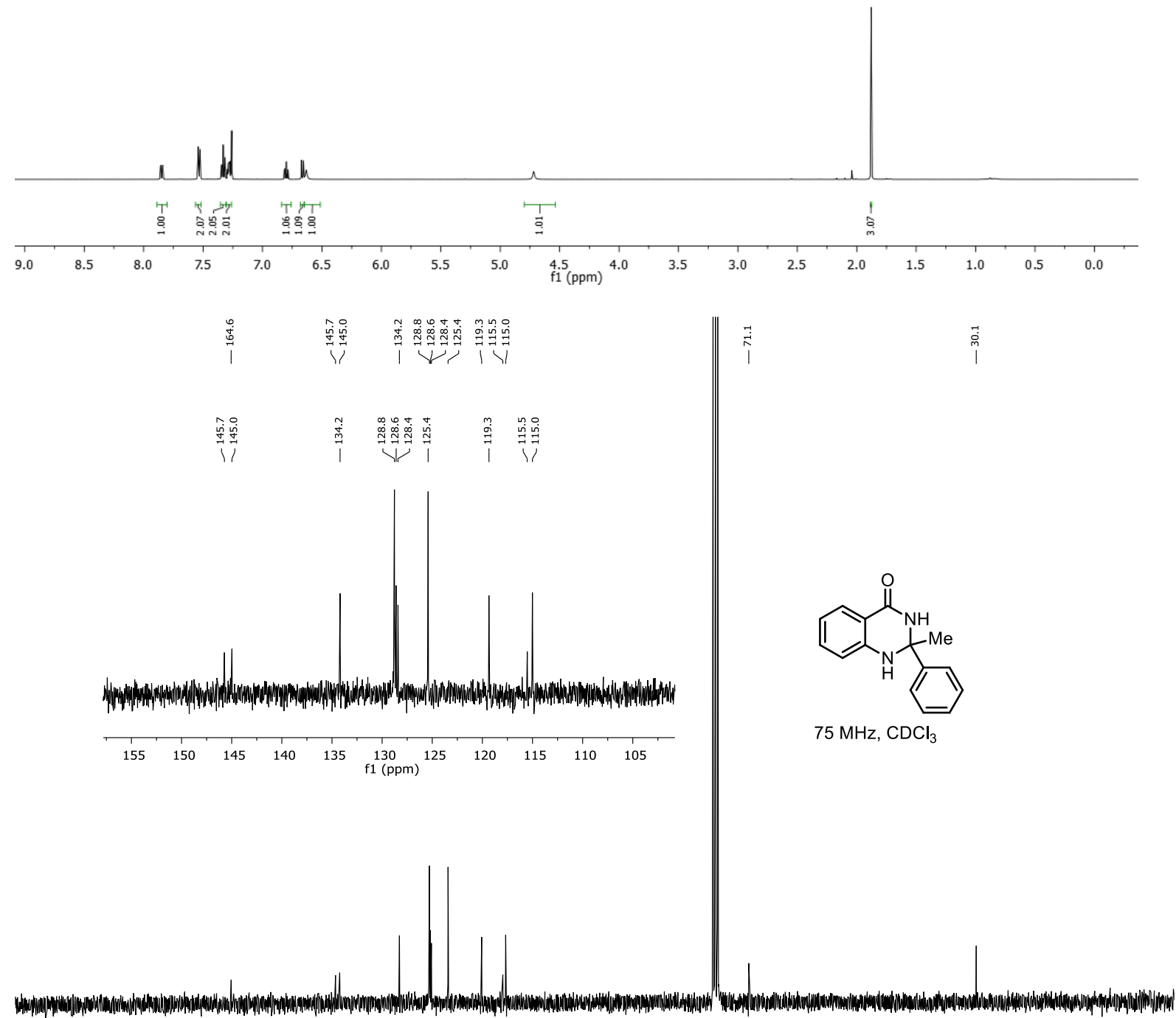

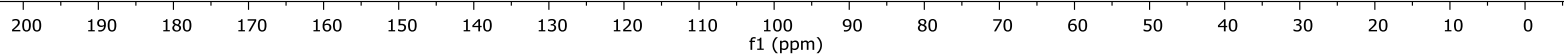


$\underline{{ }^{1} H \text { and }{ }^{13} C\left\{{ }^{1} H\right\} \text { NMR of compound } 5 f}$

$\underbrace{\text { Bon }}$

$500 \mathrm{MHz}$, DMSO- $d_{6}$

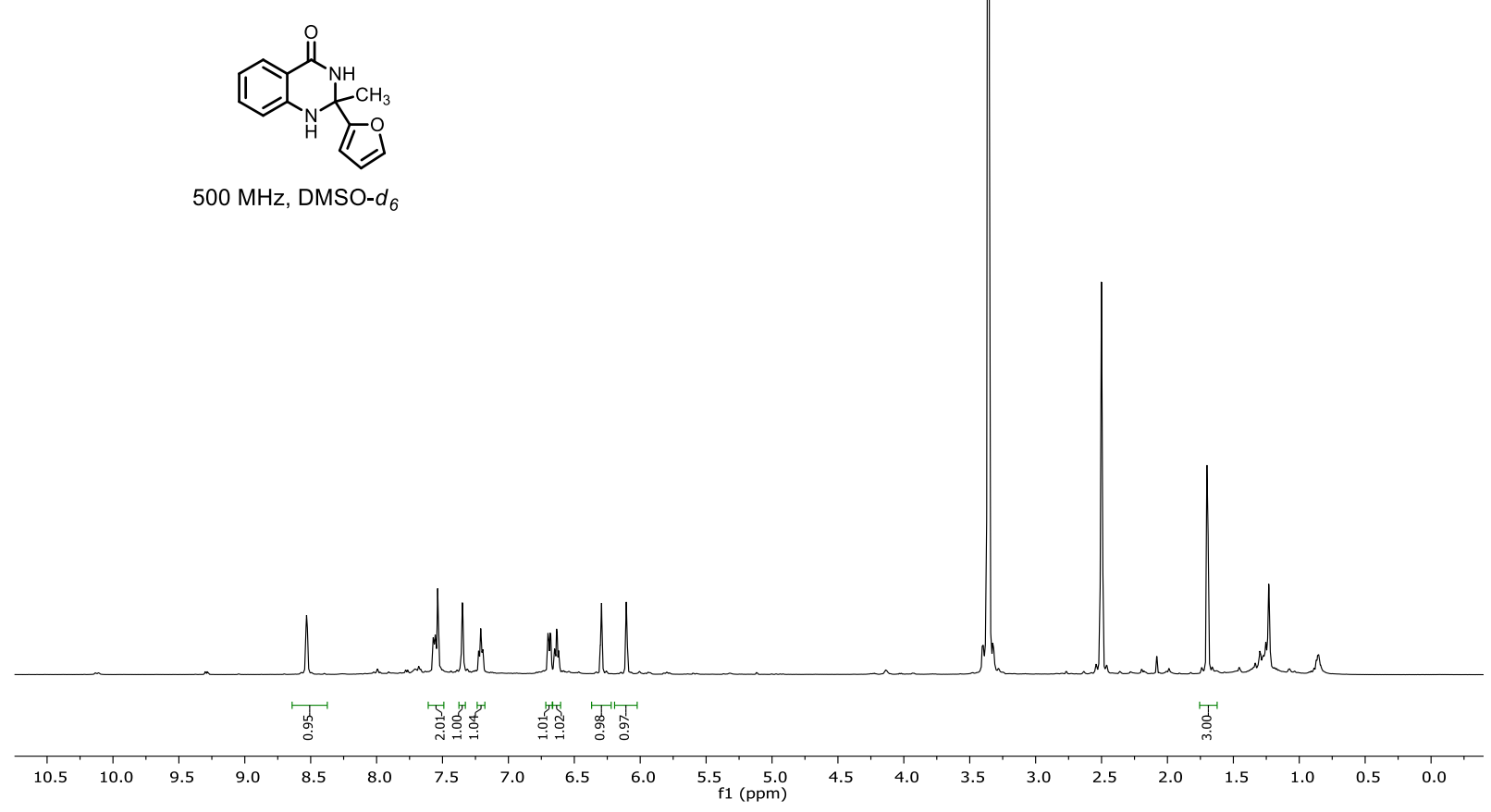

望

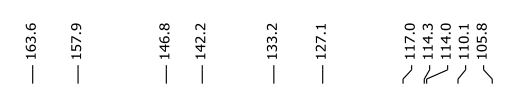

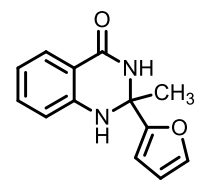

$101 \mathrm{MHz}, \mathrm{DMSO}_{6}$
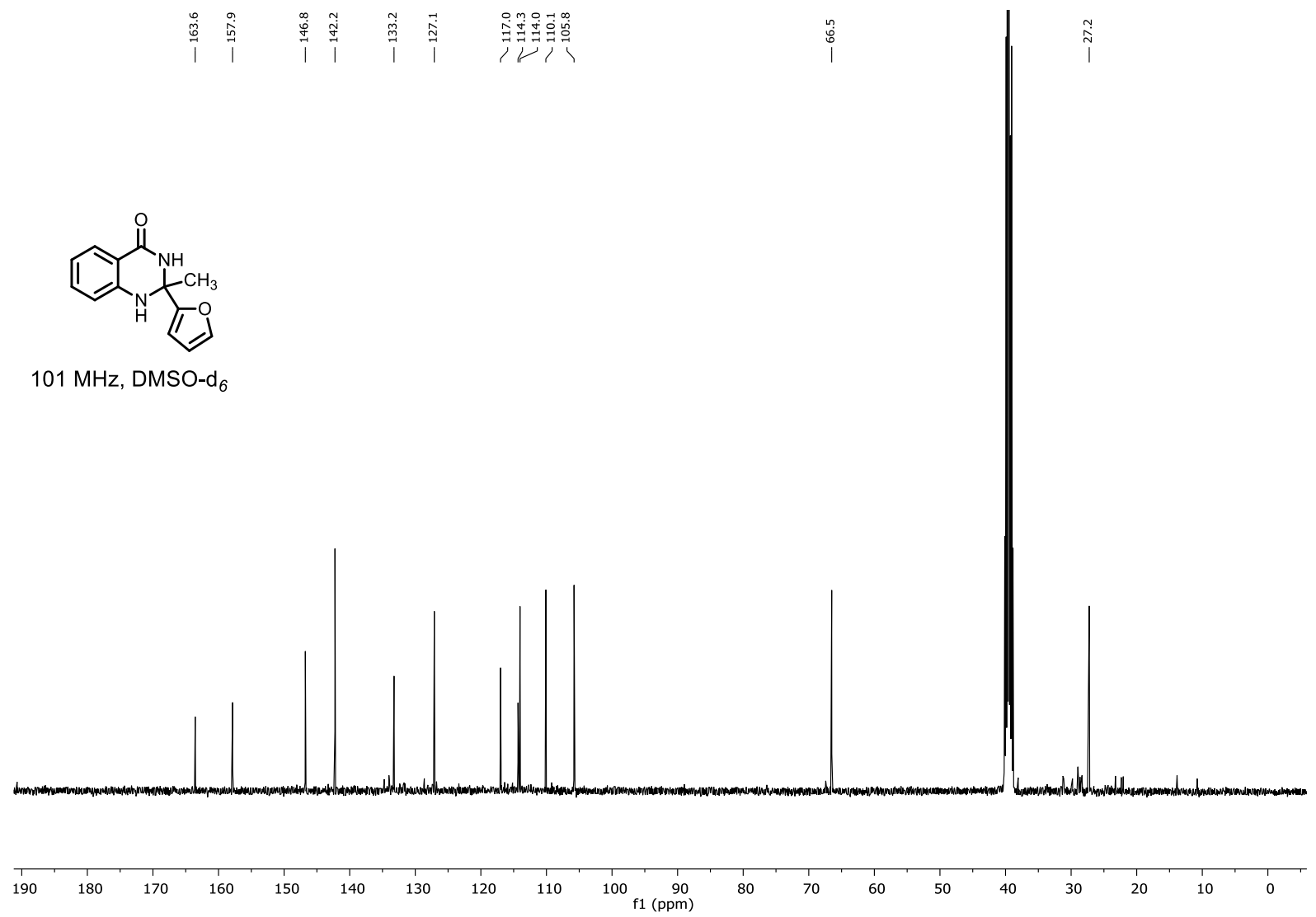

S38 


\section{$\underline{{ }^{1} \mathrm{H} \text { and }{ }^{13} \mathrm{C}\left\{{ }^{1} \mathrm{H}\right\} \text { NMR of compound } 5 \mathrm{~g}:}$}
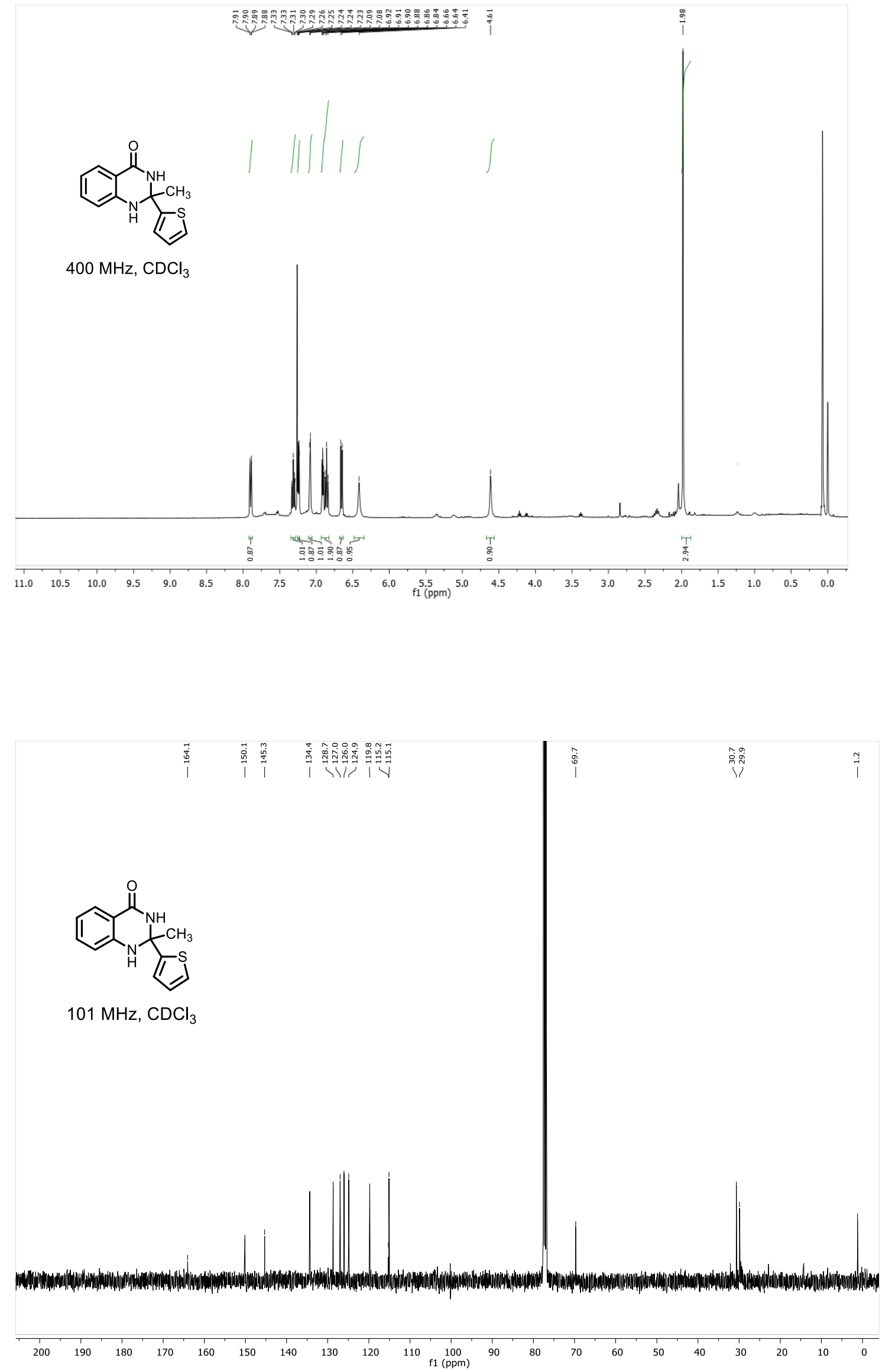


\section{$\underline{{ }^{1} \mathrm{H} \text { and }}{ }^{13} \mathrm{C}\left\{{ }^{1} \mathrm{H}\right\}$ NMR of compound $5 \mathrm{~h}:$}
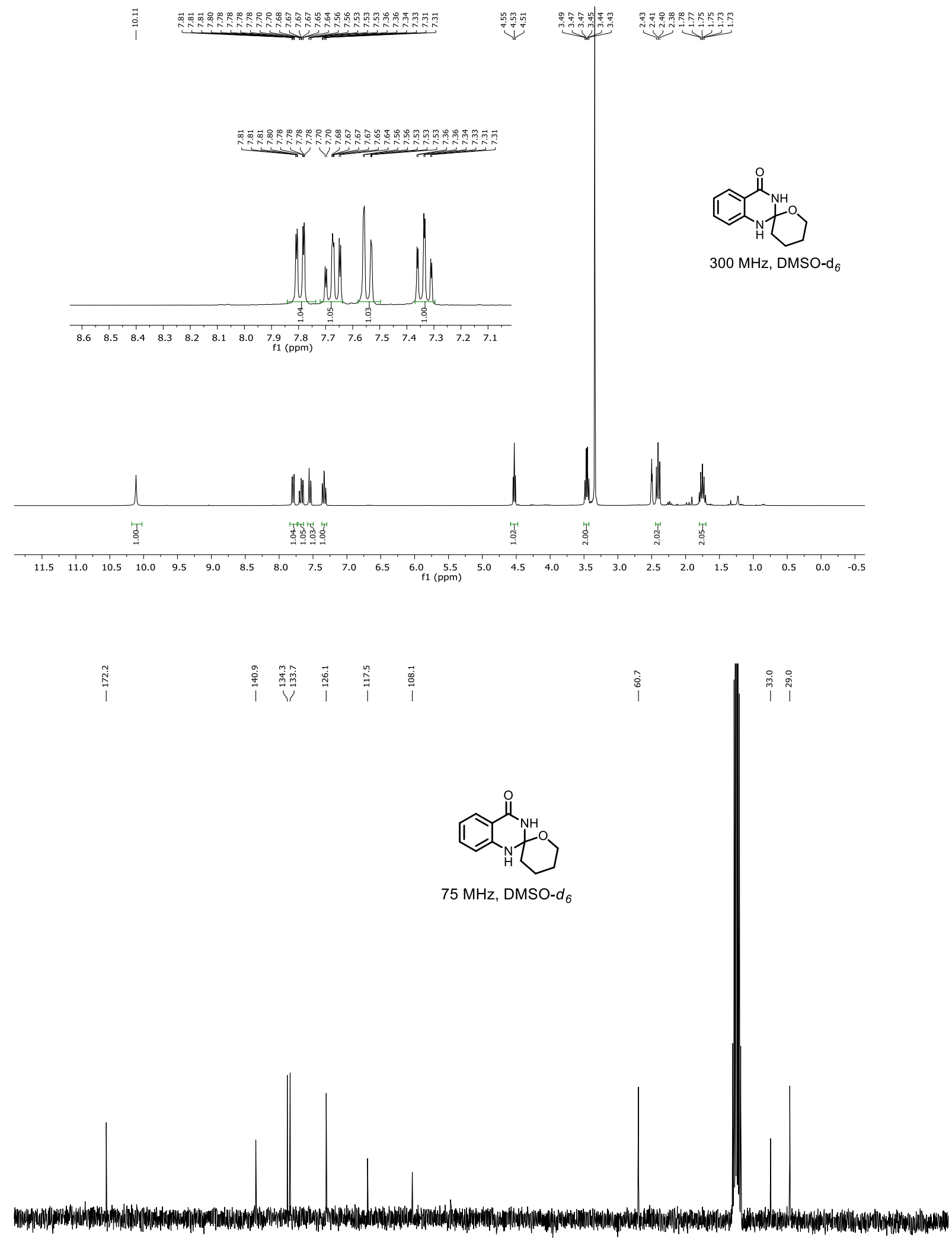

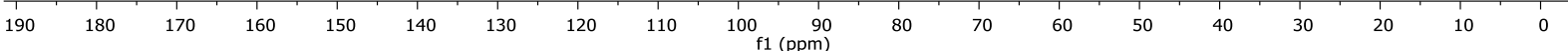




\section{$\underline{{ }^{1} \mathrm{H} \text { and }{ }^{13} \mathrm{C}\left\{{ }^{1} \mathrm{H}\right\} \text { NMR of compound 5i: }}$}

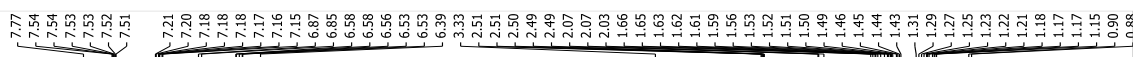
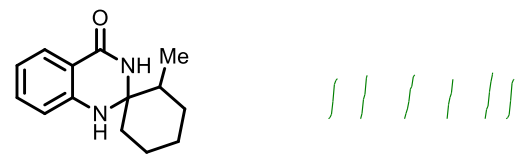

$300 \mathrm{MHz}$, DMSO-d 6
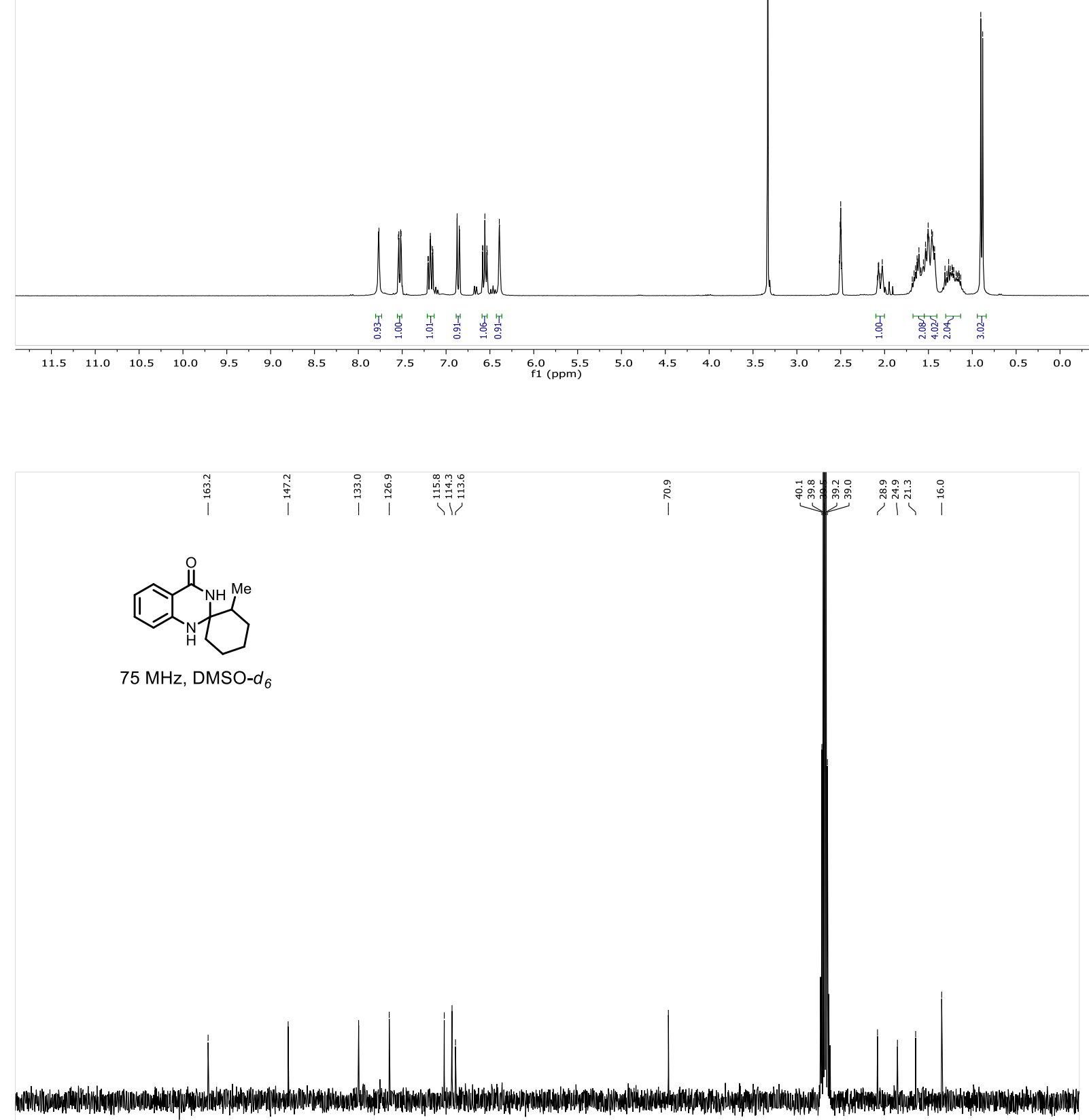

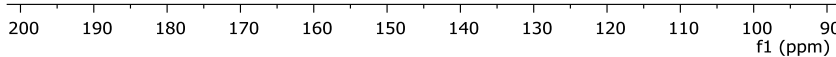


$\underline{{ }^{1} \mathrm{H} \text { NMR of compound 5i: }}$

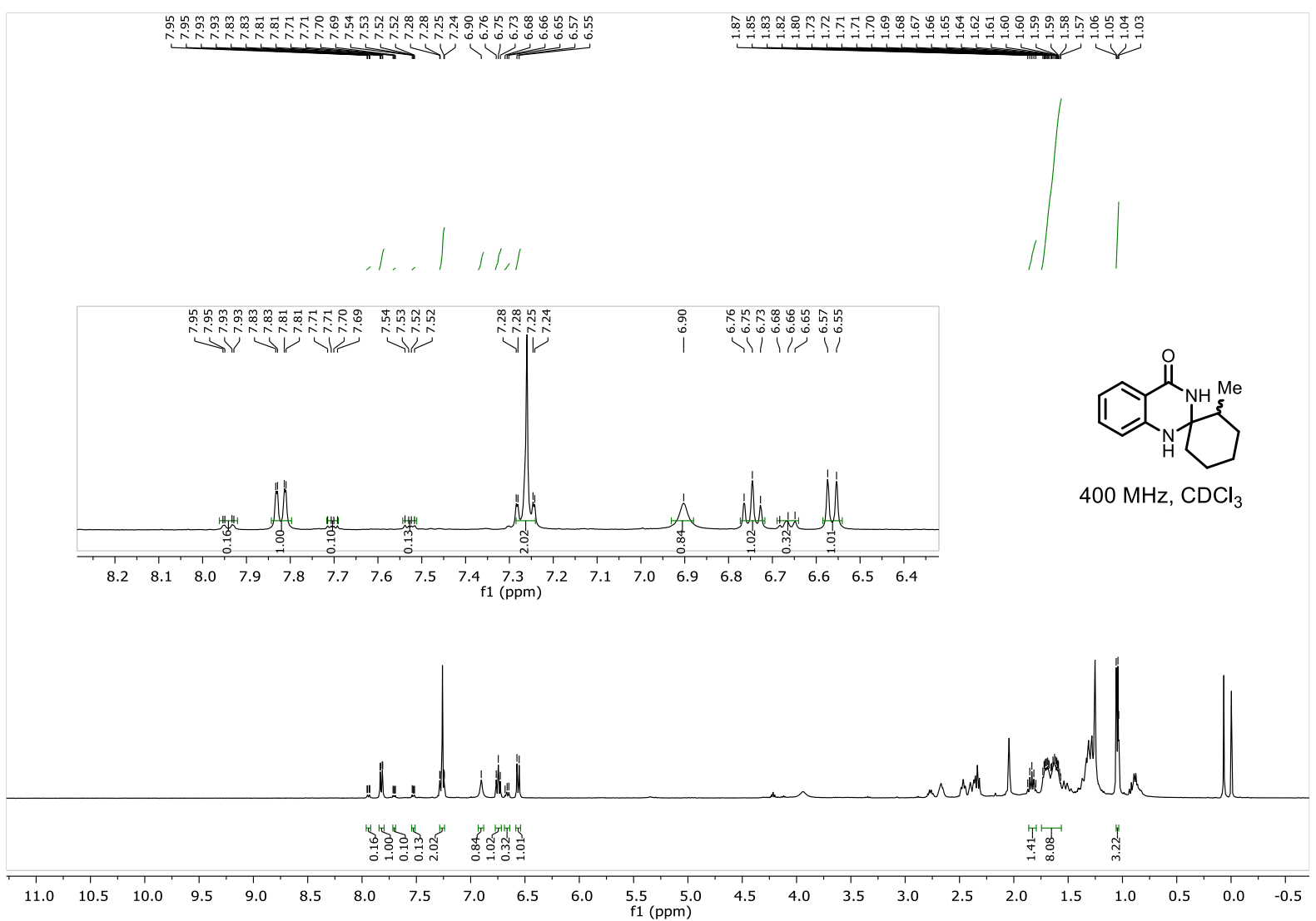




\section{$\underline{{ }^{1} \mathrm{H} \text { and }{ }^{13} \mathrm{C}\left\{{ }^{1} \mathrm{H}\right\} \text { NMR of compound 5j: }}$}
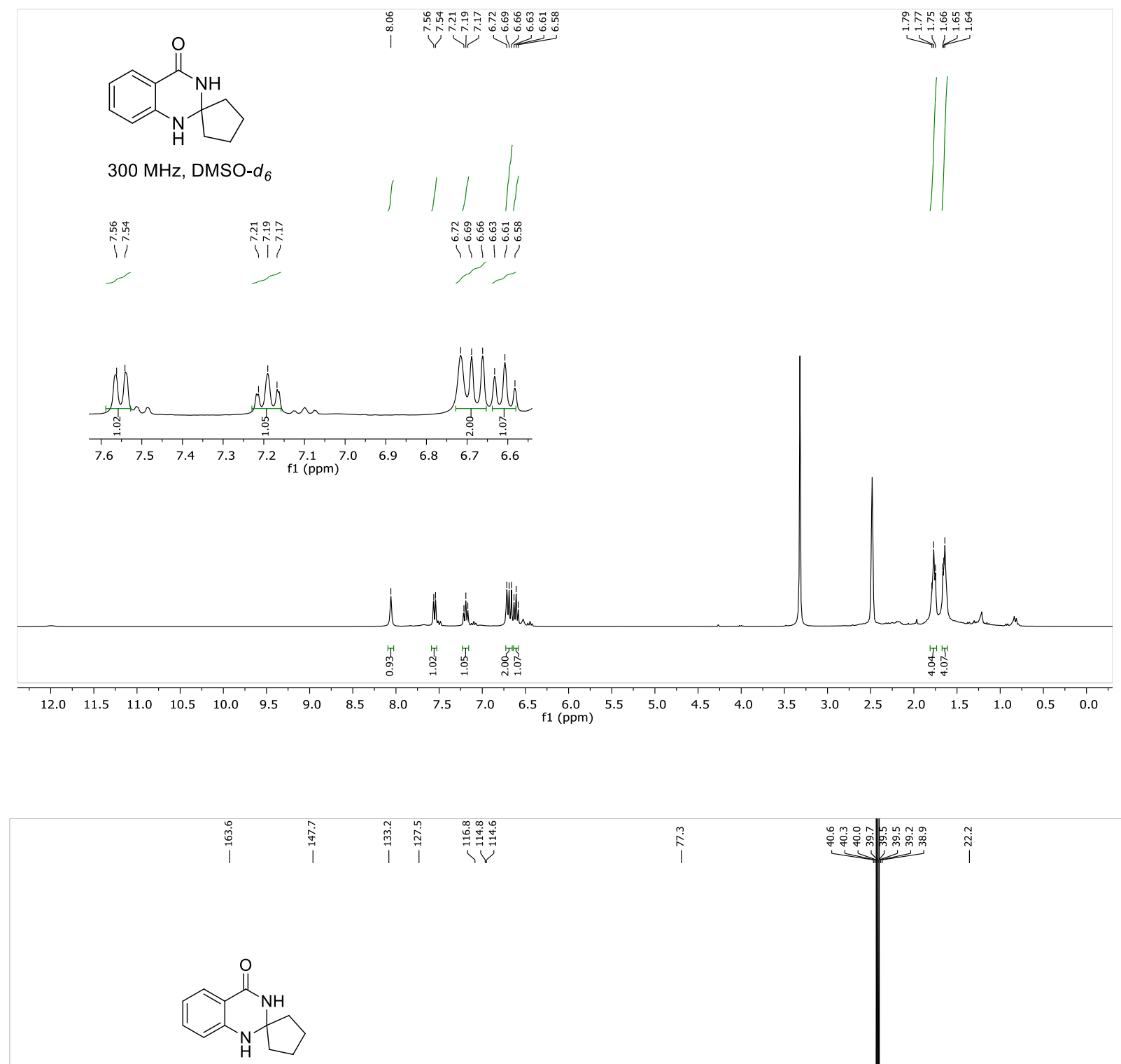

$75 \mathrm{MHz}, \mathrm{DMSO}-d_{6}$

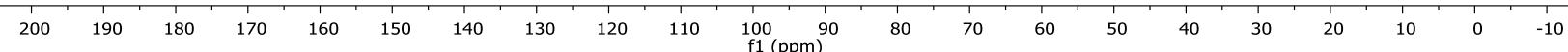




\section{$\underline{{ }^{1} \mathrm{H} \text { and }{ }^{13} \mathrm{C}\left\{{ }^{1} \mathrm{H}\right\} \text { NMR of compound 5k: }}$}

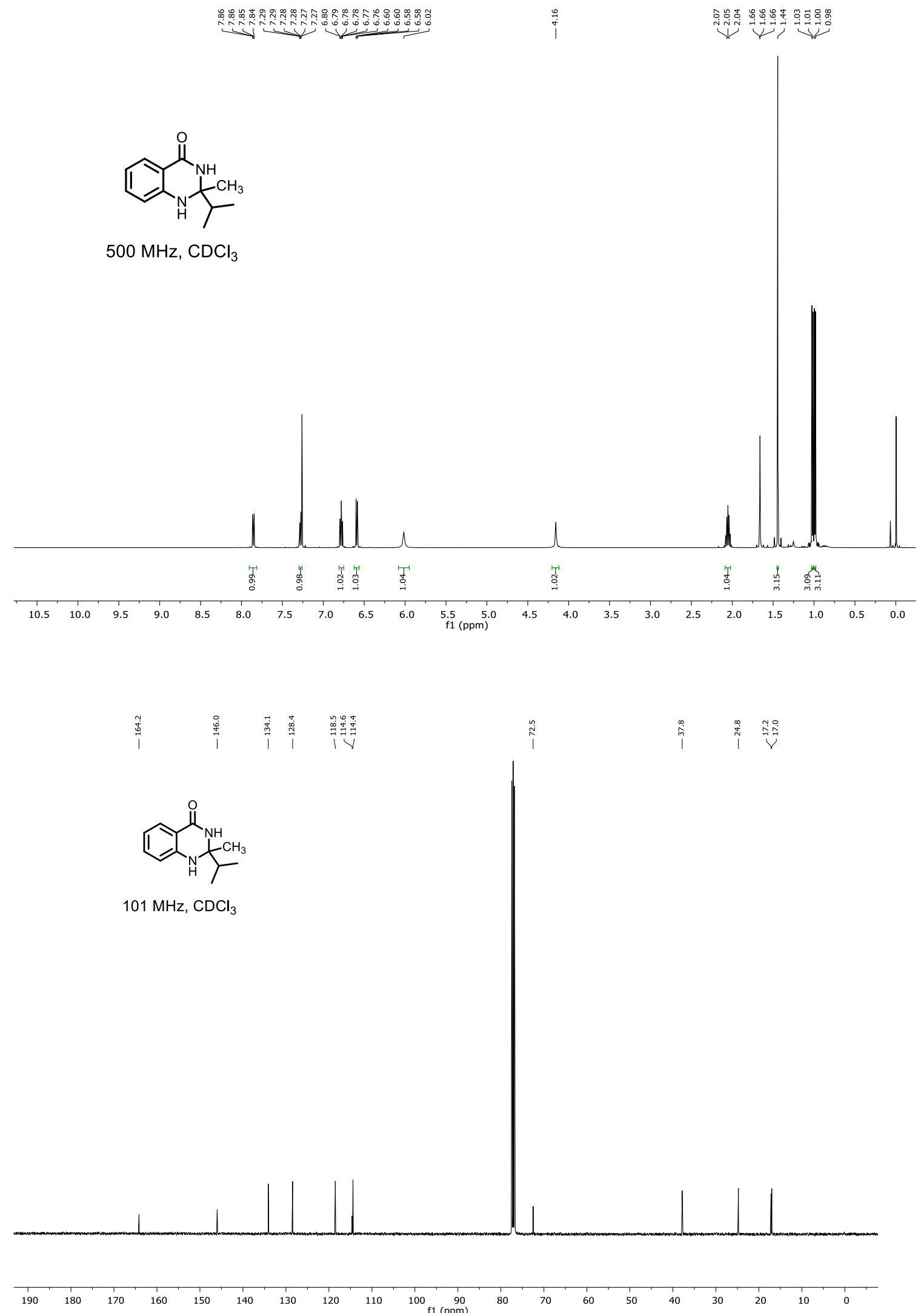


$\underline{{ }^{1} H \text { and }{ }^{13} C}\left\{{ }^{1} H\right\}$ NMR of compound Fl:

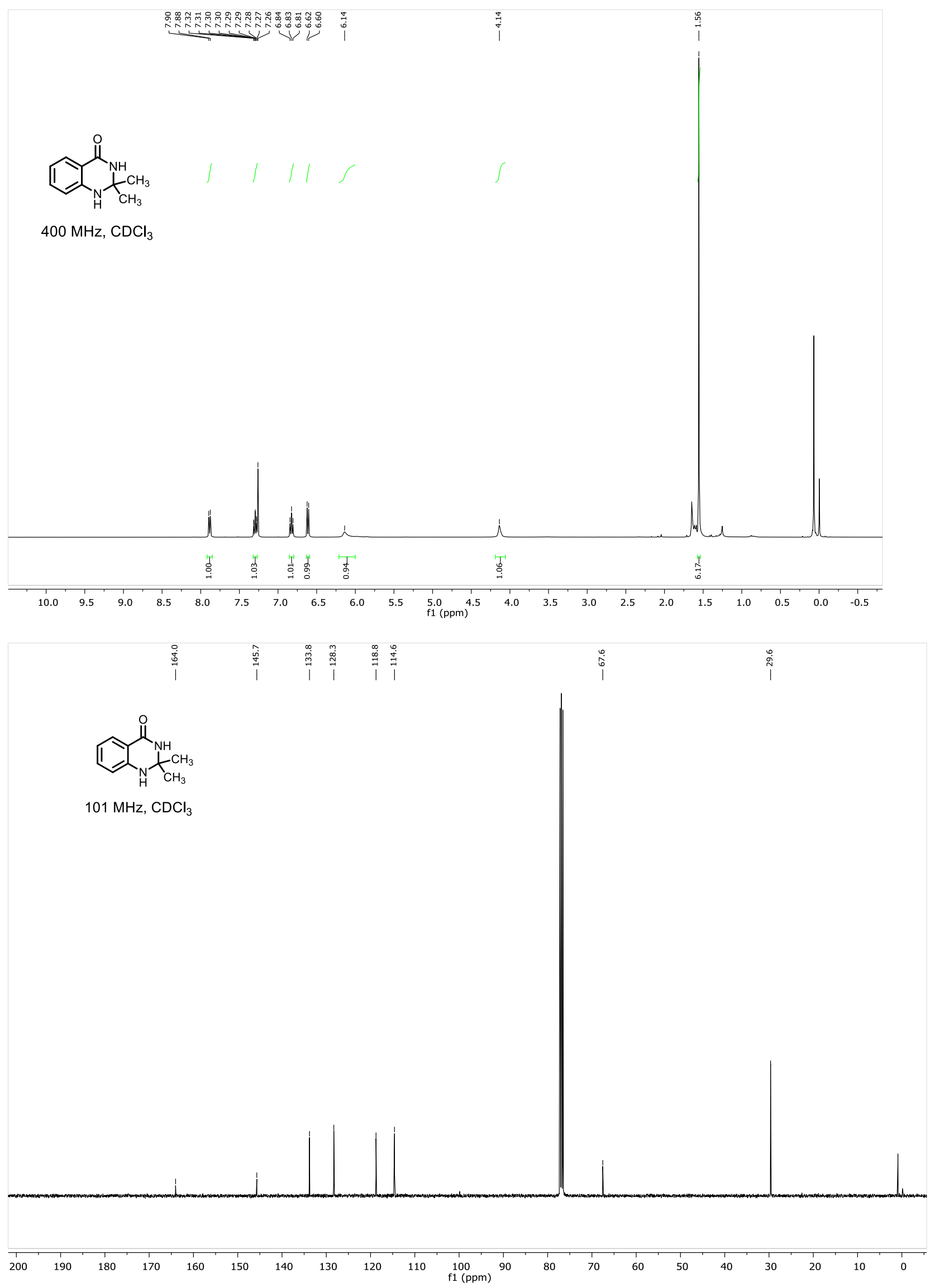

S45 


\section{$\underline{{ }^{1} \mathrm{H} \text { and }{ }^{13} \mathrm{C}\left\{{ }^{1} \mathrm{H}\right\} \text { NMR of compound 5m: }}$}

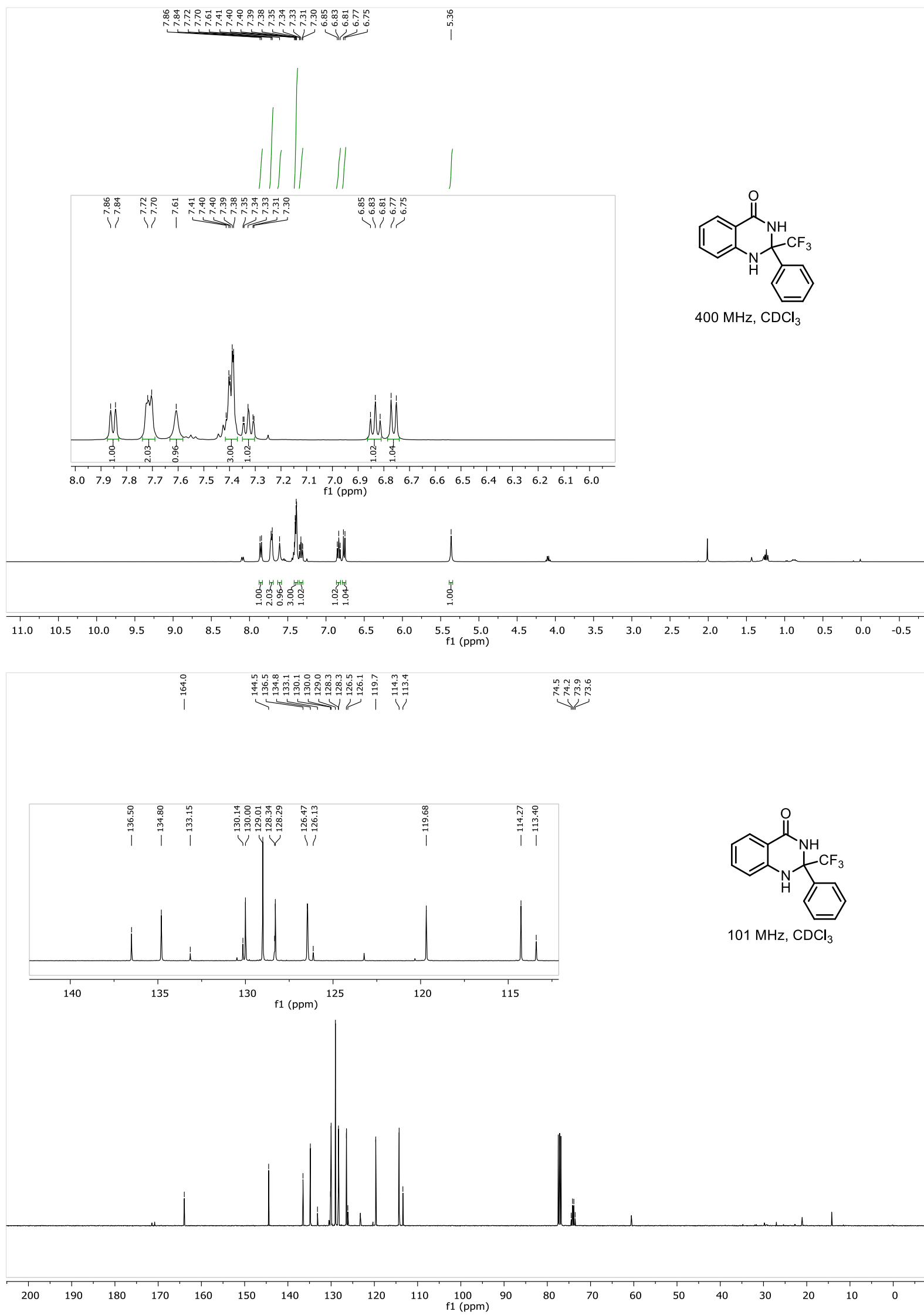


$\underline{{ }^{1} \mathrm{H} \text { and }{ }^{13} \mathrm{C}\left\{{ }^{1} \mathrm{H}\right\} \text { NMR of compound ba: }}$
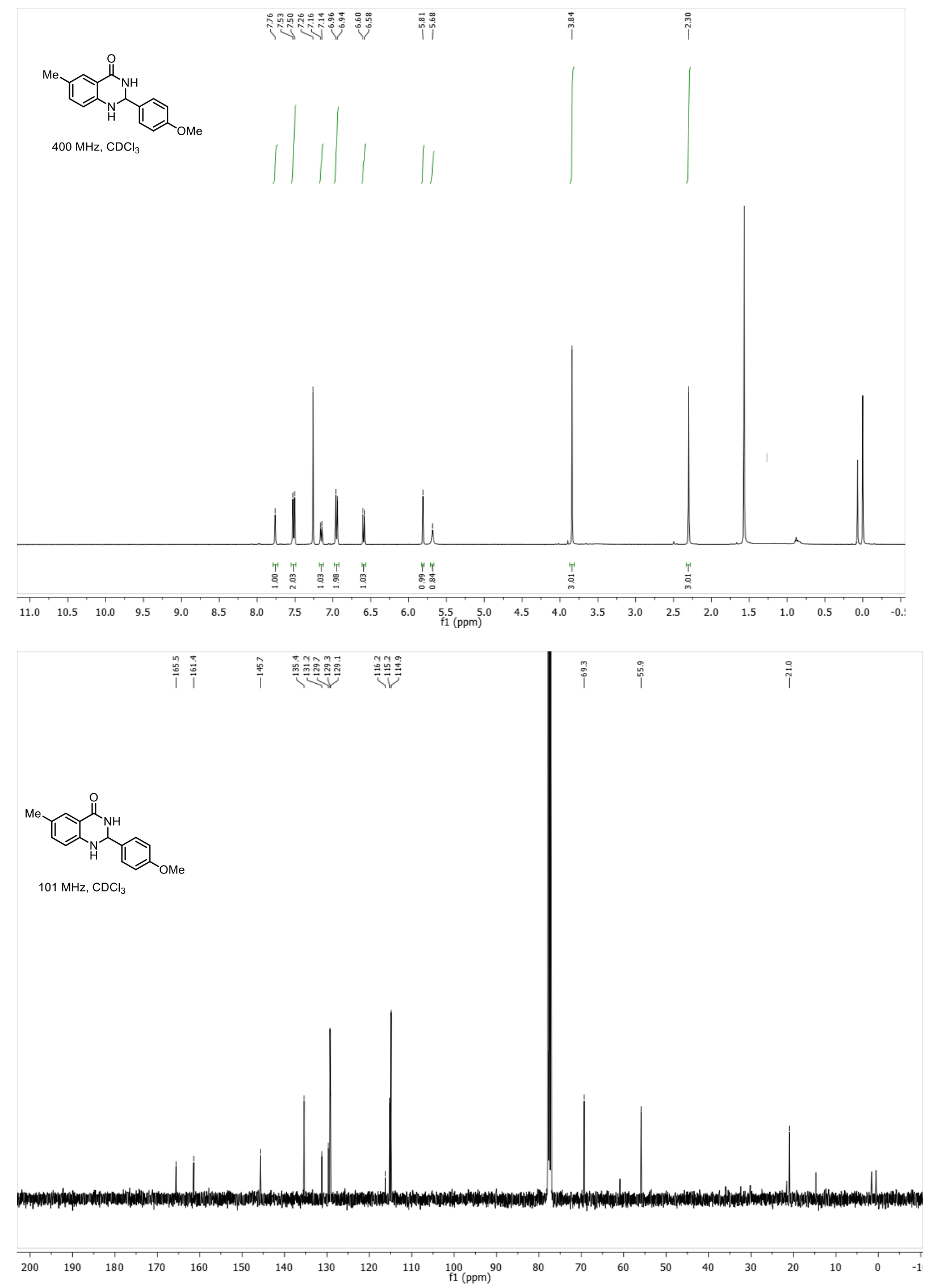

S47 
$\underline{{ }^{1} H \text { and }{ }^{13} C\left\{{ }^{1} H\right\} \text { NMR of compound } 6 b:}$

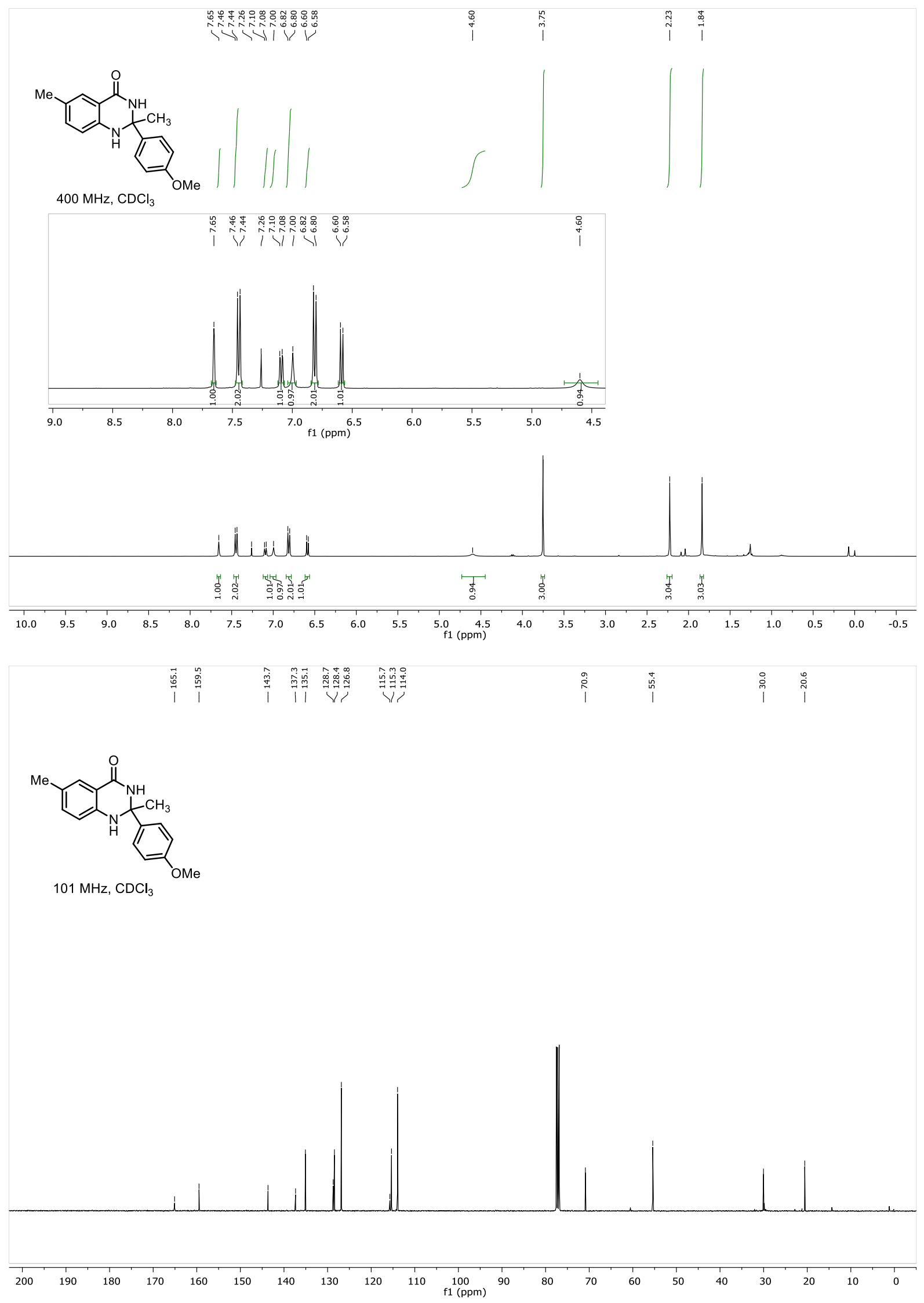

S48 
$\underline{{ }^{1} H \text { and }{ }^{13} C\left\{{ }^{1} H\right\} \text { NMR of compound } 6 \mathrm{c}:}$

|
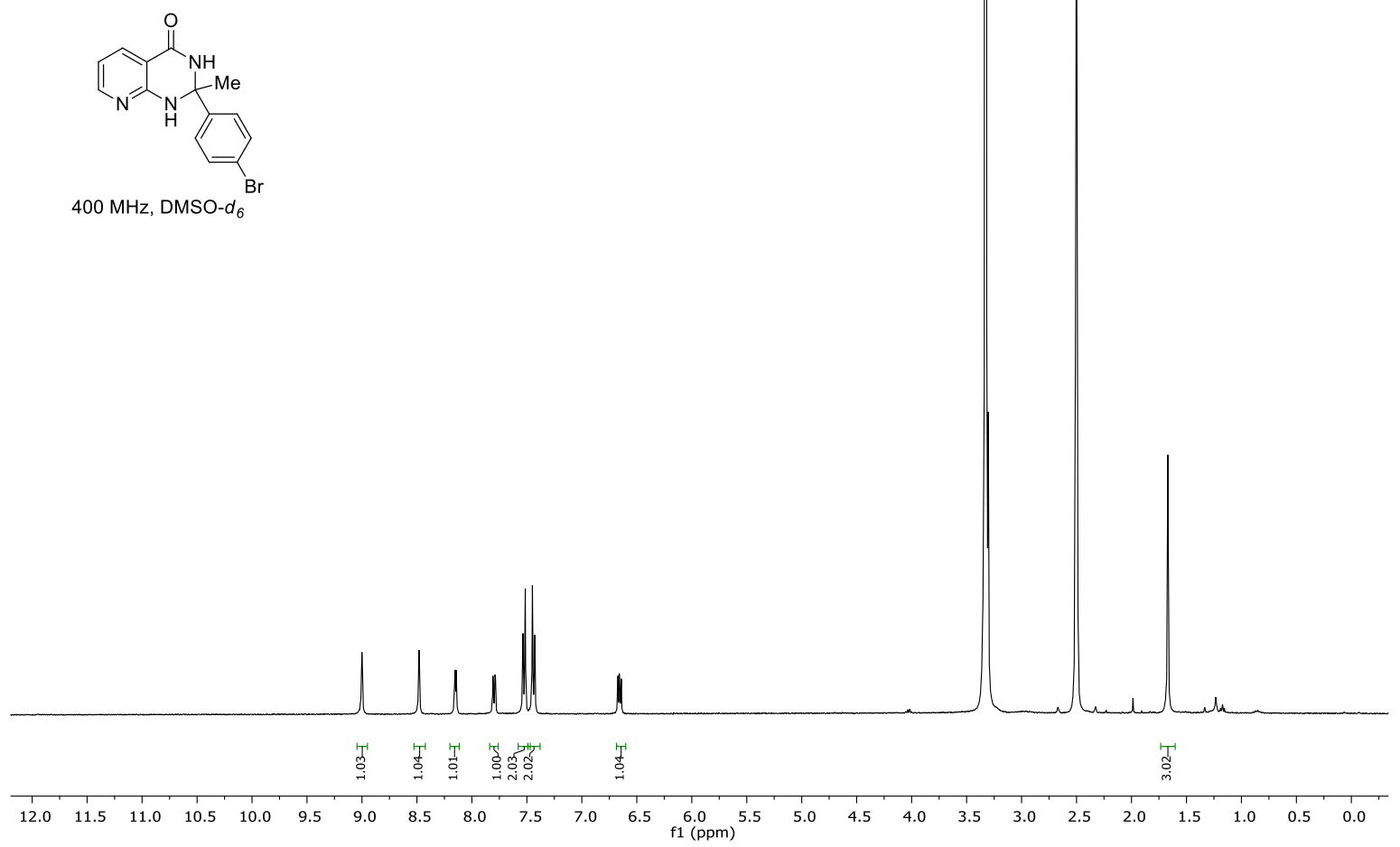

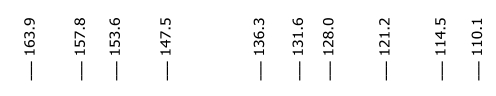

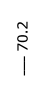
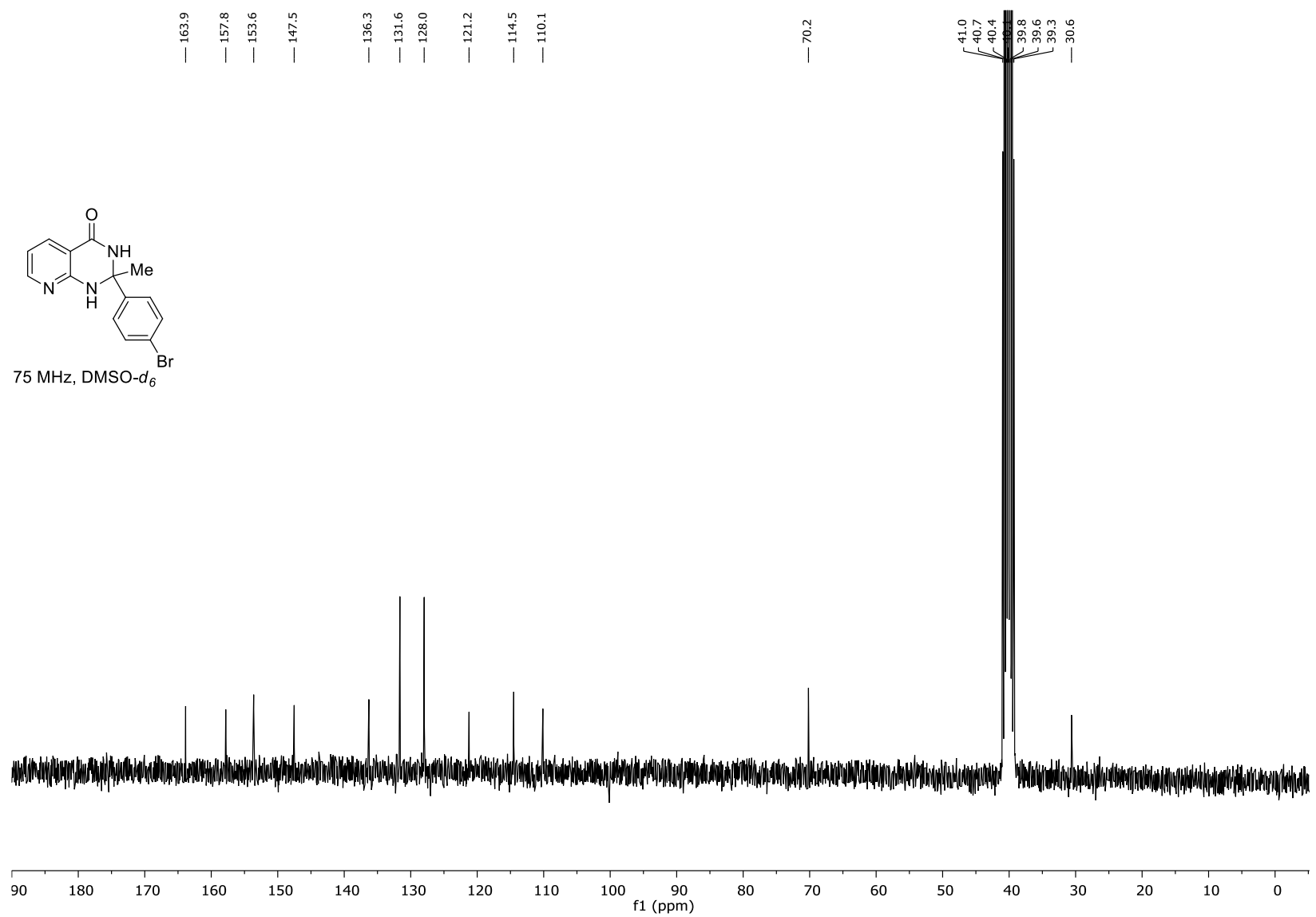

S49 
$\underline{H}$ and ${ }^{13} \mathrm{C}\left\{{ }^{1} \mathrm{H}\right\}$ NMR of compound $6 \mathrm{~d}:$
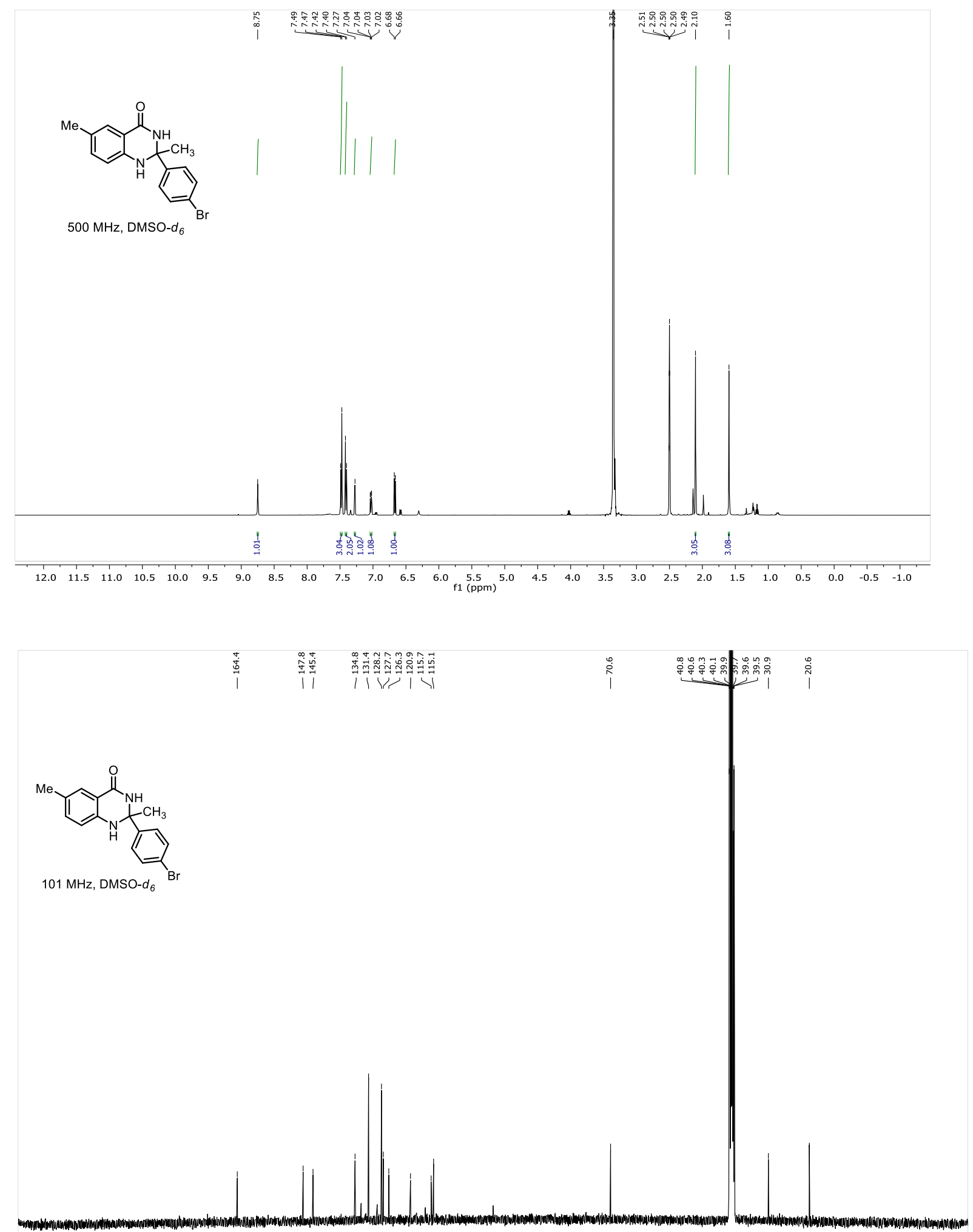

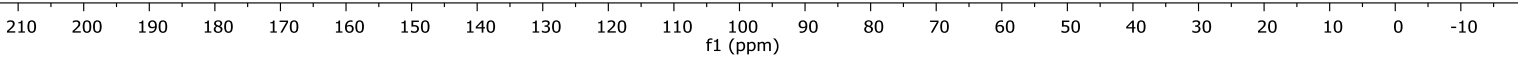


$\underline{{ }^{1} \mathrm{H} \text { and }{ }^{13} \mathrm{C}\left\{{ }^{1} \mathrm{H}\right\} \text { NMR of compound } 6 \mathrm{e}}$
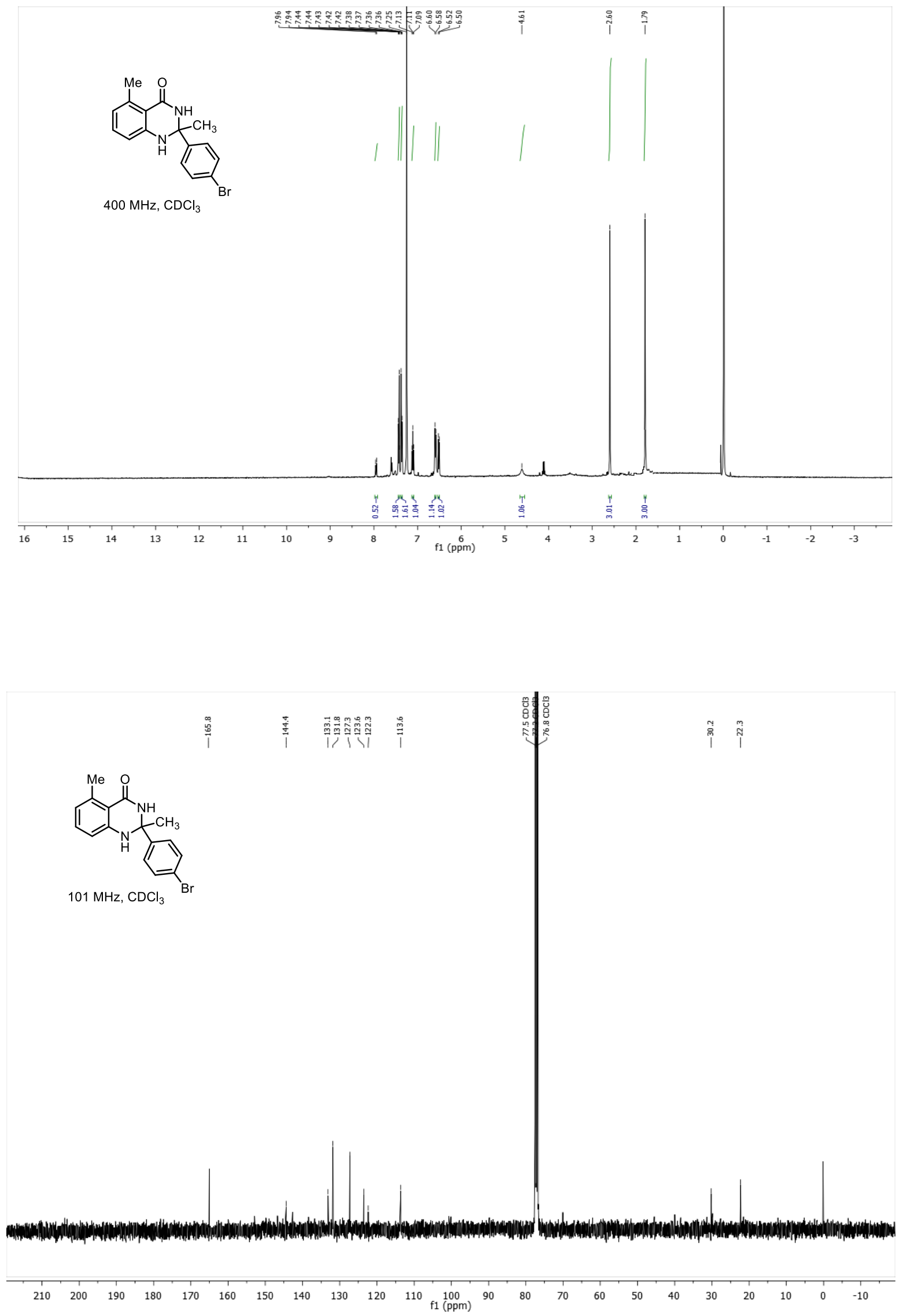


\section{$\underline{{ }^{1} \mathrm{H} \text { and }{ }^{13} \mathrm{C}\left\{{ }^{1} \mathrm{H}\right\} \text { NMR of compound } 6 \mathrm{f}}$}
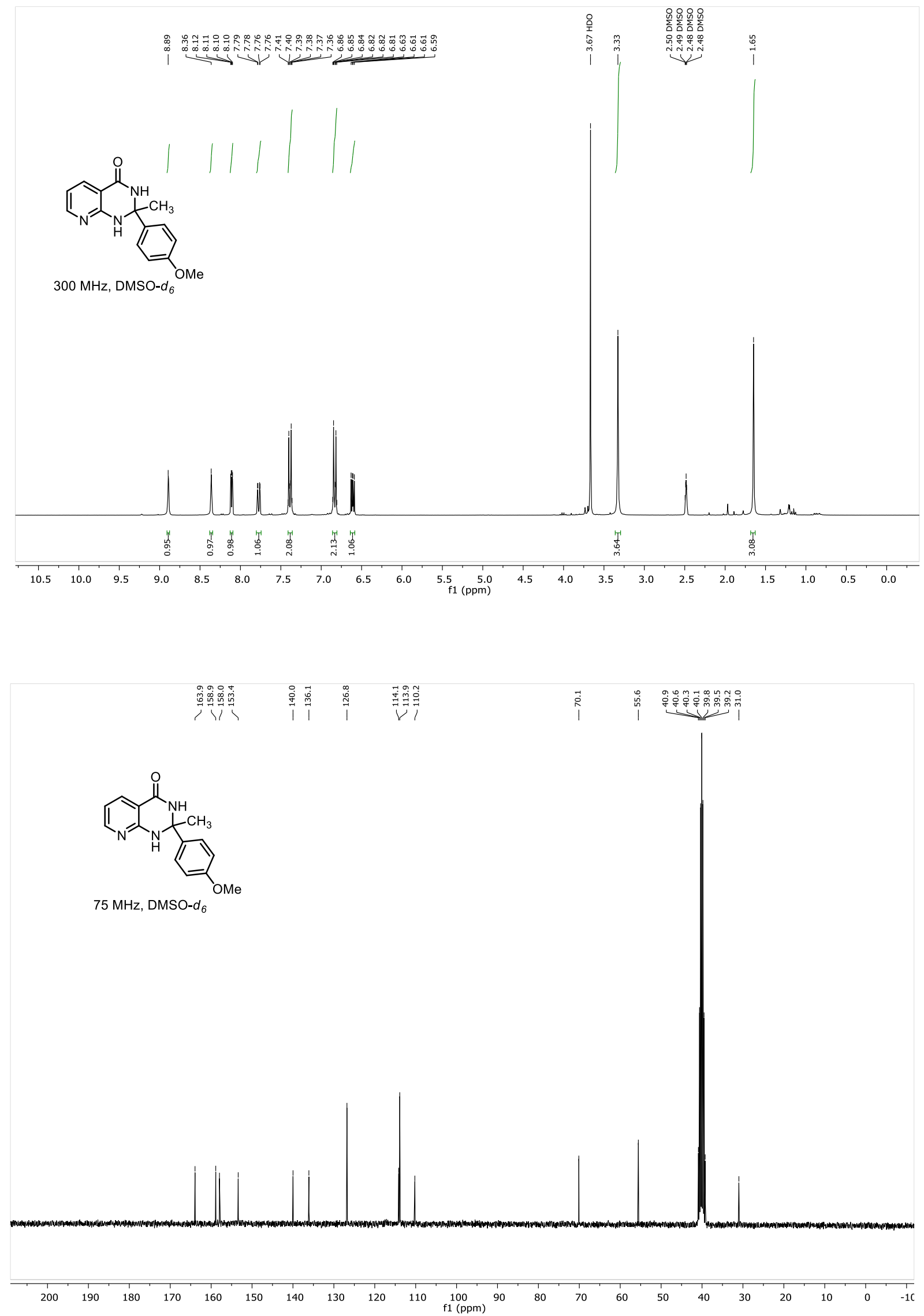
$\underline{{ }^{1} \mathrm{H} \text { and }{ }^{13} \mathrm{C}\left\{{ }^{1} \mathrm{H}\right\} \text { NMR of compound } 6 \mathrm{~g}}$ :
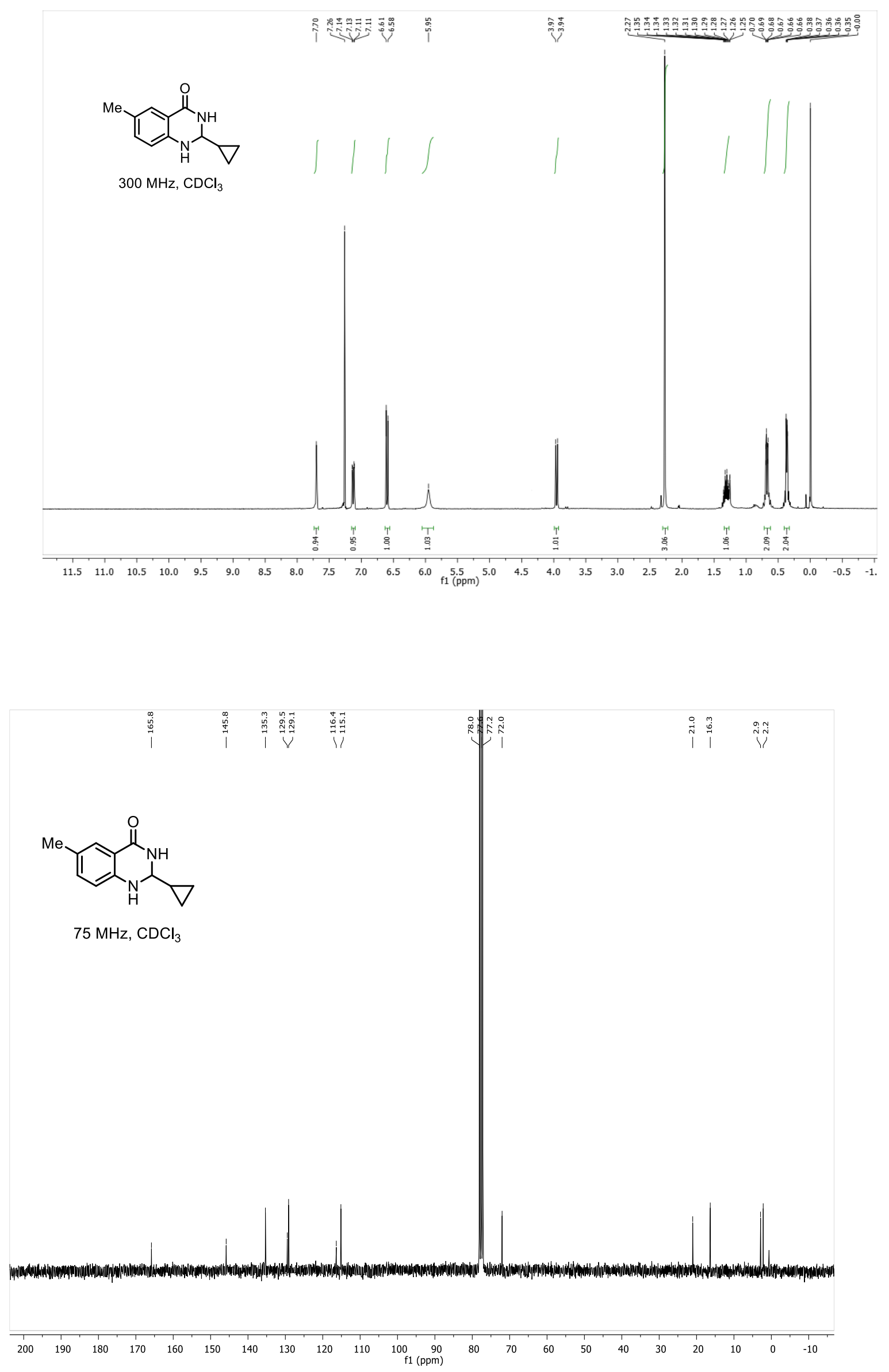

S53 


\section{$\underline{{ }^{1} H \text { and }{ }^{13} C\left\{{ }^{1} H\right\} \text { NMR of compound } 6 h:}$}

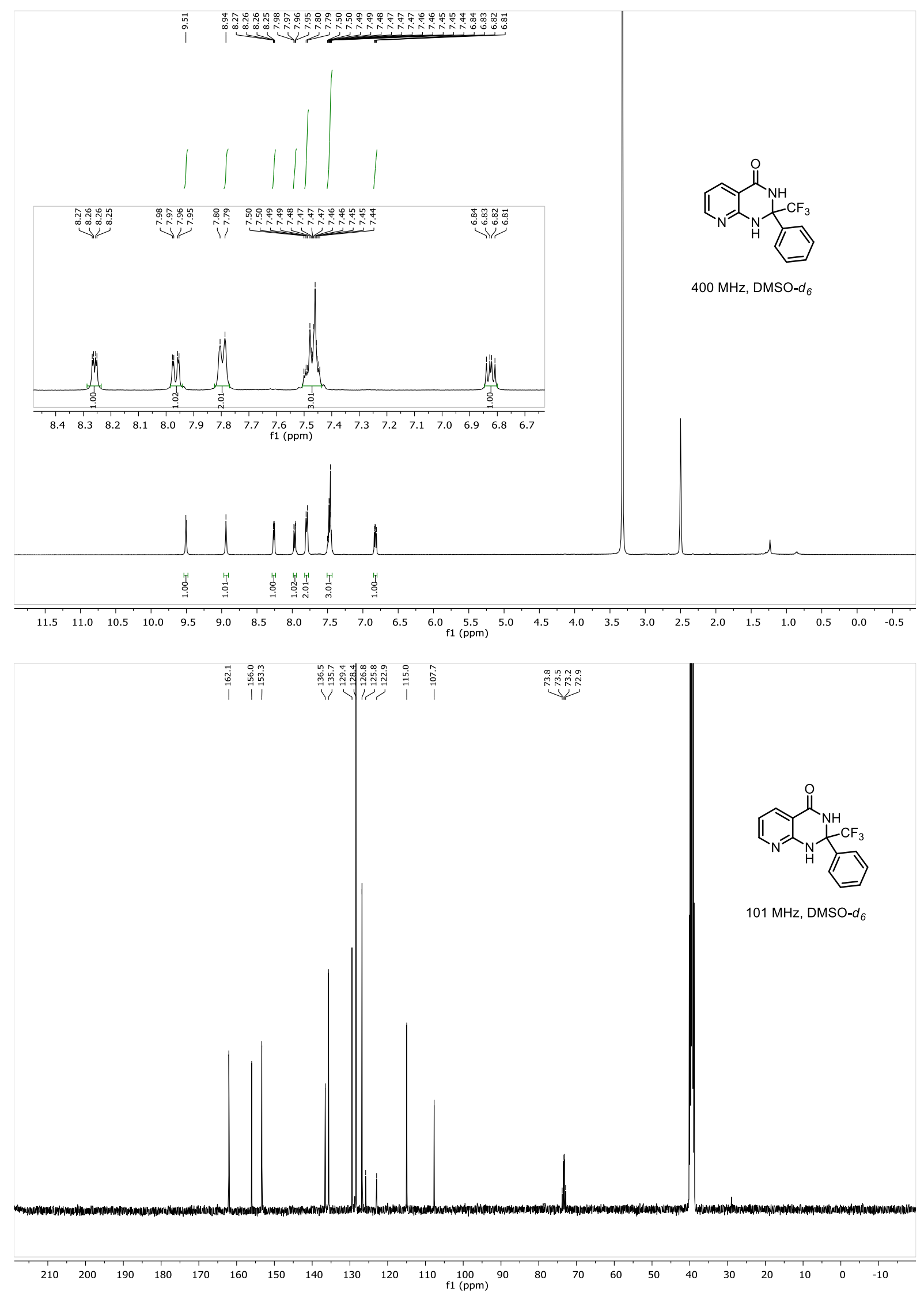


$\underline{{ }^{1} \mathrm{H} \text { and }{ }^{13} \mathrm{C}\left\{{ }^{1} \mathrm{H}\right\} \text { NMR of compound 7: }}$
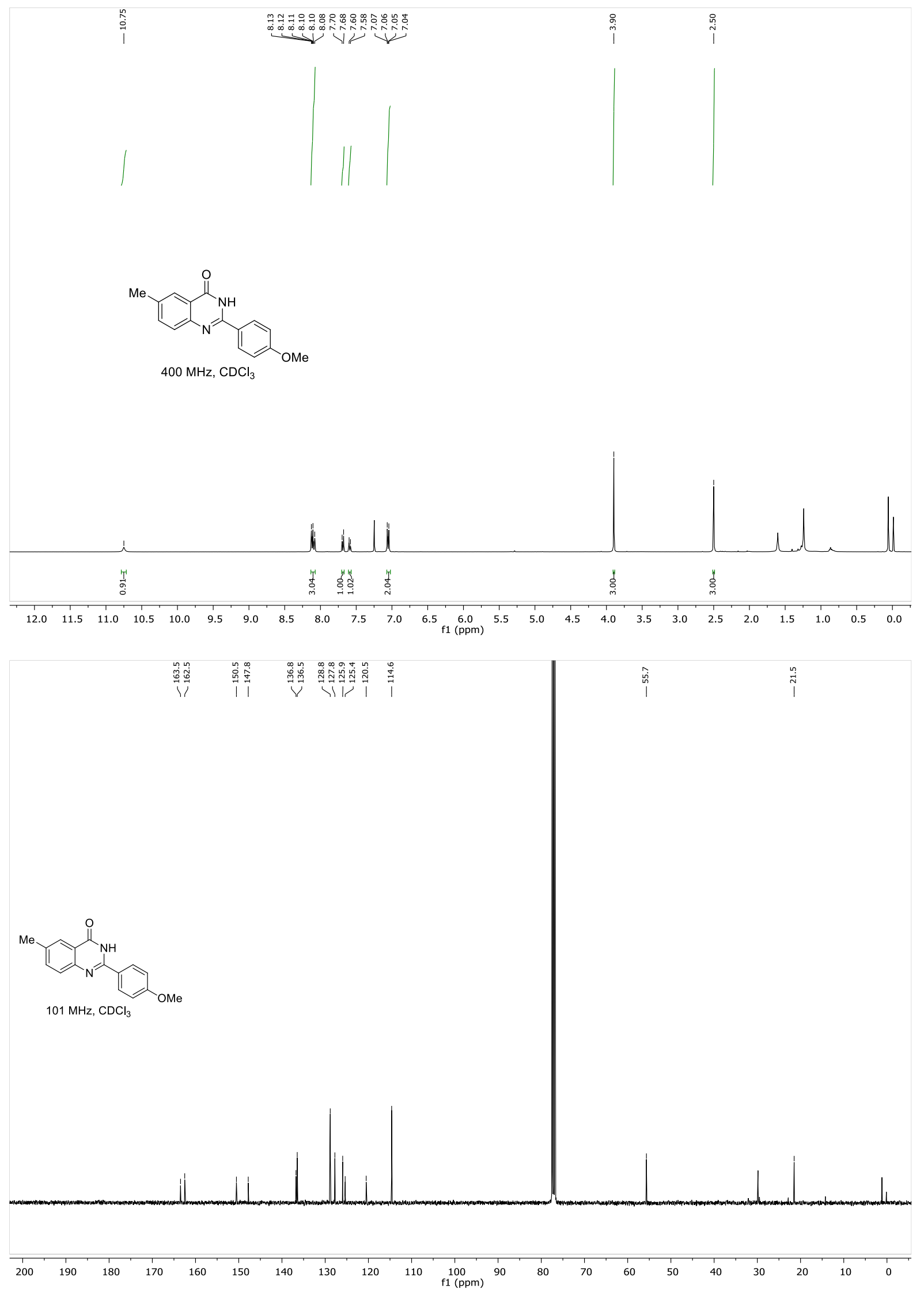

S55 
$\underline{{ }^{1} \mathrm{H} \text { and }{ }^{13} \mathrm{C}\left\{{ }^{1} \mathrm{H}\right\} \text { NMR of compound Ba: }}$
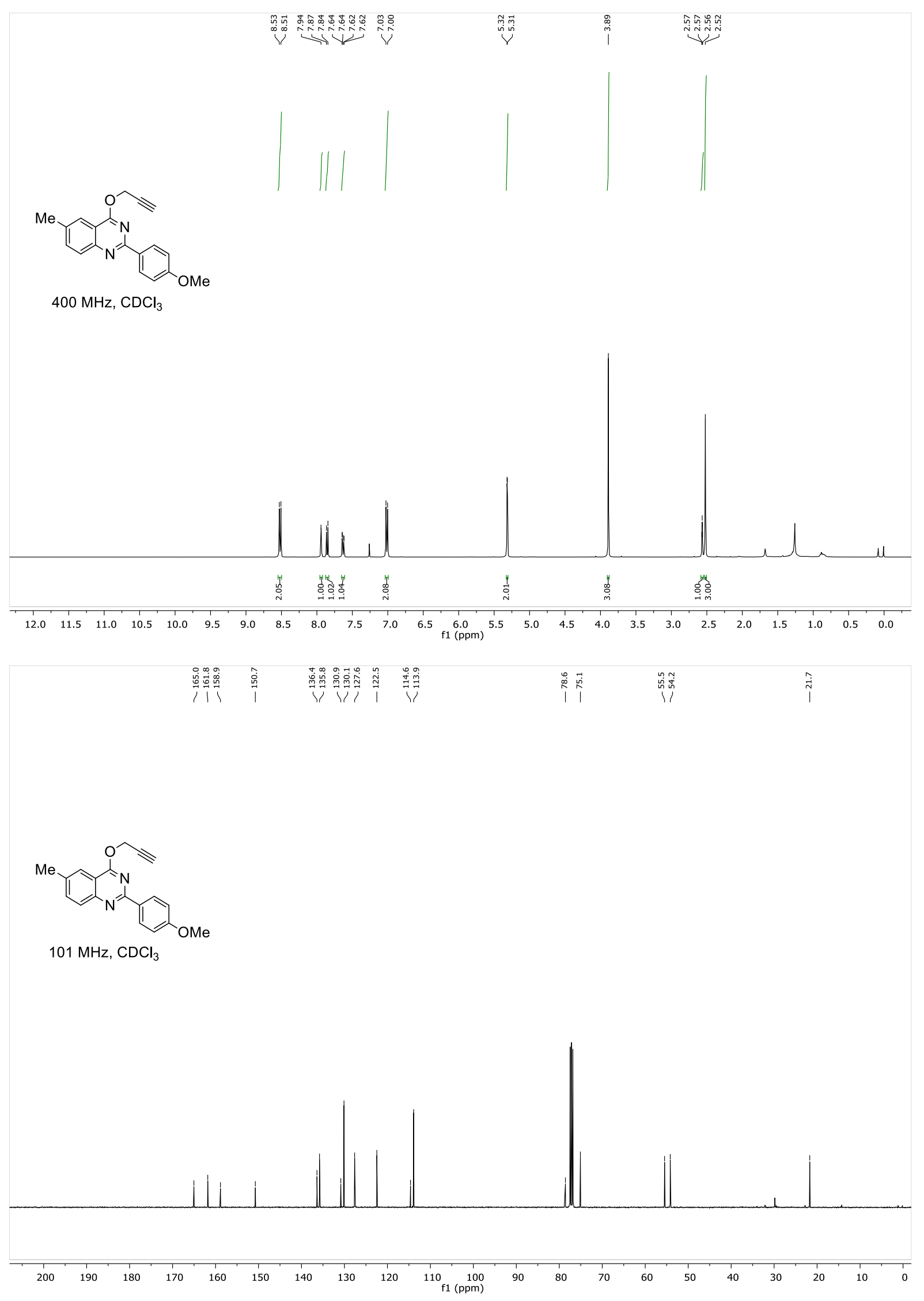

S56 


\section{$\underline{{ }^{1} H \text { and }{ }^{13} C\left\{{ }^{1} H\right\} \text { NMR of compound } 8 b:}$}
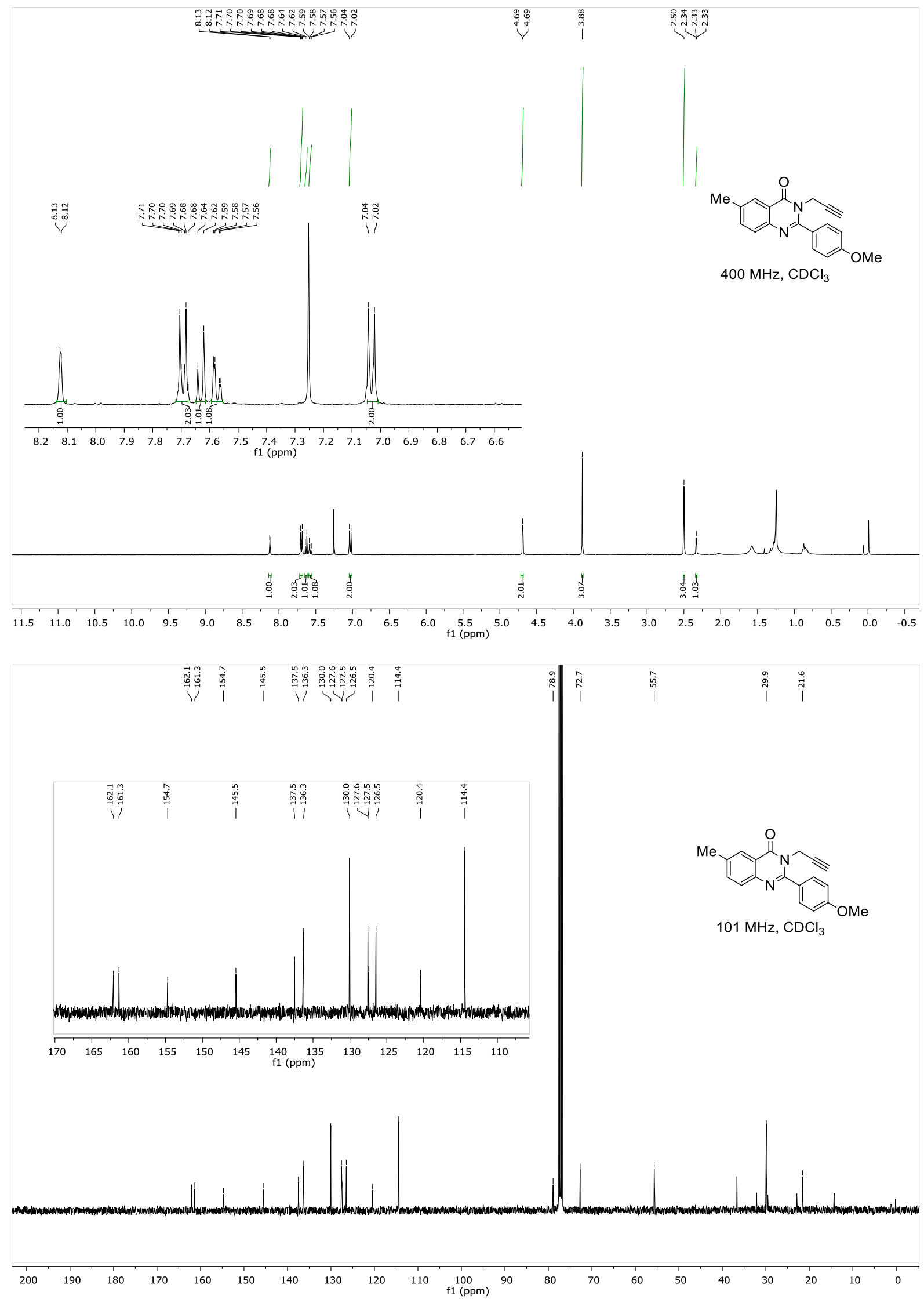